UCRL-ID-129331

\title{
The Science of NIF Scale Capsule Development (Activities for FY97)
}

\author{
K. E. Hamilton \\ S. R. Buckley \\ R. R. Cook
}

November 12, 1997

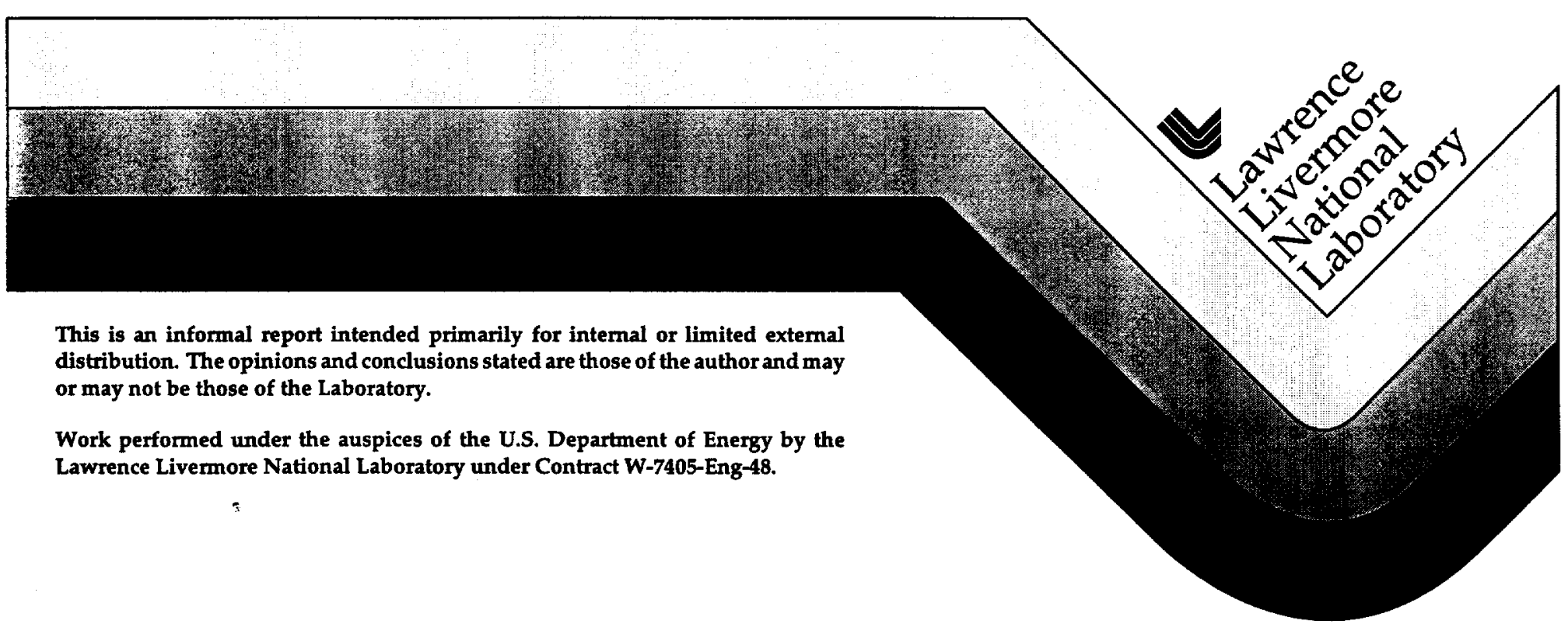




\section{DISCLAIMER}

This document was prepared as an account of work sponsored by an agency of the United States Government. Neither the United States Government nor the University of California nor any of their employees, makes any warranty, express or implied, or assumes any legal liability or responsibility for the accuracy, completeness, or usefulness of any information, apparatus, product, or process disclosed, or represents that its use would not infringe privately owned rights. Reference herein to any specific commercial product, process, or service by trade name, trademark, manufacturer, or otherwise, does not necessarily constitute or imply its endorsement, recommendation, or favoring by the United States Government or the University of California. The views and opinions of authors expressed herein do not necessarily state or reflect those of the United States Government or the University of California, and shall not be used for advertising or product endorsement purposes.

This report has been reproduced directly from the best available copy.

Available to DOE and DOE contractors from the Office of Scientific and Technical Information

P.O. Box 62, Oak Ridge, TN 37831

Prices available from (615) 576-8401, FTS 626-8401

Available to the public from the

National Technical Information Service

U.S. Department of Commerce

5285 Port Royal Rd.,

Springfield, VA 22161 


\title{
THE SCIENCE OF NIF SCALE CAPSULE DEVELOPMENT (Activities for FY97)
}

\author{
Kenneth E. Hamilton \\ Steven R. Buckley \\ Robert R. Cook
}

$11 / 12 / 97$ 


\title{
STATUS REPORT: Microencapsulation
}

\section{THE SCIENCE OF NIF SCALE CAPSULE DEVELOPMENT}

\author{
Principal Investigators: Ken Hamilton, Steven Buckley, and Bob Cook
}

\begin{abstract}
The focus of this work is the production of 2-mm P $\alpha$ MS mandrels by microencapsulation for use as National Ignition Facility (NIF) laser targets. It is our findings thus far that the processing techniques used previously for the 0.5 $\mathrm{mm}$ and $1.0-\mathrm{mm}$ targets are no longer useful for preparation of the larger targets for a few fundamental reasons. The driving force for sphericity (from the minimization of interfacial energy) decreases as the radius of curvature increases. Simultaneously, the mechanical robustness / stability of the wateroil-water emulsion droplets decreases as the droplet size increases. The impact of these physical conditions and the possibilities of circumventing these limitations have been examined while attempting to meet the NIF shell power spectrum criteria. Identifying the key parameters in the transition (solidification) from a w-o-w droplet to a solid polymer shell has been understood implicitly to be the paramount goal. It is believed through the knowledge gained that it will be possible to minimize the deleterious forces and maximize shell sphericity. At this point it is believed that properties intrinsic to the polymer (i.e., P $\alpha$ MS) such as its solution behavior and evolution of film stresses control the overall shell sphericity.
\end{abstract}

\subsection{INTRODUCTION}

The goal of the this work is the production of 2-mm mandrels by microencapsulation for use in National Ignition Facility (NIF) laser targets. The most important specification for the shells (after the size) is a high degree of sphericity. Secondarily, good surface finish is needed for viable targets (Haan, 1995). Both characteristics are required to obtain targets with the proper implosion characteristics and to limit the Rayleigh-Taylor instabilities, i.e., thereby offering the highest possible compression ratio before ignition. Additionally, a reasonably good level of concentricity (estimated to be $\sim 5 \%$ ) is needed to proceed with subsequent processing steps and overcoating routines. Mandrels of sufficient quality have a high value to the laser program as target materials when combined with glow discharge polymer (GDP) overcoating, highstrength polyimide coating (preferably via vapor deposition), beryllium overcoating, or a combination of overcoats. The decomposable mandrel approach is depicted in Fig. 1. It involves several steps: 1) the formation of a concentric, 2) solvent removal, 3) the core fluid is removed, 4) it is overcoated with plasma 
a)
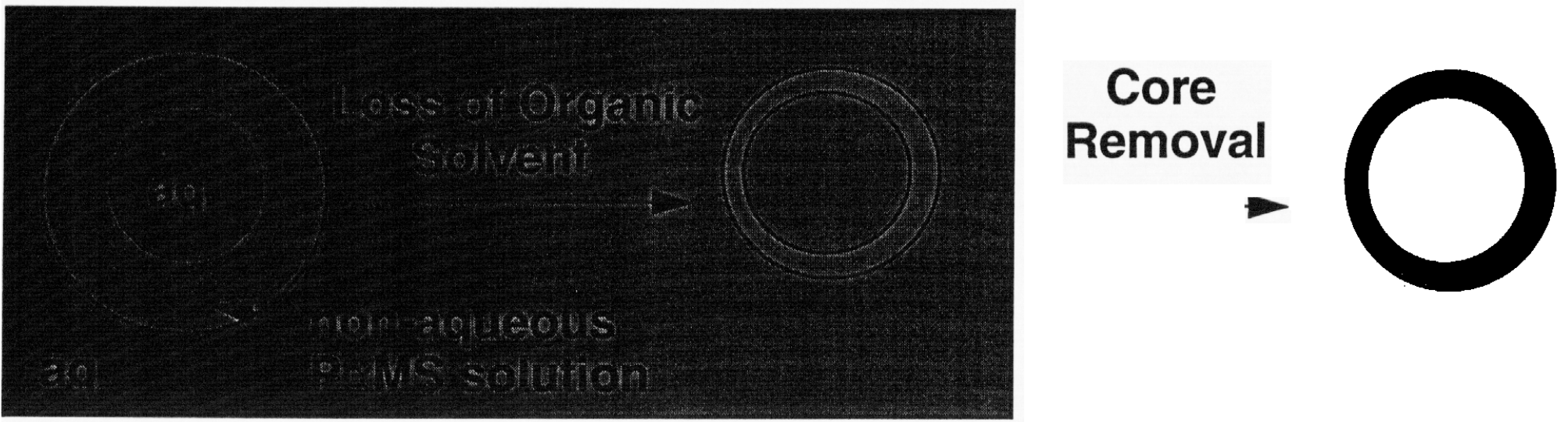

b)
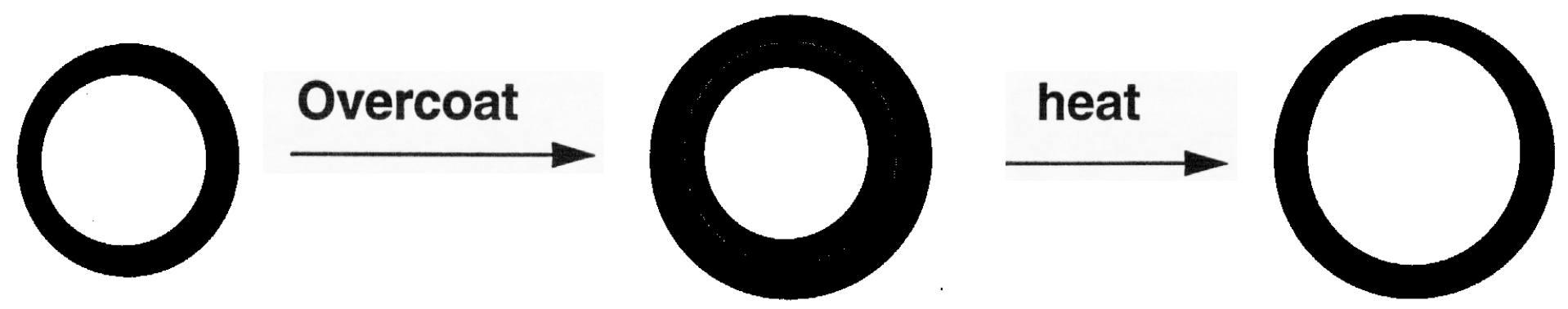

Fig. 1: The "decomposable mandrel" approach offers the best opportunity to produce high quality plastic mandrels. It involves to steps: a) the preparation of 2-mm diameter poly( $\alpha$-methyl styrene), P $\alpha M S$, shells by microencapsulation with high quality exterior surfaces, b) overcoating with a very uniform CHplasma polymer film. Heat to $300{ }^{\circ} \mathrm{C}$ to decompose the P $\alpha$ MS to gaseous products which diffuse out leaving a high-quality, vacuole-free $\mathrm{CH}$ shell. With this approach only mandrel exterior surface sphericty characteristic are important. Other imperfections such as vacuoles are negated by step b). 
deposited polymer from trans-2-butene and hydrogen feed stock, 5) mandrel depolymerization.

Smaller shells for previous and ongoing laser experiments have been made previously by drop tower techniques, interfacial reactions (Arshady, 1989; Takagi, 1993; Letts, 1996; Hamilton, 1997), ballistic furnace methods (Merkuliev, 1995; Nikitenko, 1997), and microencapsulation. Drop tower approaches suffer from transport limitations (in scaling from 0.5-mm diameter to $2.0 \mathrm{~mm}$ diameter). Difficulties were observed in the interfacial reaction approach such as exterior surface roughness, shell sphericity, and the complications affiliated with a pH-dependent poly(electrolyte) / diffusion-limited reaction. Furthermore, the results obtained from the ballistic furnace approach have not been particularly reliable. The final option to be investigated, microencapsulation, is currently being explored and is discussed here.

Other groups working recently in the area of microencapsulation of large shells include: General Atomics (McQuillan, 1997), Osaka University (Takagi, et al.), Soane Technologies, Inc., and Kinki University (Kubo, 1986; Nakano, 1996). Differences in approach to shell making have been reported with varying results. General Atomics has been working on the preparation of P $\alpha$ MS shells with the use of a single solvent system (F-Benzene). The shells that have been produced were smaller than $2-\mathrm{mm}$ (below $1500 \mu \mathrm{m}$ ). Osaka University has made sizable shells from PS in the range of 2-7 mm, and the wall thickness of the their shells tended to be quite large (in the range of $100 \mu \mathrm{m}$ ). To achieve some degree of density-matching they are working with a two solvent system, 1,2dichloroethane $\left(p=1.256 \mathrm{~g} / \mathrm{cm}^{3}\right.$ at $\left.20^{\circ} \mathrm{C}\right)$ and toluene $\left(\rho=0.8669 \mathrm{~g} / \mathrm{cm}^{3}\right.$ at $\left.20{ }^{\circ} \mathrm{C}\right)$. Because the Osaka university group uses PS (in lieu of P $\alpha M S$ ) and they do not subsequently decompose the mandrel, the requirements for shells are more severe in terms of needing vacuole-free walls and a higher degree of concentricity. This is not explicitly true for the decomposable mandrel approach. Details of vacuole formation and the associated phase separation have been investigated previously (Wilemski, 1995; Boone, 1995). Because we are implementing a decomposable mandrel approach (Letts, 1995a; 1995b; 1996), vacuoles are not an issue for us (provided their formation does not affect the exterior shell surface), and they will not be discussed further in any great detail.

\subsection{BACKGROUND}

Currently, we are forming a water-oil-water (W-O-W) emulsion via a microencapsulation technique (Fig. 2). The entire shell making process by microencapsulation includes several steps such as droplet generation, solidification, core extraction, final drying, overcoating, and pyrolysis (Fig. 1). Because the processing is performed in a sequential manner, each step affects (usually negatively) all subsequent steps, hence judicious choices / procedures made at the early stages will result in the optimum shell properties. The encapsulation routine involves the concentric flow in three cylindrical conduits. 


\section{1) Compound Droplet Formation}

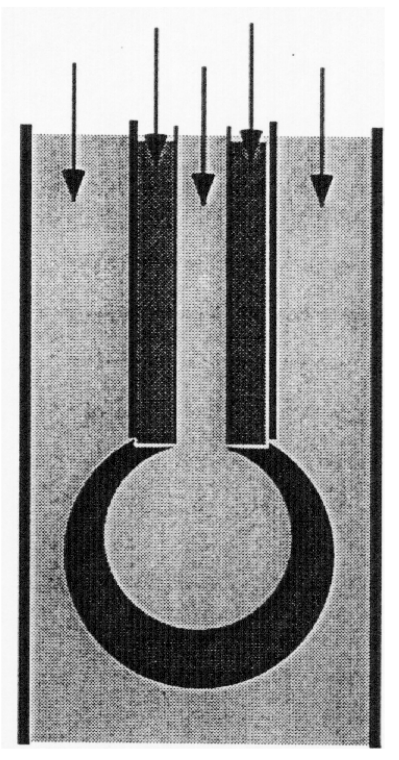

2) Solid Shell Formation

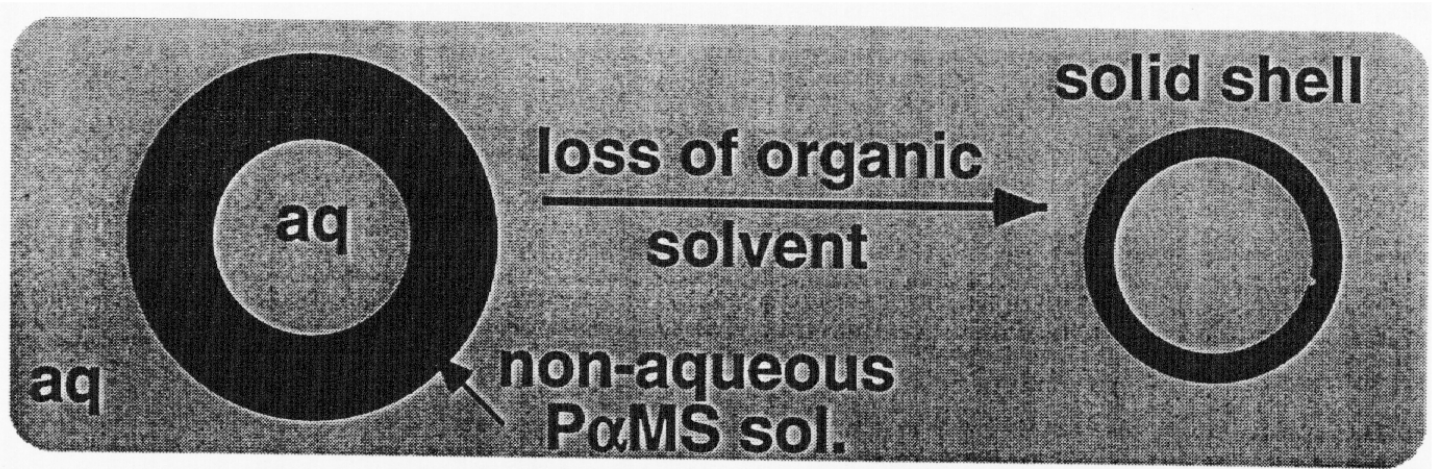

Fig. 2: The microencapsulation route to shells involves three critical steps: 1) Compound droplet formation involving encapsulation dynamics and fluid viscosity, 2) Solid shell formation involving density matching, agitation, time-temperature profile, and sphericity, 3) solvent exchanges and core fluid removal. 
The innermost fluid, exiting the center orifice, is water. The next fluid, exiting the orifice exterior the core fluid, consists of a polymer solution (ranging from 5$20 \mathrm{wt} \%$ polymer) in an organic solvent(s). Lastly, a water-based polymer solution containing $0.5 \mathrm{wt} \%$ poly(vinyl alcohol), PVA, flows through the outermost tube. Compound drops (i.e., a water drop inside an oil drop) are formed at the end of the oil orifice which are removed by the flow PVA solution.

A number of shells (in the hundreds) are collected into a vessel partially filled with PVA solution (PVA acts as a colloidal suspending agent / emulsification stabilizer). This vessel is then transferred to a water bath at elevated temperatures (in the range of $65^{\circ} \mathrm{C}$ ) at which point the organic solvent dissipates into the PVA fluid in the beaker, and it evaporates off of the top open surface. The selection of suspension method of shells in the bath is vitally linked to the overall survivability of shells in the 2-mm size range (Fig. 3).

Furthermore, the degree of solubility and rate of evaporation are dependent on several factors including temperature, volatility of solvent(s), and the amount and nature of stirring employed during solidification (Fig. 4). It is important to maintain a suspension of shells to avoid coalescence, shell-wall interactions, and flat spots on shells. However, sufficient but not excessive mixing is required. Overly aggressive mixing will results in shell breakage and size attrition due to shear forces (Stone, 1990; Flumerfelt, 1972; Lagisetty, 1986). Upon dissipation of the organic solvent, the core fluid is removed from the shell either by chemical extraction means (osmotically with ethanol) or by imposed concentration gradients (air drying at slightly elevated temperatures). At this point the shells may be overcoated with a plasma / glow discharge polymer (GDP), and the inner mandrel can be removed by pyrolysis/depolymerization.

Presently, very little is understood about the fundamentals of creating nearly-perfect, spherical drops in the millimeter size range. For the most part and for most applications, a high degree of sphericity is not needed for functionality, and few measurements have been taken to optimize it. In emulsion technology (Becher, 1983; Smith, 1976; Friberg, 1988), only emulsion stability is desired; actual drop radius, distribution of sizes, and overall sphericity of droplets are not specified, and therefore this topic has received little attention. The needs for laser implosion experiments are much more stringent (Haan, 1995). In terms of driving forces toward sphericity, one only can rely on interfacial tension $(-10-40$ dyne/cm). Unfortunately, one typically can only decrease it by adsorbing amphiphilic species (surfactants) to the interface of the water-oil double emulsion. Surfactants inevitably will reduce the surface tension and thereby stabilize the emulsion, but will simultaneously reduce the driving force for sphericity. Maximizing the interfacial tension by use of a nonpolar hydrocarbon / water pairing is the most desirable, but this only yields an interfacial tension of approximately 35 dyne/cm.

By definition, interfacial forces act upon a surface. As the droplet size increases, the relative surface area to volume ratio decreases by a factor of $3 / R$. 

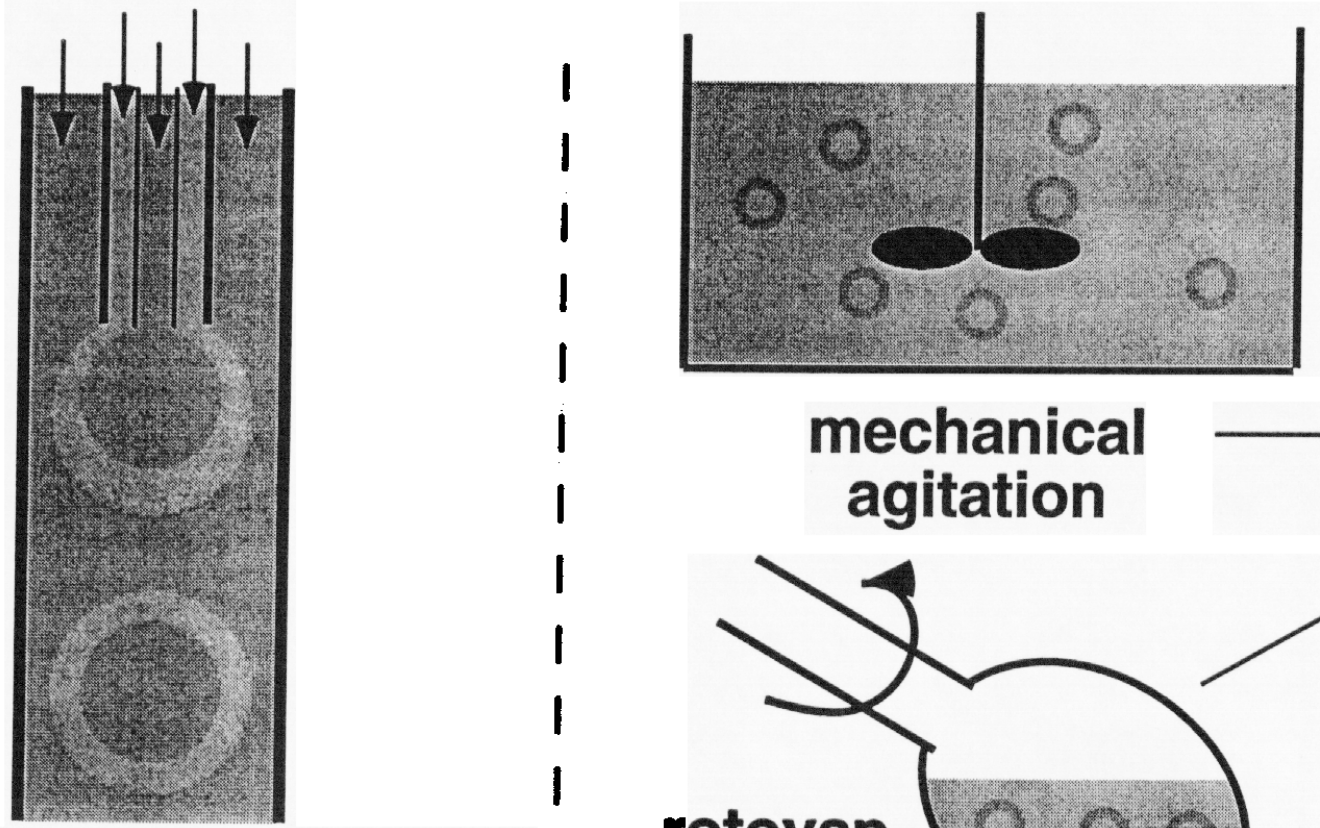

mechanical agitation

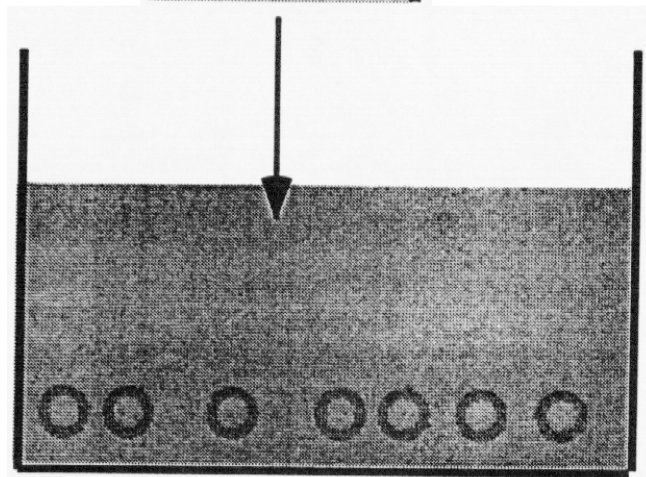

1
1
1
1

contact spots coalescence

1
1
1
1
1
1
1
1
1
1
1
1
1
1
1
1
1
1
1
1
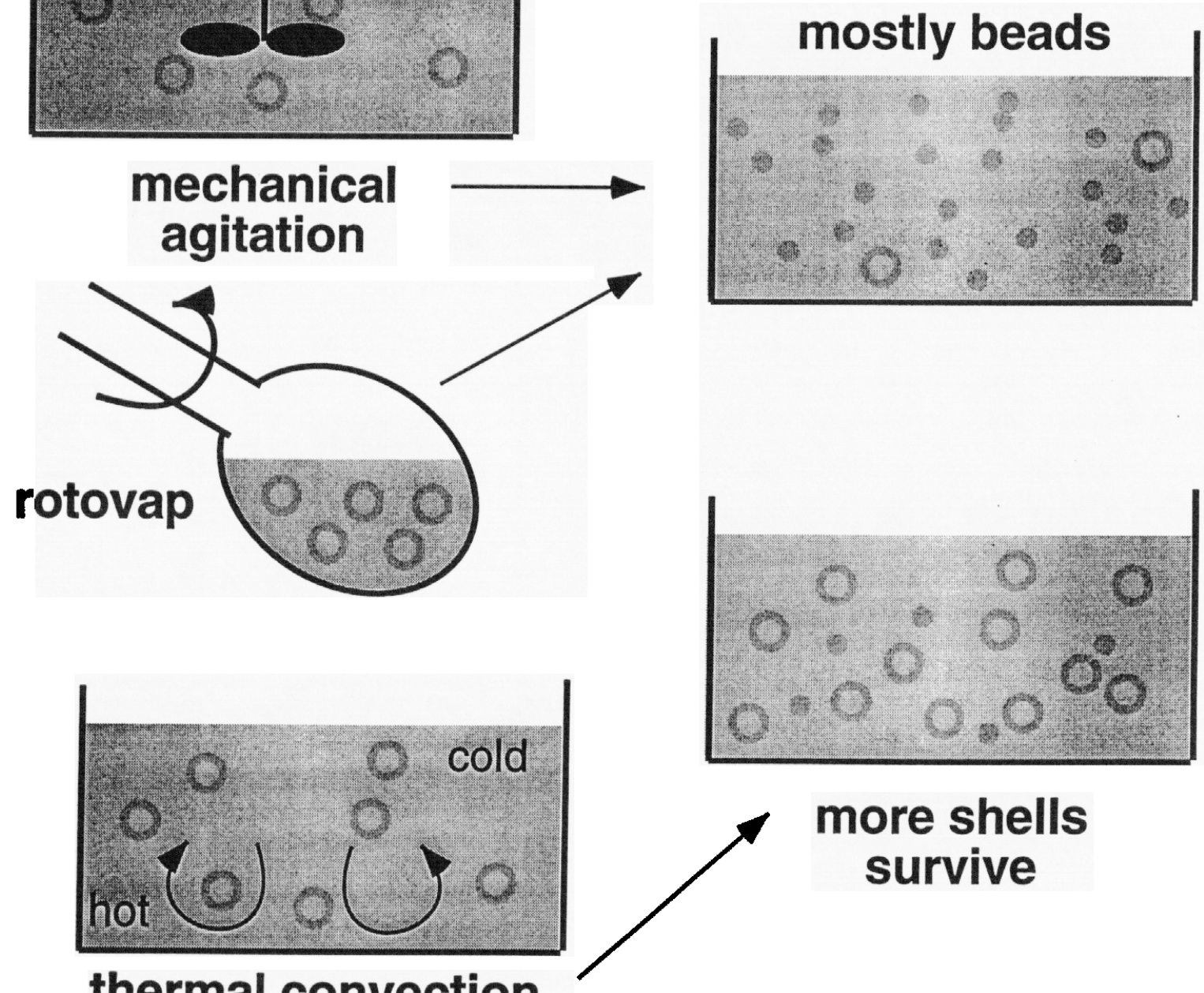

more shells survive

Mixing /suspension of shells during solidification is important. A large number of shells are produced in a single batch. The shells have a tendency to settle to the bottom of the vessel and form contact spots, and they may coalsece. Mechanical means of suspension are too vigorous yielding mostly beads. By using a thermal convection approach, most the compound droplets / shells survive. 


\section{Solvent volatility}

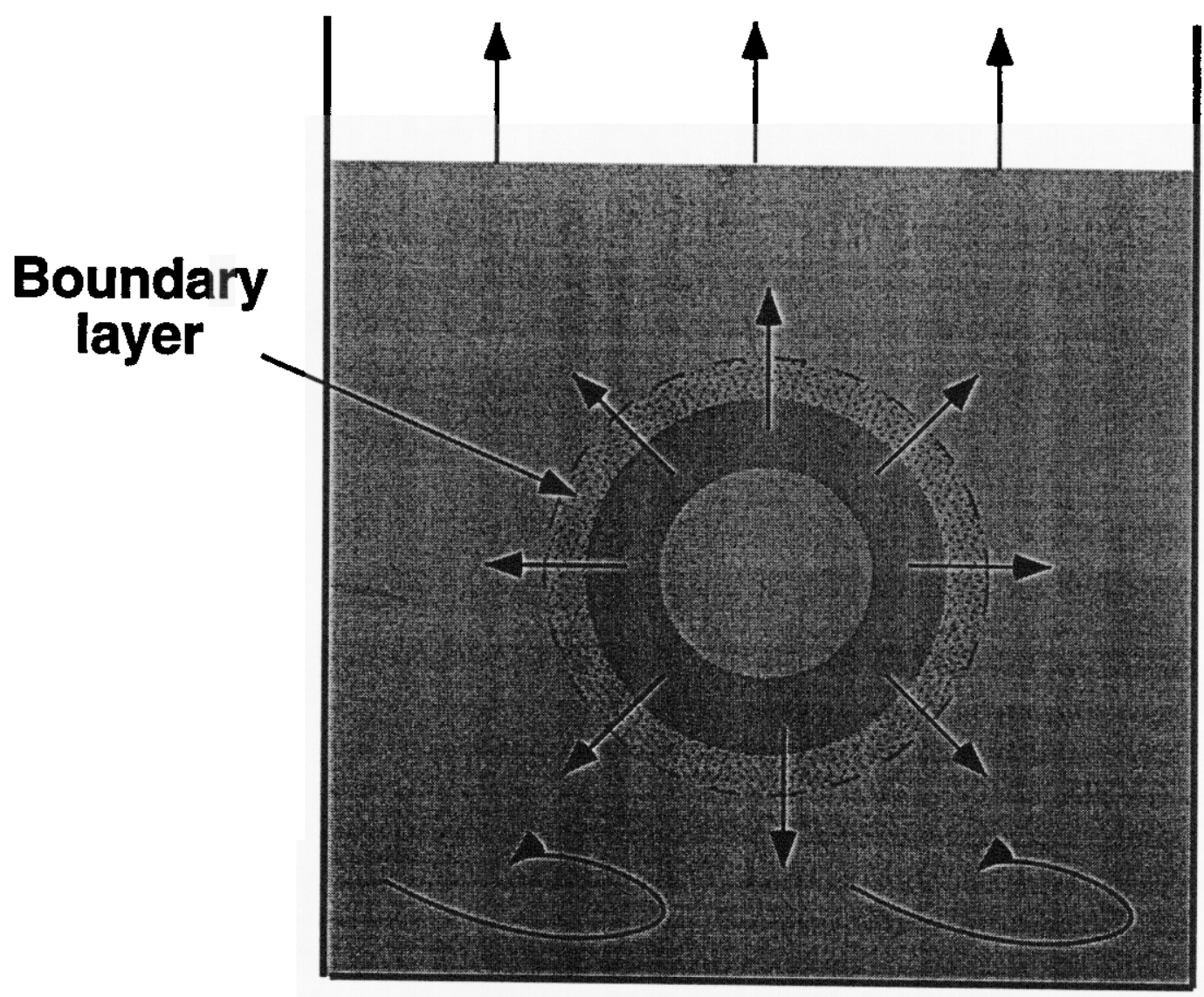

\section{Fluid circulation}

Fig. 4: Shell solidification involves a number of factors including: a) density matching,

b) permeation rates, $f(T, \delta)$, c) boundary layer thickness, $\delta$, f(stirring rate),

d) solvent volatility, $f(T)$, e) agitation alters shell quality. 
Simultaneously, as the droplet grows in size so does the gravitational body forces and various drag forces (depending on the nature of the mixing and the associated velocity profiles) which will act on the droplet, and the resulting shells will be aspherical. The gravitational deformation can be mitigated by working in neutrally buoyant conditions (equal density of both droplet and suspending fluids). For shell sizes in the millimeter range, other forces than previously considered, such as hydrostatic pressure differences, temperature gradient, surfactant gradient (intentionally added or otherwise), can have a large impact on the overall sphericity of the shell when acting upon the shell / droplet in a non-uniform manner. Other questions regarding the hydrodynamic behavior of two water-oil interfaces of double emulsion remain unanswered. For instance, are the motions of the two interfaces coupled, i.e., do they act as one thin membrane, or do they act as two hydrodynamically independent entities? What are the key parameters affecting sphericity?

\subsection{RESULTS}

\subsection{Details before the Shell Solidification Stage (Droplet Formation)}

The activities for the first half of the FY97 were somewhat varied.

Significant thought went into the choice of the droplet generator design in terms of construction ease, parts replacement, and overall encapsulation reliability. When possible, commercially available parts were used to minimize down time. Two designs (differing in the magnitude and direction of the PVA solution delivery and the location of the collection tube) were implemented and tested (Fig. 5). Both configurations resulted in sufficient droplet generation; however, in terms of reliability and ease of operation, one design proved to be the superior.

\subsubsection{Droplet Generator}

After observing both droplet generators (Fig. 6) in operation, it was determined that both generators had their advantages and disadvantages. The Soane-like design was simple and effective, but did not offer much in terms of being able to generate a large range of shell sizes. Nor was it possible to make subtle changes to orifice positioning. In the GA/Osaka design the center orifice was positioned by an $\mathrm{X}-\mathrm{Y}-\mathrm{Z}$ translational stage. This feature offers for the possibility of examining the effect of axial and radial offsets on the encapsulated droplet and their possible role in non-concentric shells.

\subsubsection{Encapsulation}

Because subtle changes in condition will result in the presence or absence of encapsulated droplets, microencapsulation is frequently viewed as a black art. After having some difficulties early on, we have found this not to be the case. We now know (some of) the prerequisites for encapulsulation and some of the variables these 
a) Soane-like Design

b) Osaka / General Atomics Design

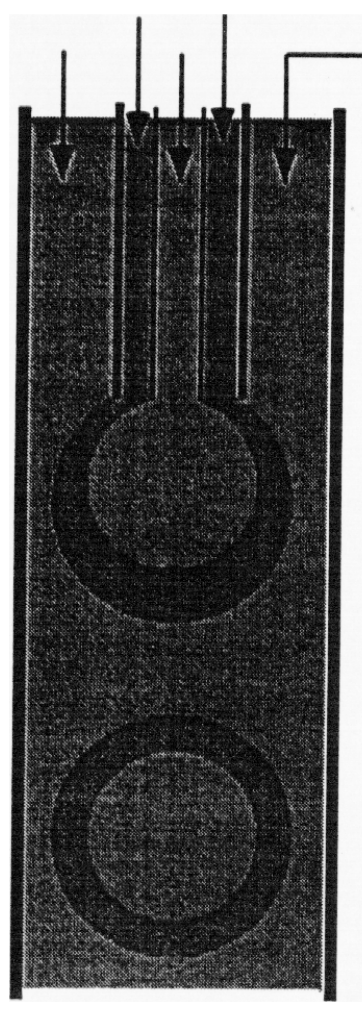

-Stripper flow

Parameters

- flow rates

- orifice positions and materials

- solution compositions

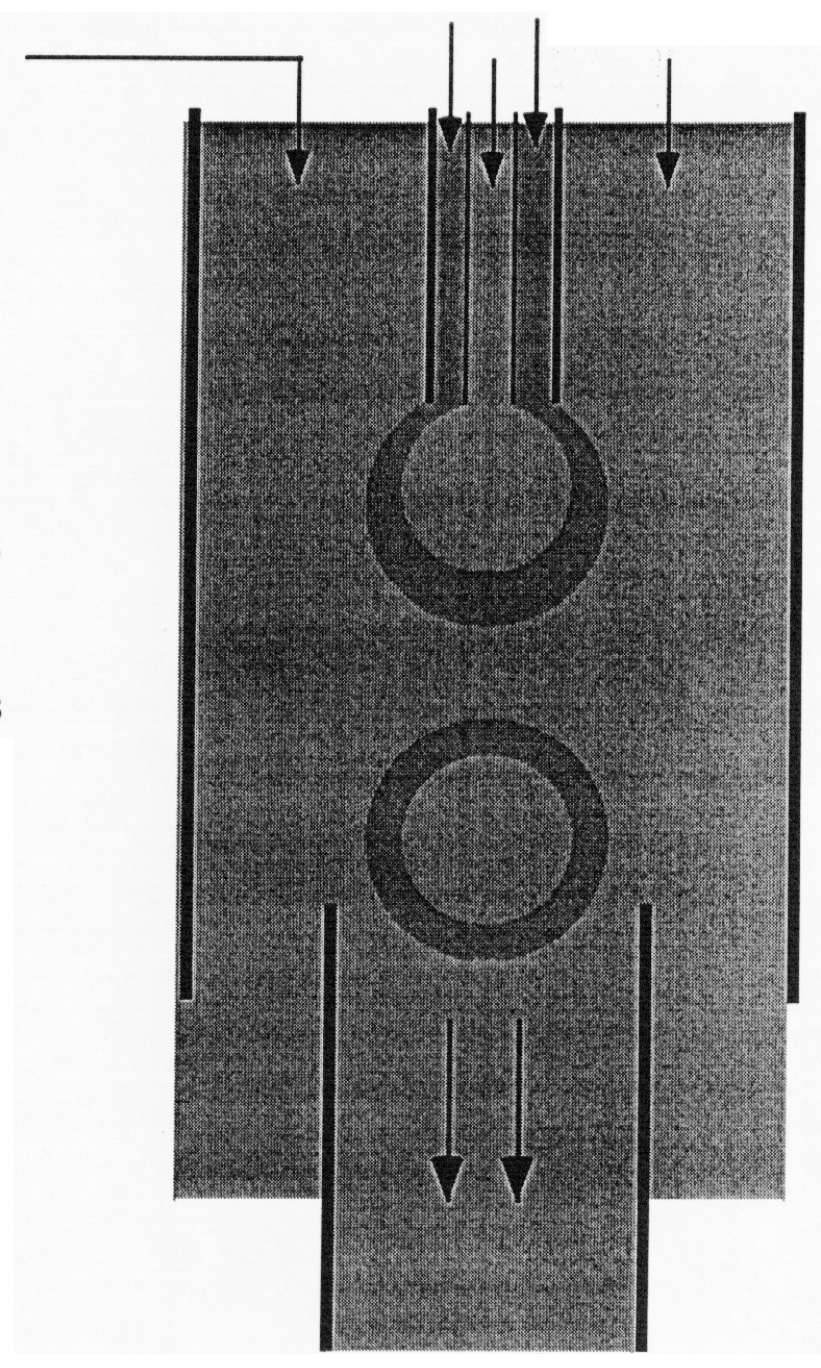

Fig. 5: Two droplet generator designs have been explored. a) Soane (STI) -like design in which the shell size is controlled predominantly by the collection diameter, b) Osaks / General Atomics design in which the shell size is controlled by stripper flow. In either design the key parameters include flow rates of the three fluids, orifice position and materials of construction, and solution compositions. 


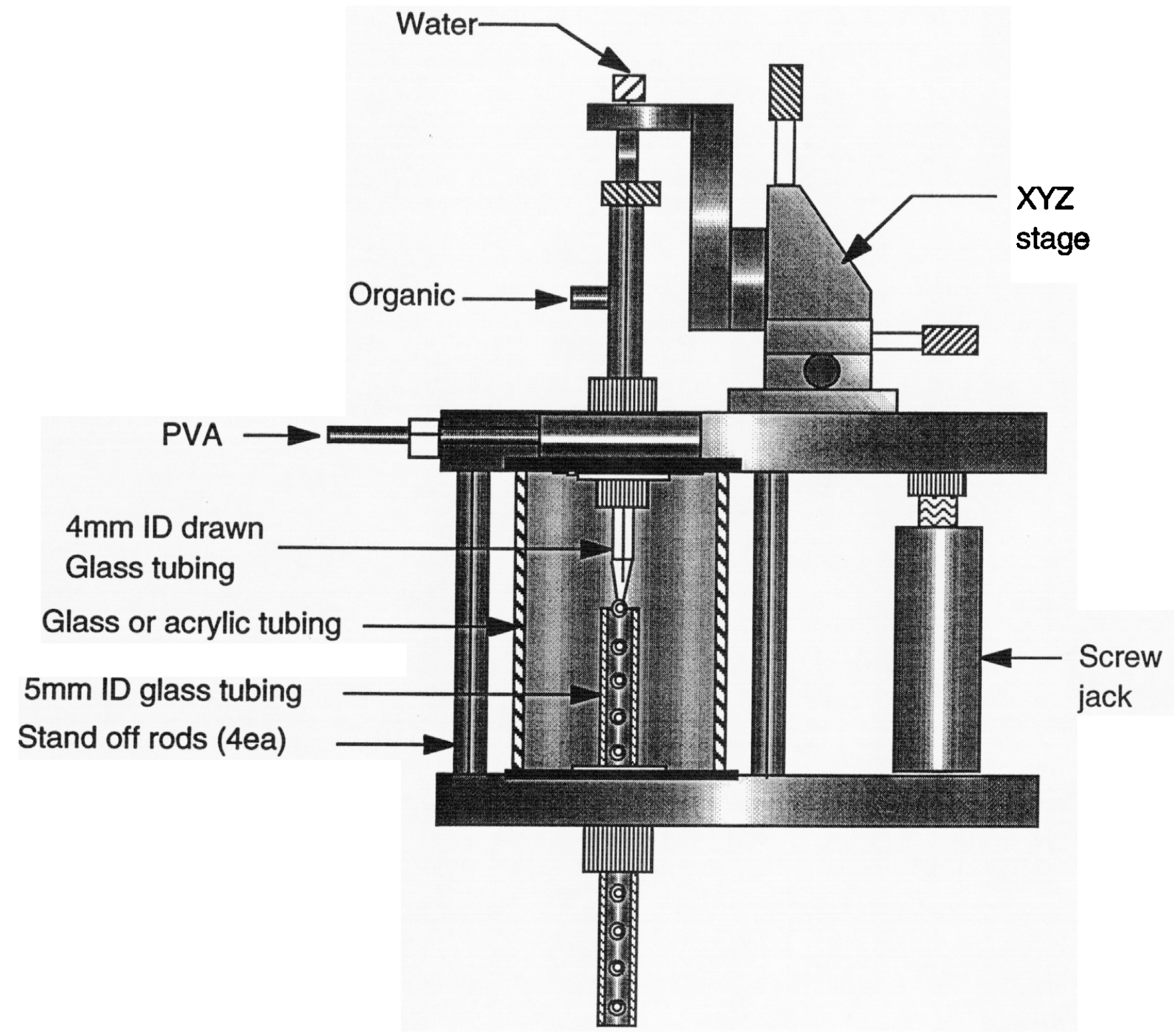

Fig. 6a: General Atomics droplet g rat 


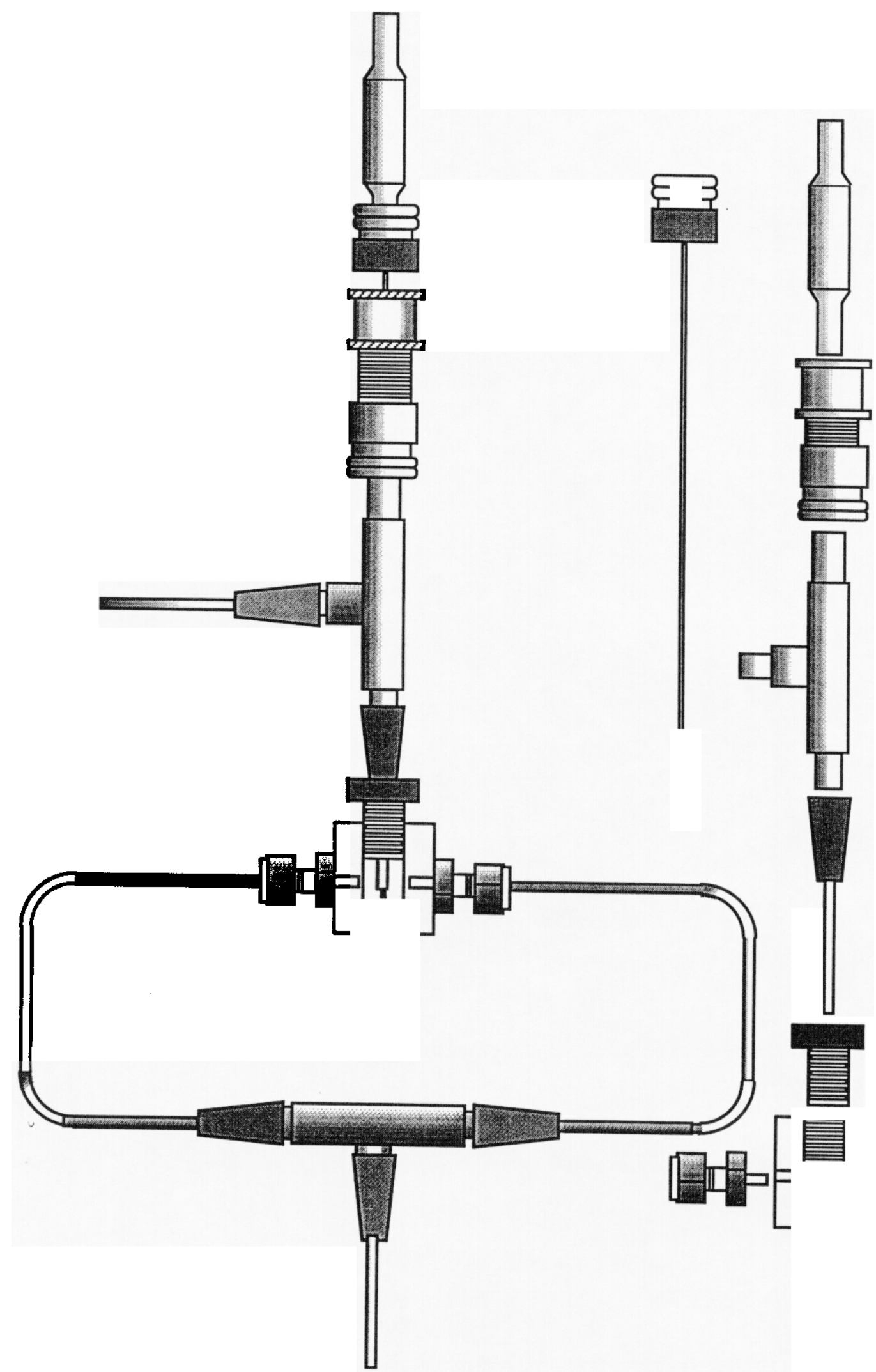

Fig. 6b: Soane-like Droplet Generator 


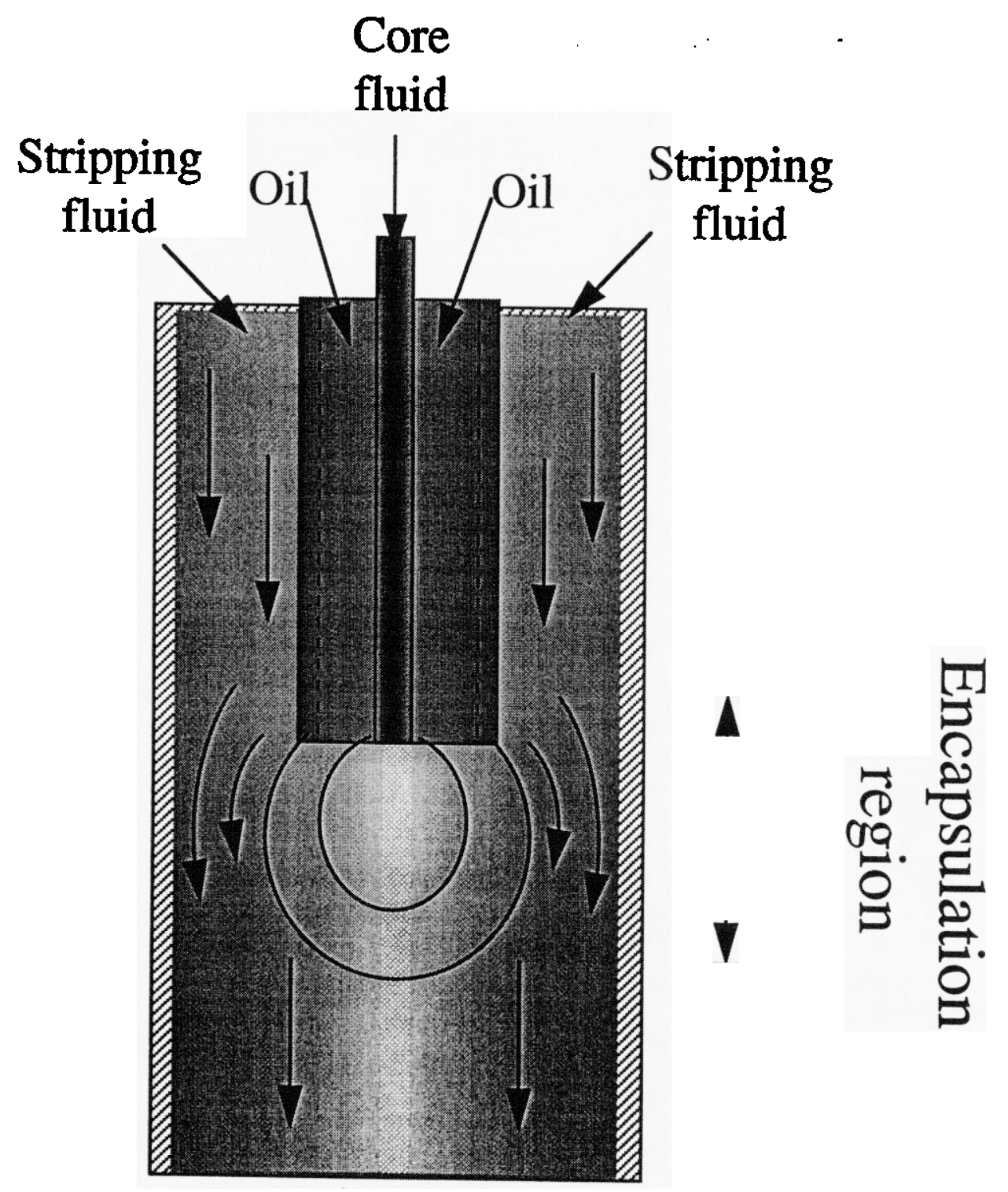

Fig. 7: The encapsulation process involving three fluids, the core, aqueous fluid, the polymer solution /oil, and the aqueous stripping fluid. 


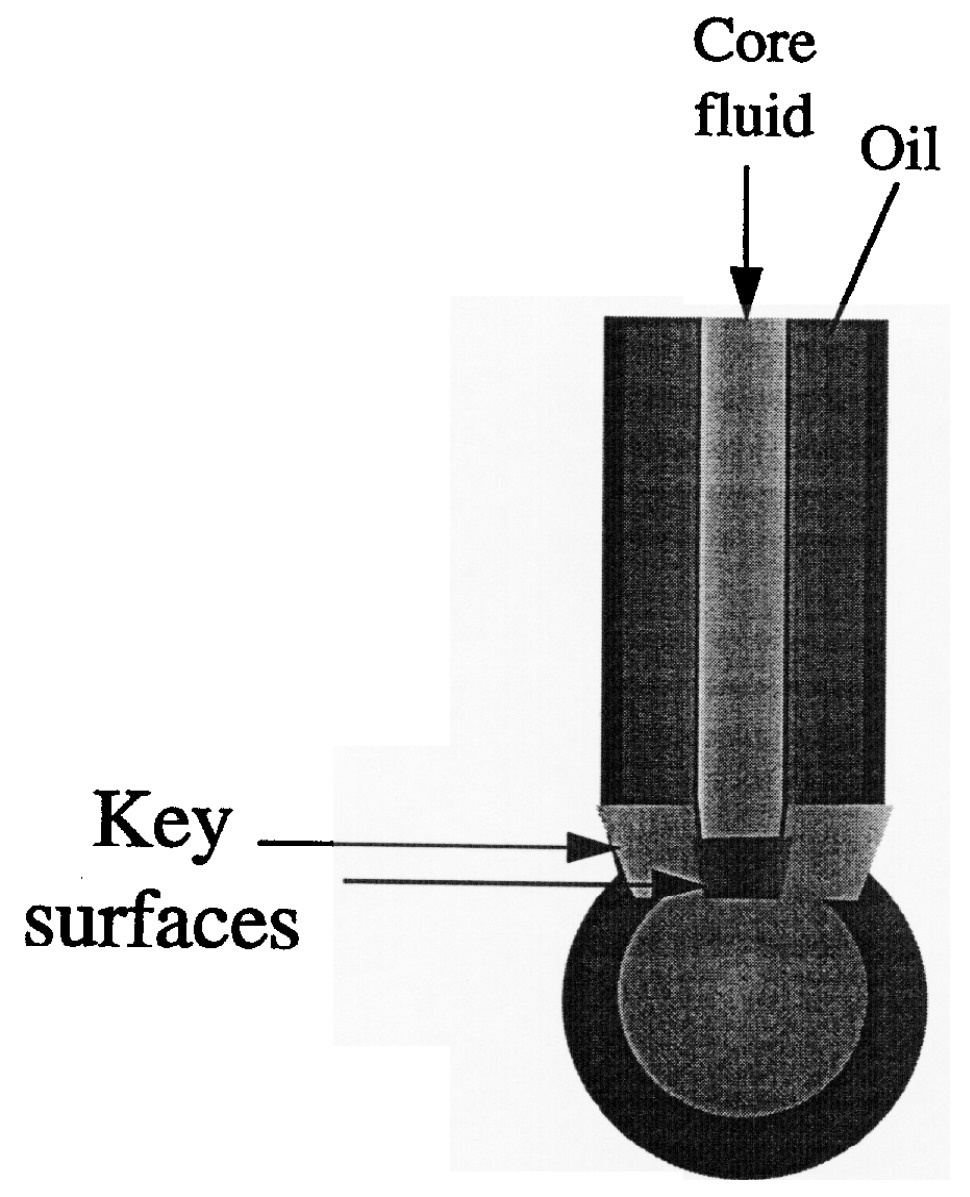

Fig. 7b: The key surfaces involved in reliable encapsulation are the exterior surface of the inside (core fluid) orifice/syringe and the exterior surface of the oil fluid orifice / syringe 
include: surface coatings, dirt or debris, surface roughness, polymer content, and orifice imperfections. It was not our goal entirely to get intimate details of the droplet generator. Our interest lies in the ability to encapsulate as desired and to encapsulate reliably.

The bottom line was simply whether the droplets would encapsulate or not. Our version of the GA/Osaka design had proven to be somewhat clumsy, had a propensity for leaking, and we had some difficulties getting encapsulation to occur at all. For these reasons, we returned to using a Soane-like droplet generator. After operating this device for eight months, we have found it to be quite reliable. Normal operation is shown schematically in Fig. 7. On occasion encapsulation difficulties were observed when either a burr was present at the end of an orifice or when a low molecular weight polymer was used. When this did occur, encapsulation frequently was initiated by one (or more) of the following routines (all of which alter the contact angle):

a) roughening the syringe with high grit sandpaper (alter contact angle)

b) pre-coating the syringes with a thin hydrophobic layer such as PS, P $\alpha \mathrm{MS}$, epoxy, or plasma polymer.

It is important to maintain a seal either at the end of the core fluid syringe or at the end of the oil syringe (Fig $7 \mathrm{~b}$ ). If either one or both of the conditions are met, encapsulation will occur. However, it is possible, if a pathway is given for the fluid, for the core aqueous phase to flow along a surface and directly into the PVA fluid (circumventing the oil phase and the encapsulation process entirely). In this case, only oil beads (organic solvent and dissolved polymer) are generated.

\subsubsection{Control of Shell Size}

After encapsulation is achieved, obtaining shells of the correct size is important. In both the GA / Osaka design and the Soane-like design, the shell size is controlled via the stripping fluid (PVA fluid) flow rate. Smaller encapsulated droplets are obtained, as the fluid moves more quickly past the droplet generator orifice exit. Early in the process, it was realized that ample PVA fluid flow was needed to get the proper stripping flow. It was clear that early efforts using a syringe pump were insufficient: Subsequent efforts utilized a peristaltic pump, and currently we are using a centrifugal pump (monitored by rotameter). In the Soanelike design, the orifices are entirely contained within the collection tube (a transfer line from the generator orifices to the solidification vessel). The ID of the collection tube has a large role defining the control of the shell size. In general, we observe an inversely proportional relationship between shell size and PVA flow rate (Fig. 8). It possible to shift this entire curve up or down by simply increasing or decreasing the $\mathrm{ID} /$ size of the tube. Initially we were generating shells that were $2.3-2.8 \mathrm{~mm}$ in size with a $4 \mathrm{~mm}$ ID collection tube. However, in order to better match the goal of the NIF program, we have taken steps to calculate the collection tube ID we would need to get shell that were $2.0 \mathrm{~mm}$ in diameter.

To do so, it was necessary to examine the forces on the shell. There are three noteworthy forces that affect the translatory motion of the shell within the droplet generator, surface tension (related to orifice diameter), drag forces (related to $\mathrm{v}^{2}$ of 
Fig.8 - Effect of PVA Flow Rate and Collection Tube Inner Diameter on Dry Shell Diameter

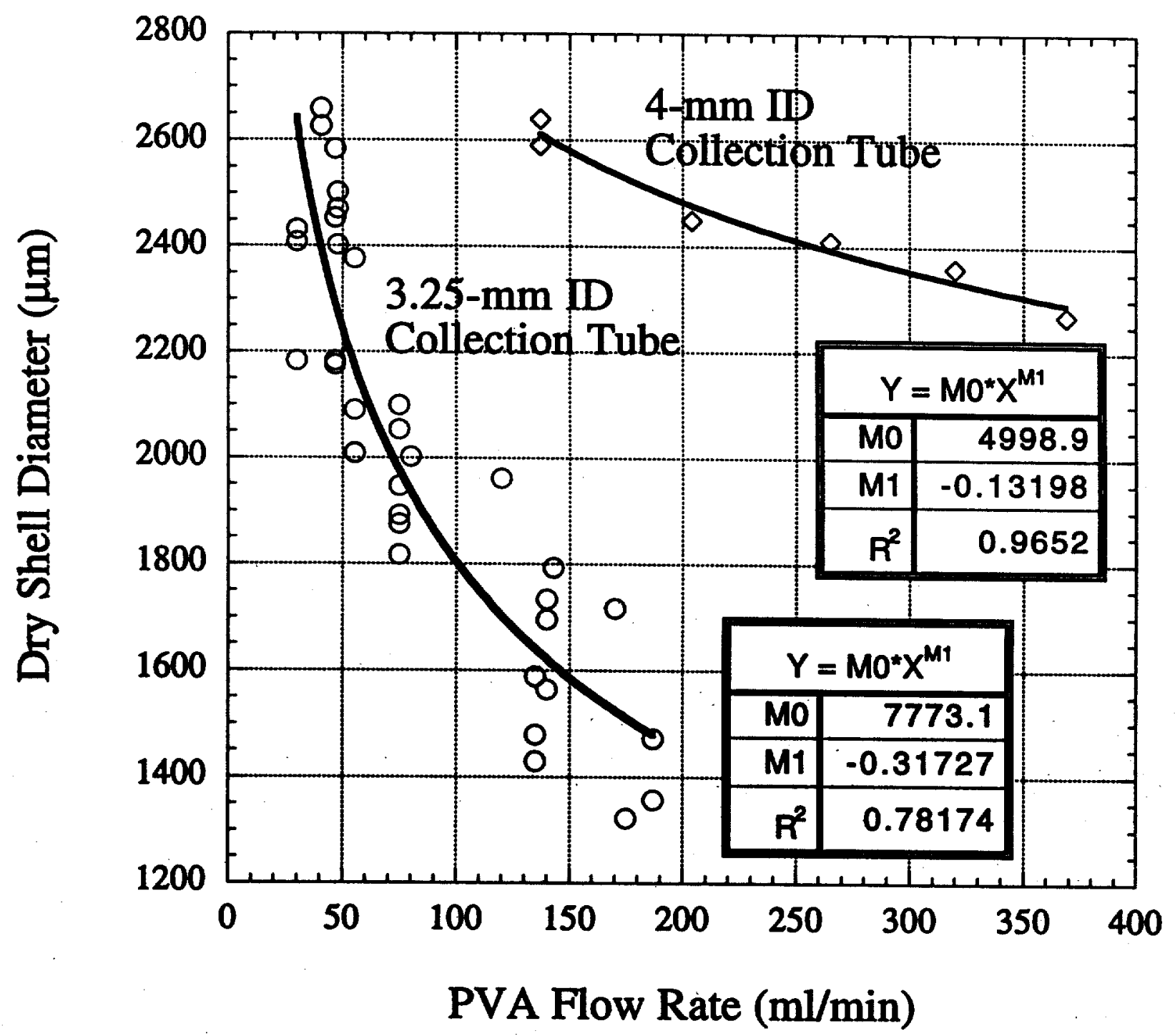


the passing fluid), and weight/buoyant forces (related to the density mismatch between oil and stripping fluid, $\Delta \rho)$.

$$
\begin{gathered}
F(\text { total })=F(\text { surface tension })-F(\text { weight } / \text { buoyancy })-F(\text { drag })=0 \\
\Sigma F=2 \pi R \gamma \sin \alpha-\Delta \rho(4 / 3) \pi r^{3} g-0.5 C_{D} \rho v^{2} A=0
\end{gathered}
$$

where $C_{D}$ is the drag coefficient for a sphere, $r$ is drop radius, $R$ is the tube radius, $\gamma$ is the interfacial tension (taken to be $27 \mathrm{dyne} / \mathrm{cm}$ representing the value for a water/F-benzene interface), $\alpha$ is the fluid contact angle, $v$ is the local fluid velocity within the tube /annulus, and $\mathrm{A}$ is the projected area of the forming droplet. By using this expression, it was possible to calculate the forces on a droplet as it grew in size. In order to be able to calculate the drag forces accurately, it was necessary to know the velocity profiles of the stripping flow in the collection tube. It was presumed that the fluid flow by the orifice was hydrodynamically well-developed so that we could ignore the entrance effects (this is unlikely to be the case, but it presumed for simplicity. Typical PVA flow rates are in the $100-300 \mathrm{ml} / \mathrm{min}$ range for a $4.0 \mathrm{~mm}$ collection tube corresponding to Reynolds numbers that are in the range of 800-2000 (laminar flow for $\operatorname{Re}<2000$, turbulent flow for $\operatorname{Re}>4000$ ) and slightly higher if one consider the presence of the forming droplets. The fluid flow between the oil orifice and the collection tube can be described by annular flow with the following expression describing the velocity profile in the annulus (Fig. 9):

$$
V(R)=\frac{1}{4 \mu} K\left[a^{2}-r^{2}-\frac{a-b^{2}}{\ln (b / a)} \ln \frac{a}{r}\right] \text { for axial concentric annular flow }
$$

where $a$ is the radius of outer cylinder, $b$ is the radius of inner cylinder, $\mu$ is the viscosity, and $\mathrm{K}$ is a constant describing the magnitude of the axial pressure drop. With this expression for velocity profiles it is possible to calculate the total drag force on the growing droplet. A plot of the total drag force as well as the surface tension force and droplet weight on the growing sphere is given in Fig 10. For comparison, the sum of the forces is also plotted on the same axes. It should be noted that the point at which the sum of the forces equals zero is 0.058 . This corresponds to a $2.3 \mathrm{~mm}$ droplet diameter which is also the size of the shell obtained by experiment with the $4.0 \mathrm{~mm} \mathrm{ID}$ tube.

By assuming a collection tube diameter and using a trial and error procedure, one can calculate the force balance based on the predicted velocity profile such that one obtains a droplet size in the $2.0 \mathrm{~mm}$ range with much slower PVA fluid flows. It was calculated for a $3.25 \mathrm{~mm}$ ID collection, one would have much greater droplet size sensitivity in the $2.0 \mathrm{~mm}$ range. Experimentally, this is exactly what was observed. The observed droplets were approximately $2.0 \mathrm{~mm}$ for the $3.25 \mathrm{~mm}$ collection tube and $\sim 75 \mathrm{ml} / \mathrm{min}$ stripping fluid flow.

It should also be noted that there is some variability of shell size and wall thickness within a batch (Fig. 11); however, these values are quite modest. The median wall thickness of $20.3 \mu \mathrm{m}$ agrees quantitatively with a relative fluid flow rates of 3 to 1 and a droplet production rate of 150-225 shells per minute.

\subsubsection{Control of Shell Wall Thickness}



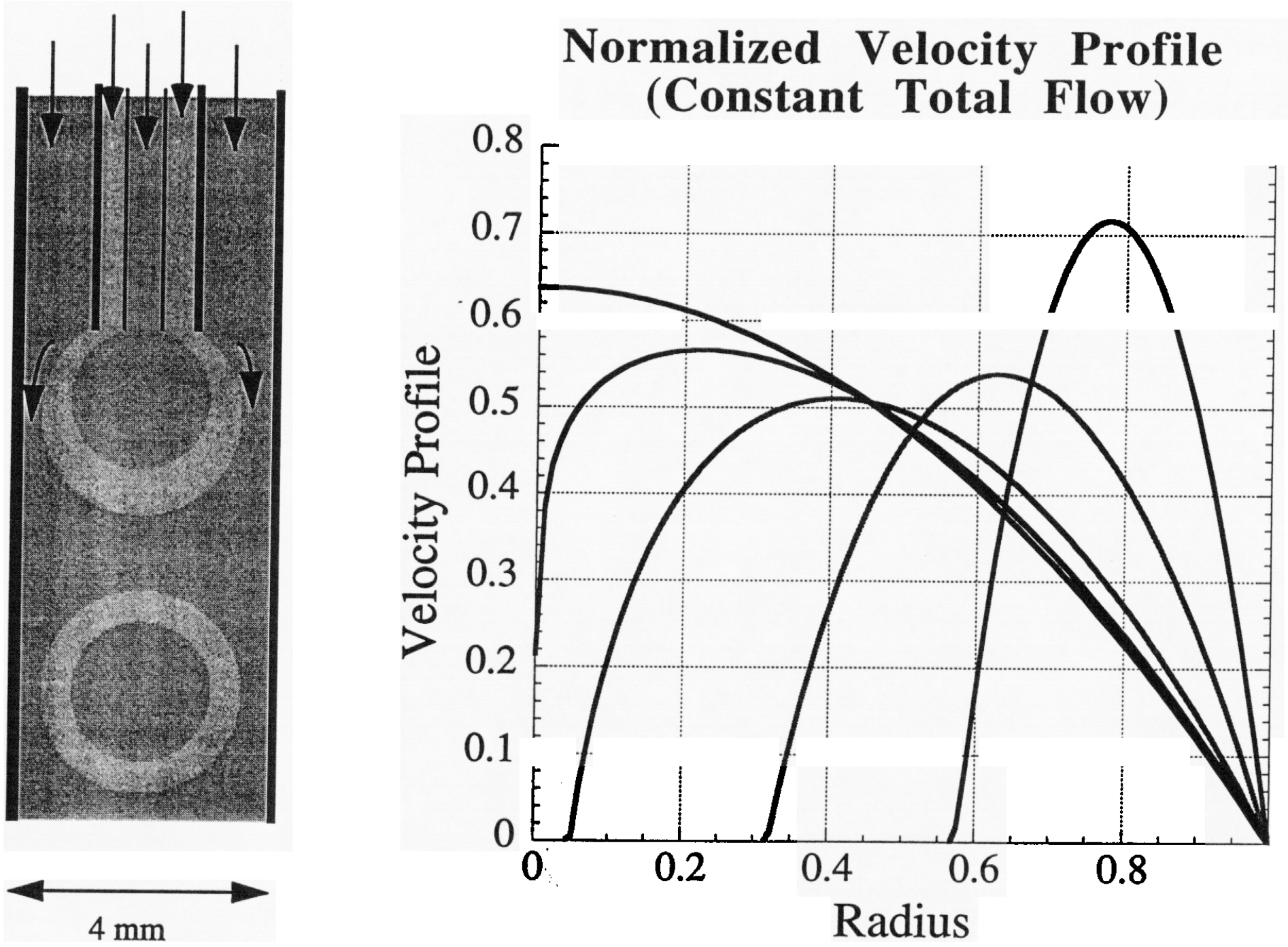

Fig. 9: Velocity profiles are important in determining the size of the encapsulated droplets. The graph includes velocity profiles for cylindrical tube and an annulus $b / a=0$ (a tube), $0.001,0.05, b / a=0.32$ (the position of the oil syringe with respect to the collection tube), and $b / a=0.58$ (the aspect ratio for the size shells obtained. $\mathrm{R}=0$ correspond to the centerline position and $\mathrm{R}=1$ corresponds to the outer wall of the conduit. The velocity profiles have been determined for a constant total flow rate. 


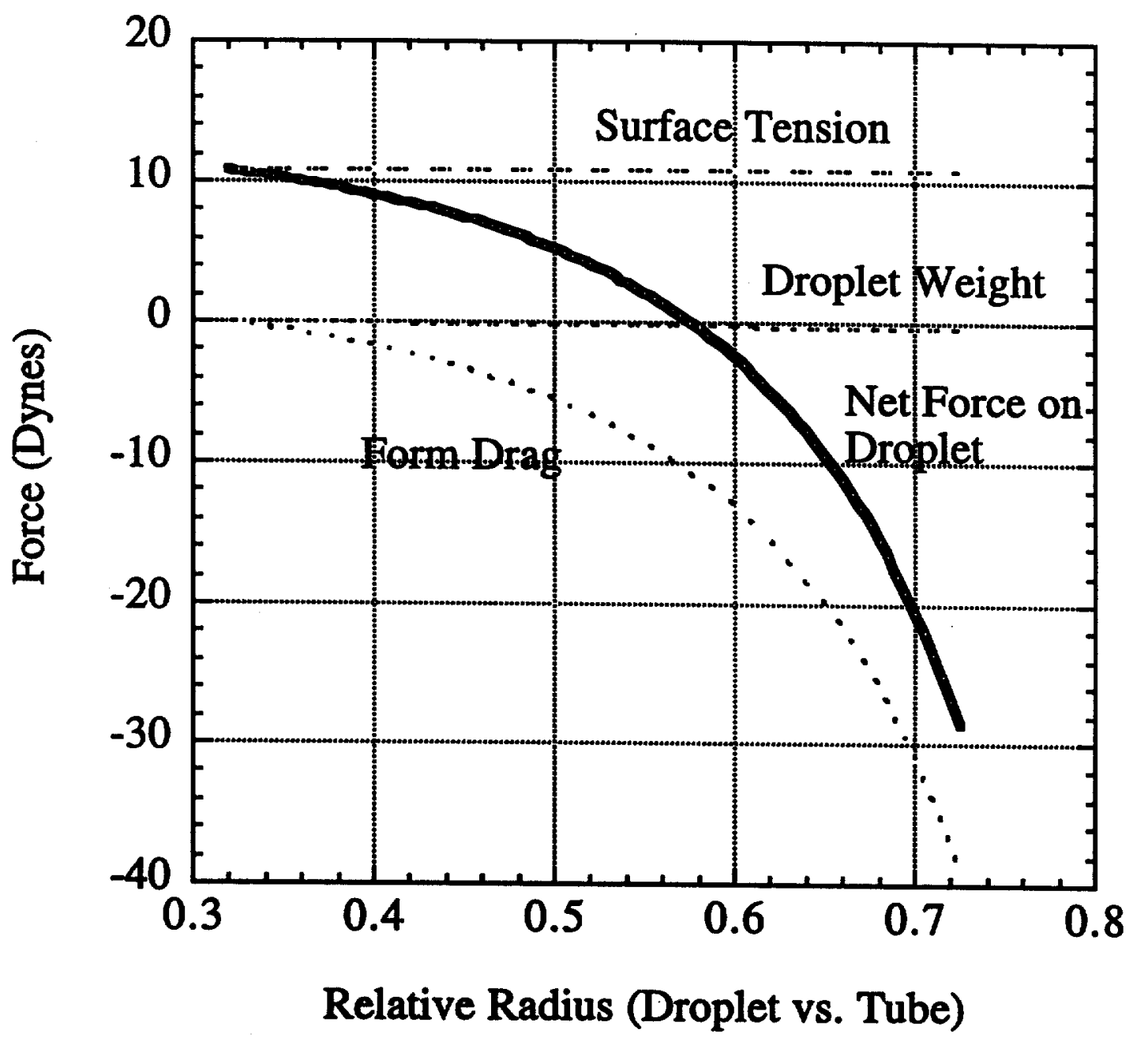

Fig. 10: Drag forces and velocity profiles control shell sizes. It is a balance of the adherend / surface tension forces, the droplet weight, and form drag that control the shell size. A compound droplet leaves the syringe orifice when the sum of the forces equals zero. In this case (with a 4-mm ID collection tube and $200 \mathrm{ml} / \mathrm{min}$ stripper fluid flow rate), it occurs at a relative radius of 0.575 which corresponds to $0.115 \mathrm{~cm}$ and $23 \%$ of the cross-sectional area of the collection tube. The actual shell size and predicted shell sizes ( $2.3 \mathrm{~mm}$ diameter) were in agreement. 
a)

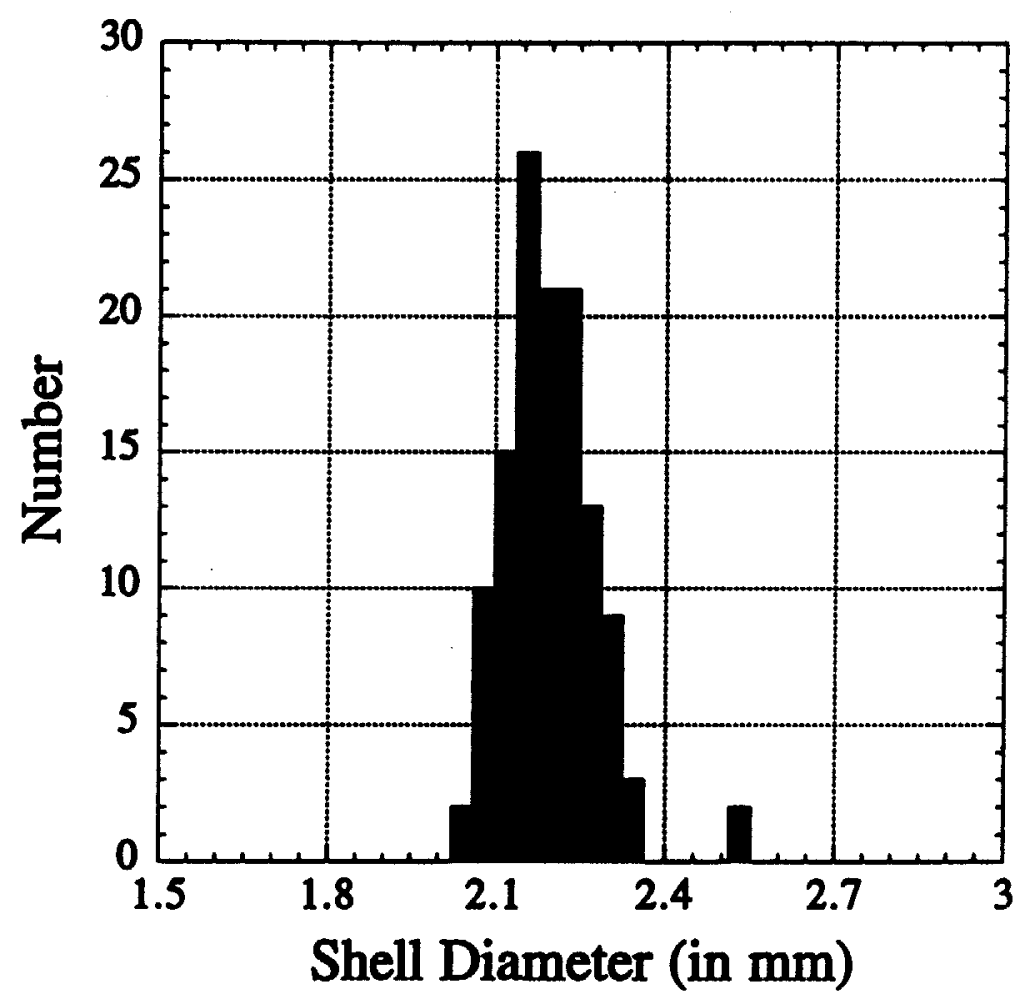

b)

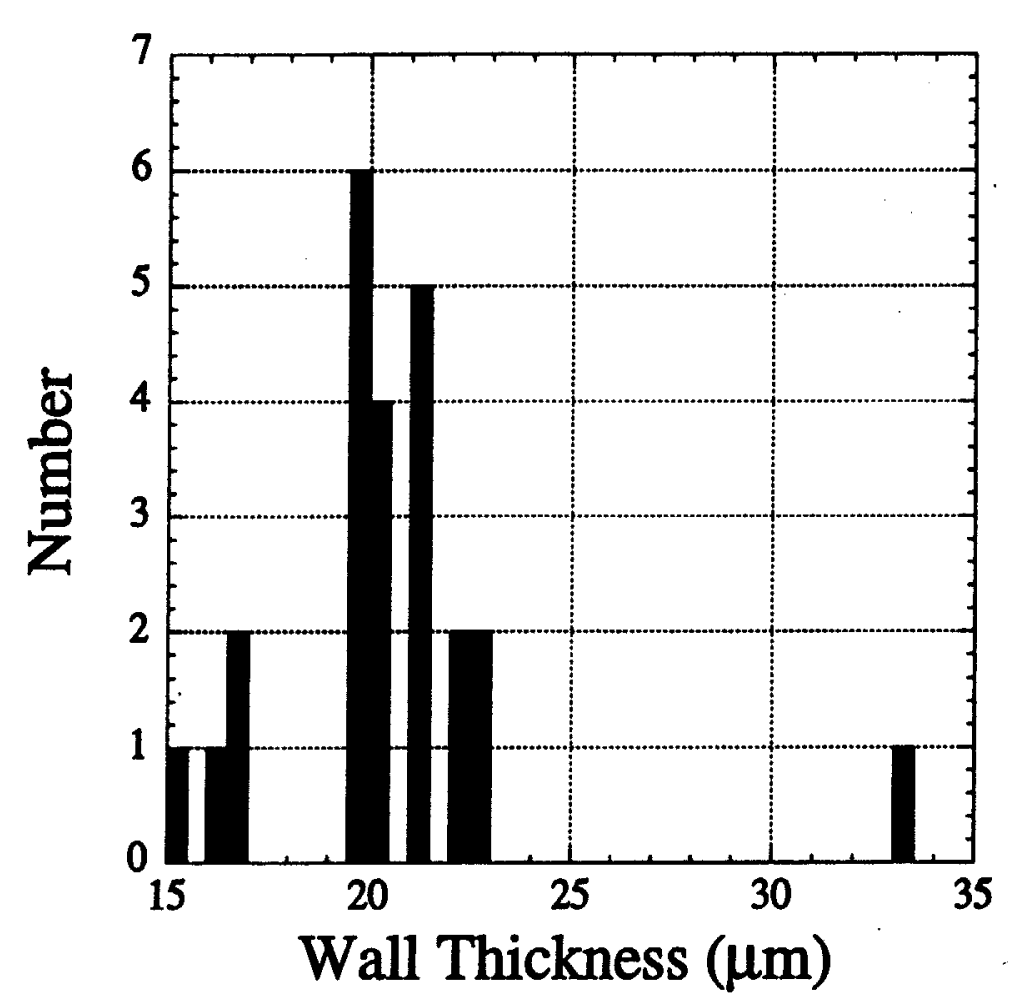

Fig. 11. A typical microencapsulation run will have a distribution of a) shell diameter and b) wall thickness. The median shell diameter of $2.21 \mathrm{~mm}$ and a standard deviation of $0.075 \mathrm{~mm}$ (as determined by either unitron or RACI). Wall thicknesses are determined by interferometry. Each number represent an average of two opposite wall on a shell. A median wall thickness of $20.3 \mu \mathrm{m}$ agrees quantitatively with a mass balance and a production rate of $150-225$ shells $/ \mathrm{min}$. 
Fig. 12: Shell Wall Thickness as a function of Relative Core to Oil Flow Rates (for 2.0-mm shells, $15 \mathrm{wt} \%$ polymer, $0.6 \mathrm{ml} / \mathrm{min}$ oil flow rate)

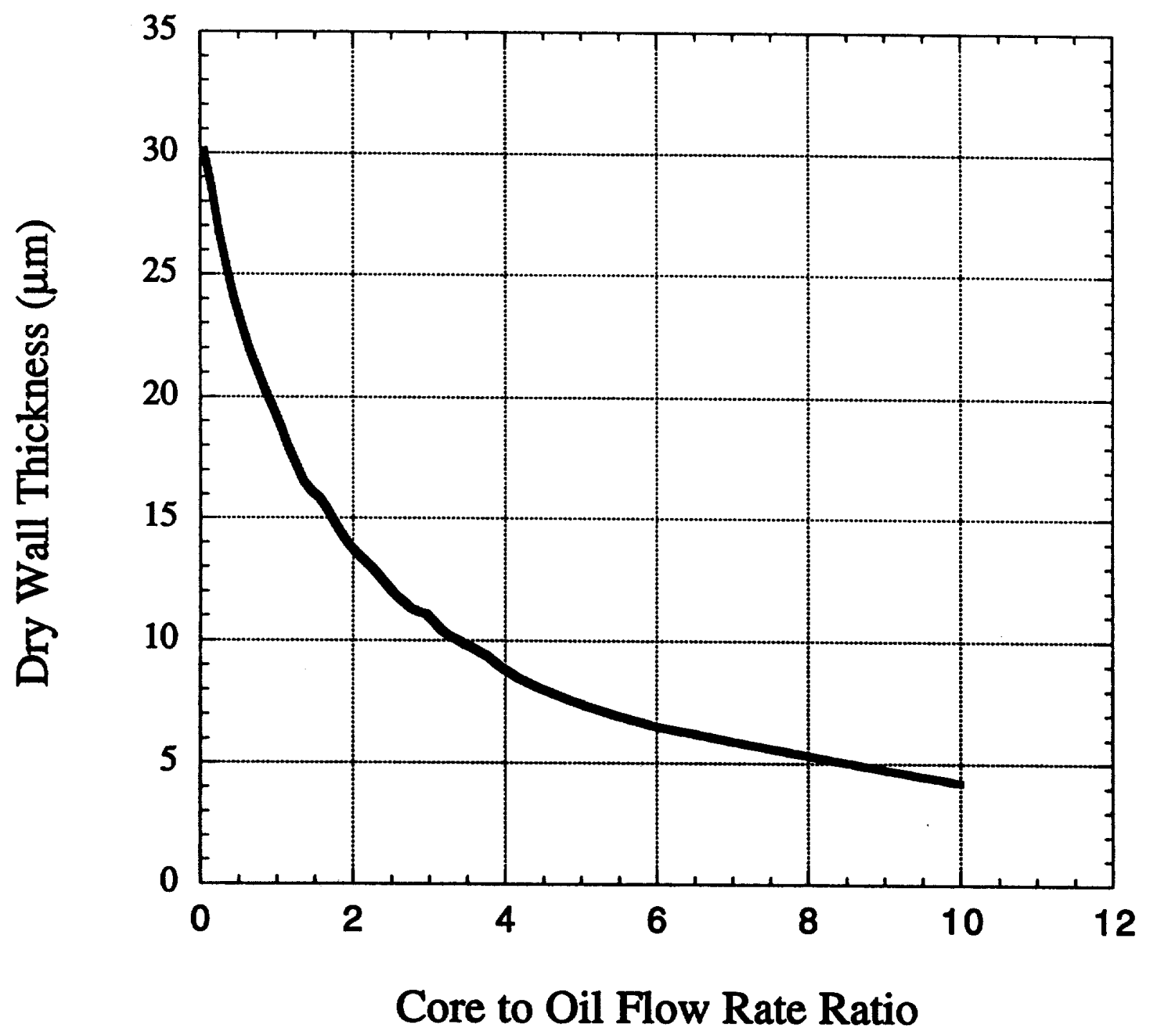


One way to control final shell wall thickness is to adjust the relative core to oil flow rate. This will adjust the relative volume occupied by each of the phases. Obviously as the relative core to oil flow rate increases the wall thickness decreases (at a given combined core and oil flow rate), (Fig. 12). The outer diameter of the forming shell is controlled by the stripping flow rate (see previous section). Similarly, one may adjust the wall thickness by adjusting the polymer concentration in the oil phase. Wall thickness increases as initial polymer content increases. Not a great deal of experimentation has been done in this area. However, early efforts suggest that there is some enhanced core-retention stability with the thinner walled droplets. Droplets with thick walls tended not to survive the solidification process. This may be due various underlying causes (some of which is related to the particular processing method used). These shells were solidified in a rotating rotary evaporator vessel and heated water bath while recent shell batches have been prepared in a stationary beaker. Alternatively, this may be due to differences in drag forces present for concentric droplets (Happel, 1965). Nonetheless, this experiment may be worth revisiting with current solidification techniques and shell sizes.

Throughout the year, a range of shell sizes have been examined. Most of the shell batches have been made at a relative core to oil flow rate of 3 to 1 . This, of course, begs the question: at a given relative fluid flow rate, does the dry shell wall thickness change as one generates larger or smaller shells? The answer is yes. The wall thickness increases as the droplet gets bigger (for a given core : oil flow rate ratio). It varies as the droplet volume to the $1 / 3$ power (Fig. 13) or as the droplet radius to the first power according to the following expression for wall thickness, $w$ :

$$
w=\frac{d}{2}\left(1-\frac{1}{\sqrt[3]{\frac{C F p_{0}}{\rho_{p}}}}\right)
$$

where $\mathrm{d}$ is the outer diameter of the dry shell, $\mathrm{C}$ is the initial concentration of the polymer in solvent (in vol\%), $F$ is the relative flow rate of oil to core, $\rho_{0}$ is the density of the oil phase, and $\rho_{p}$ is the density of the dry polymer. Therefore the larger droplet have a thicker shell wall and longer solidification times (as the diffusion path length increases).

\subsubsection{Oil -Phase Density Matching}

It is believed that it is necessary to mininize the density mismatch of a) the core and oil phases and $b$ ) the composite drop density and the bath fluid. The latter density match condition is necessary to find the correct condition for the shells to float in the PVA bath since we are not using mechanical means to suspend the droplets. Efforts in meeting both these criteria are hampered by the temperature dependent densities of the three phases (water, PVA solution, and oil phases). Additionally the oil phase (i.e., a polymer solution) changes density as the lighter Fbenzene dissipates into the aqueous phase. Furthermore, the densities are all temperature dependent (Fig. 14) as well as the permeation rates of solvent from the 
Fig. 13 - Wall Thickness as a function of shell size at constant core to oil flow rate ratio (3:1)

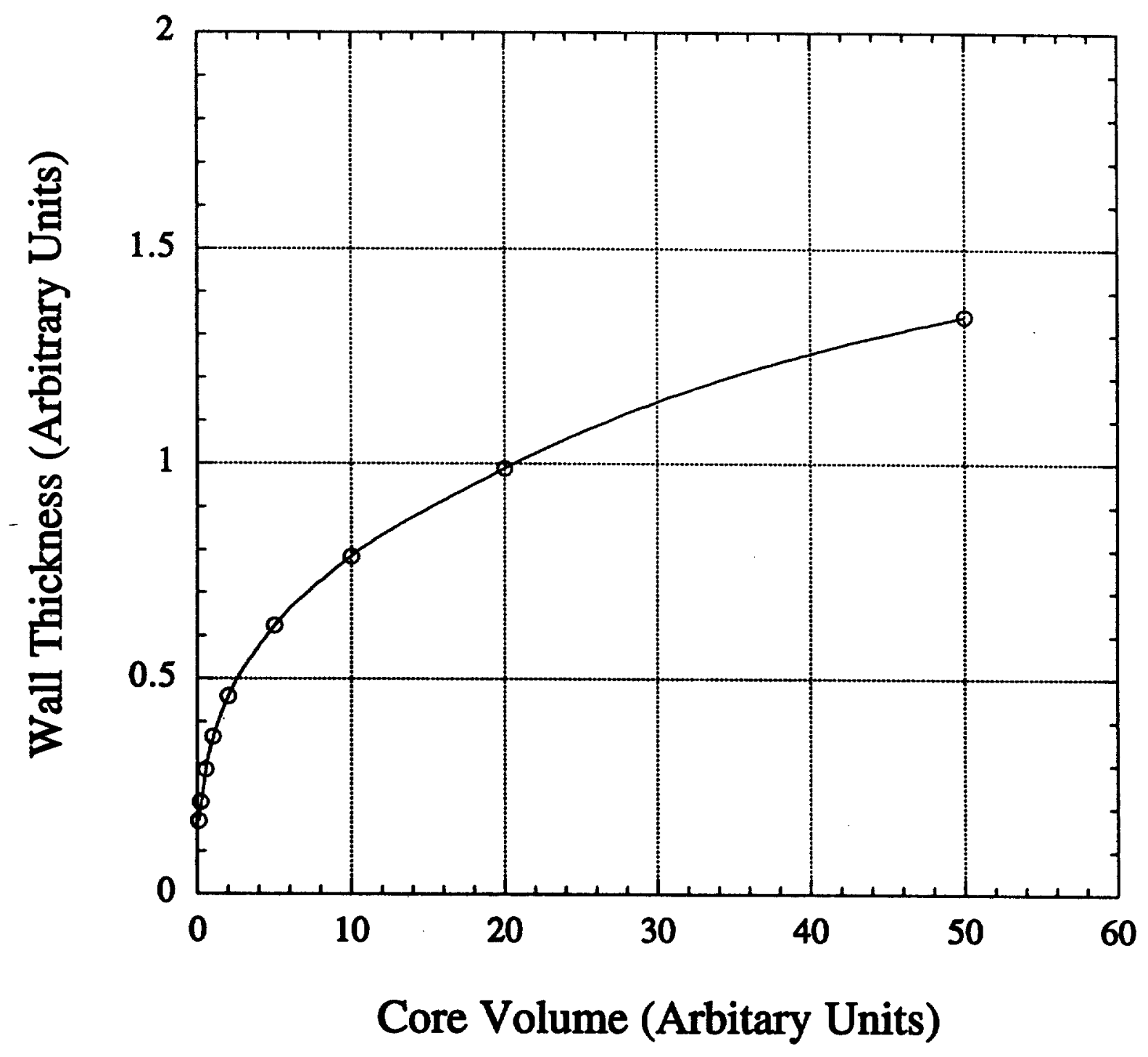




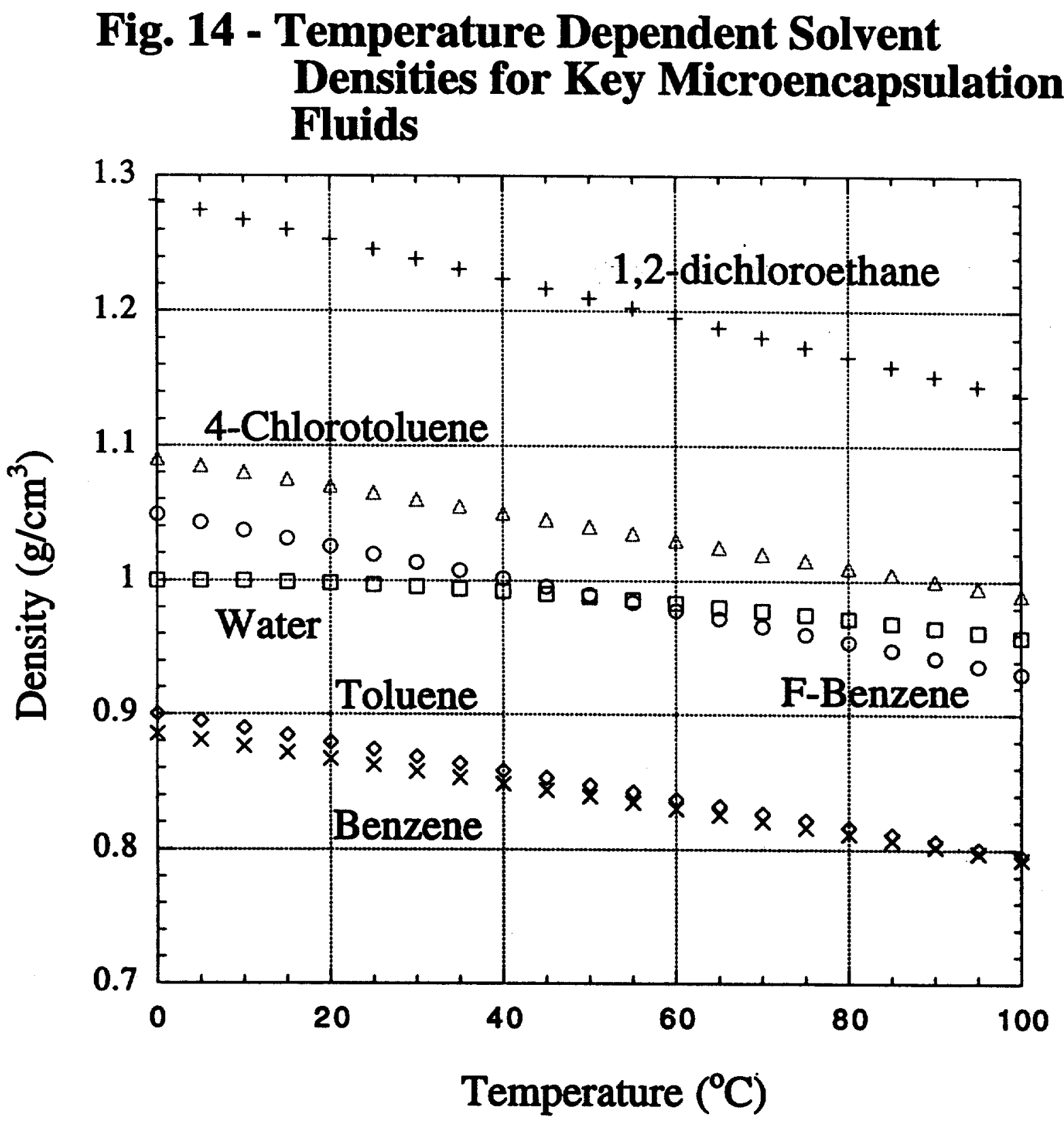




\section{Table 1: Solubility Information on Key Organic Solvents to be used in Microencapsulation}

\begin{tabular}{|c|c|c|c|c|c|c|c|c|}
\hline Fluid & $\begin{array}{l}\text { Density } \\
\left.\text { (in } \mathrm{g}^{\prime} \mathrm{cm}^{3}\right) \\
\text { at } 25^{\circ} \mathrm{C}\end{array}$ & $\begin{array}{c}\text { Solnbility } \\
\text { in } B_{2} 0 \\
(w t \%) \\
\left(\alpha_{12}\right)\end{array}$ & $\begin{array}{l}\text { Relative } \\
\text { Solubility } \\
\text { (Tolu.=1) }\end{array}$ & $\mathrm{T}\left({ }^{\circ} \mathrm{C}\right)$ & $\begin{array}{c}\mathrm{H}_{2} \mathrm{O} \\
\text { Solubility } \\
\text { in fluid } \\
(w \mathrm{t} \%) \\
\left(\alpha_{21}\right)\end{array}$ & $\begin{array}{c}\text { Relative } \\
\text { Solubility }\end{array}$ & $\mathrm{T}\left({ }^{\circ} \mathrm{C}\right)$ & $\begin{array}{c}\alpha_{11} / \alpha_{21} \text { ratio } \\
\text { (estimate) } \\
\mathrm{T}=25^{\circ} \mathrm{C}\end{array}$ \\
\hline Benzene & 0.87897 & 0.1791 & 3.48 & $\overline{25}$ & 0.0635 & 2.01 & 25 & 2.82 \\
\hline Toluene & .86219 & 0.0515 & 1.00 & 25 & 0.0334 & 1.06 & 25 & 1.54 \\
\hline F-benzene & 1.0190 & 0.1530 & 2.97 & 30 & 0.0316 & 1.00 & 25 & 4.84 \\
\hline $\begin{array}{l}\text { 4-Chloro- } \\
\text { Toluene }\end{array}$ & 1.0647 & N/A & N/A & $\overline{N / A}$ & N/A & $\overline{\mathrm{N} / \mathrm{A}}$ & N/A & N/A \\
\hline $\begin{array}{l}\text { 1,2-Dichloro } \\
\text { ethane } \\
\text { (DCE) }\end{array}$ & 1.2449 & 0.810 & 15.7 & 20 & 0.1870 & 5.917 & 25 & 4.33 \\
\hline
\end{tabular}

Note 1: Data from Organic Solvent Handbook

Note 2: DCE is the only non-aromatic solvent considered

Note 3: While $\alpha_{12}$ is a measure of the "diffusion sink" strength, the $\alpha_{12} / \alpha_{21}$ ratio is a measure of the "diffusion sink" relative to the oil phase water uptake (and potential vacuole formation through supersaturation after subsequent oil solvent diffusion). It is desireable to have both of these valuses be as high as possible.

Note 4: $\mathrm{d} \alpha_{12} / \mathrm{DT}$ and $\mathrm{d} \alpha_{21} / \mathrm{DT}$ would be helpful for process variable selection (obtain or predict phase diagrams for individual solvent systems as a function of $T$ ). 


\section{Fig. 15: Large Density Swing Observed with Toluene / 1,2-Dichloroethane Binary Solvent System (for PS)}

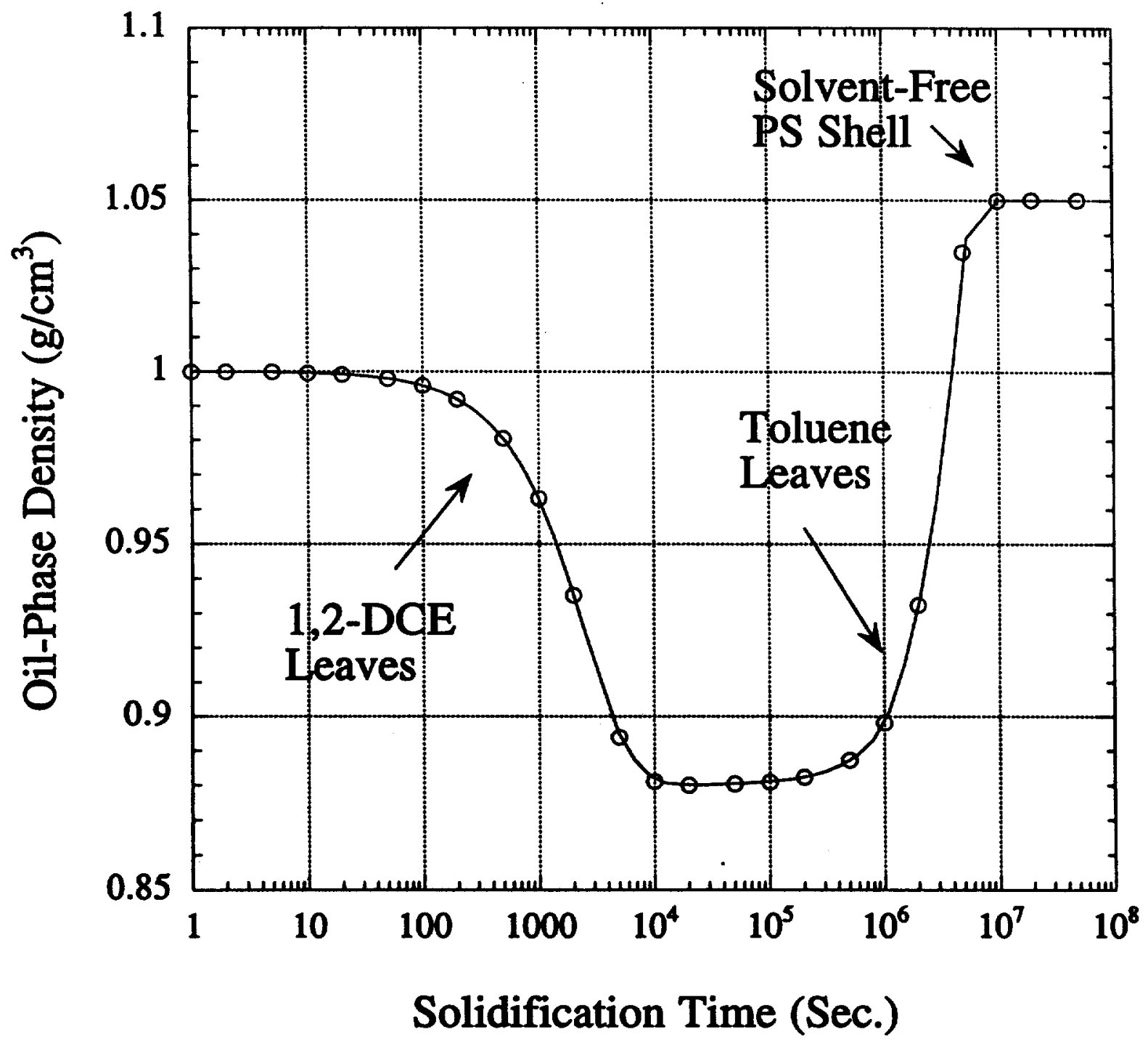


oil phase into the aqueous phase. Permeation rate is a function of both diffusion coefficient and solubility. Solubility values for organic solvents in water and water in the organic solvent are given in Table 1.

It was originally thought that one could attain any oil phase density one would like if one uses a mixture of two solvents, e.g., 1,2-dichloroethane (DCE, $\left.\rho=1.256 \mathrm{~g} / \mathrm{cm}^{3}\right)$ and toluene $\left(\rho=0.8669 \mathrm{~g} / \mathrm{cm}^{3}\right)$. However, it was found that this was difficult to implement since the relative permeation rates of DCE and toluene was so disparate. The dense DCE would permeate quickly into the aqueous phase leaving behind a light oil phase (Fig. 15). The net result of this was that the core fluid would exit through the bottom of the shell; this is without consideration of the concentric sphere drag force described by Happel and Brenner (1965). The velocity of the core fluid is given by:

$$
\mathrm{V}_{\text {core }}=\mathrm{g} \mathrm{D}_{\text {core }}^{2}\left(\rho_{\text {core }}-\rho_{\text {oil }}\right) / 18 \eta_{\text {oil }}
$$

where $V_{\text {core }} D_{\text {core }} \rho_{\text {core }}$ are the terminal velocity, diameter, and density of the core fluid, respectively, and $\rho_{\text {oil }}$ and $\eta_{\text {oil }}$ are the density and viscosity of the oil phase, respectively (both of which are time and concentration dependent). This expression is derived from a balance of effective weight (bouyant force) and the drag force (given by Stokes Law for a solid sphere). This corresponds to the condition where the sum of the forces is equal to zero and the condition of zero acceleration. There were not any obvious solutions to the problem despite some efforts to minimize this effect. Since we knew the core fluid would exit out of the bottom of the droplet, we tried adjusting the mixture so that there was less of the lighter fluid to start out the experiment. It was conceivable the oil phase would "solidify" before the core could exit. Unfortunately, these experiments did not work. The inherent problem is that the density will be matched only for a short time, and that one solvent inevitably permeates faster than the other one. In the case of DCE and toluene, the density swings in the oil phase are quite large $\left(\sim p_{D C B}-p_{\text {tolvenes }}\right)$ whereas the core density is constant. The two solvent system could work successfully if the permeation rate of the two solvents were equal (no matter what densities the individual components were), (Fig. 16); the density swings would only be as large as the solution starting density and the final polymer shell wall density. As expected this varies depending on the polymer chosen, i.e., the wall density of P $\alpha M S$ is greater than that of PS, and PS is greater than wall comprised of poly(4-methyl styrene).

Soane Technologies, Inc. (STI) had been making smaller shells $(0.5$ to $1.0 \mathrm{~mm})$ successfully with the two solvent systems. We had started to work with the two solvent system, but we had found, for the reasons stated above, that the two solvent system was problematic. Since our early efforts with the two solvent system (October to December), we almost exclusively used F-Benzene as our organic solvent. The density swing is smaller (Fig. 17), and it is decreased as the initial polymer content in the oil phase is increased. The density of F-benzene is 1.024 $\mathrm{g} / \mathrm{cm}^{3}$ at room temperature $\left(20^{\circ} \mathrm{C}\right)$. Because water has a fairly low thermal expansion coefficient relative to most organic solvents, there is a cross-over in the curve for the temperature dependence of the oil phase density (polymer and FBenzene) with the curve for the temperature dependence of water (Fig. 18). In order to calculate the polymer solution density, we presumed the the solution was ideal, i.e., linear sum of volumes. Better estimates of solution densities can be made, but 


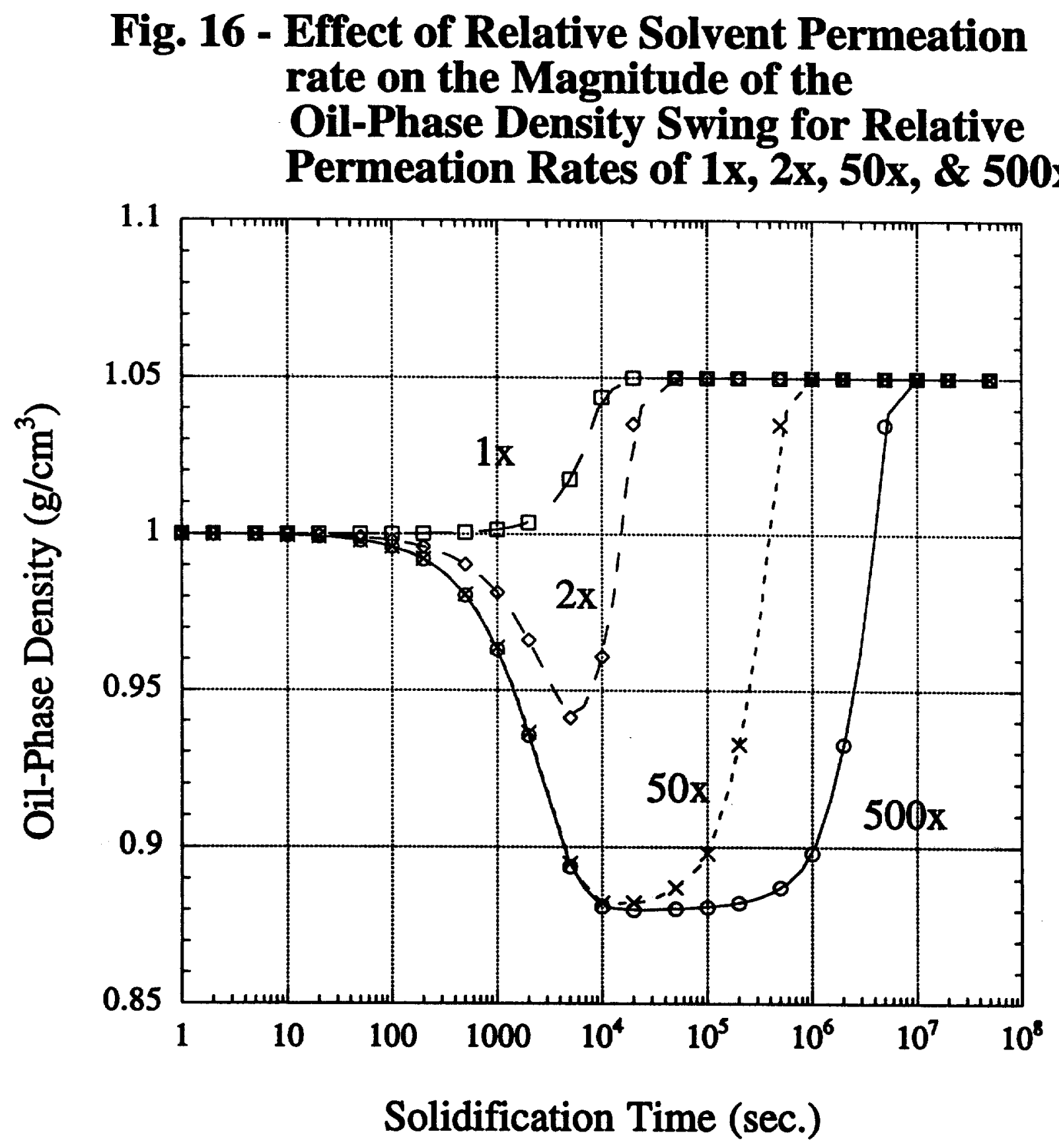




\section{Fig. 17 - Comparison of Oil-Phase Density Swing for a single (F-Benzene) and binary (Toluene / DCE) solvent system.}

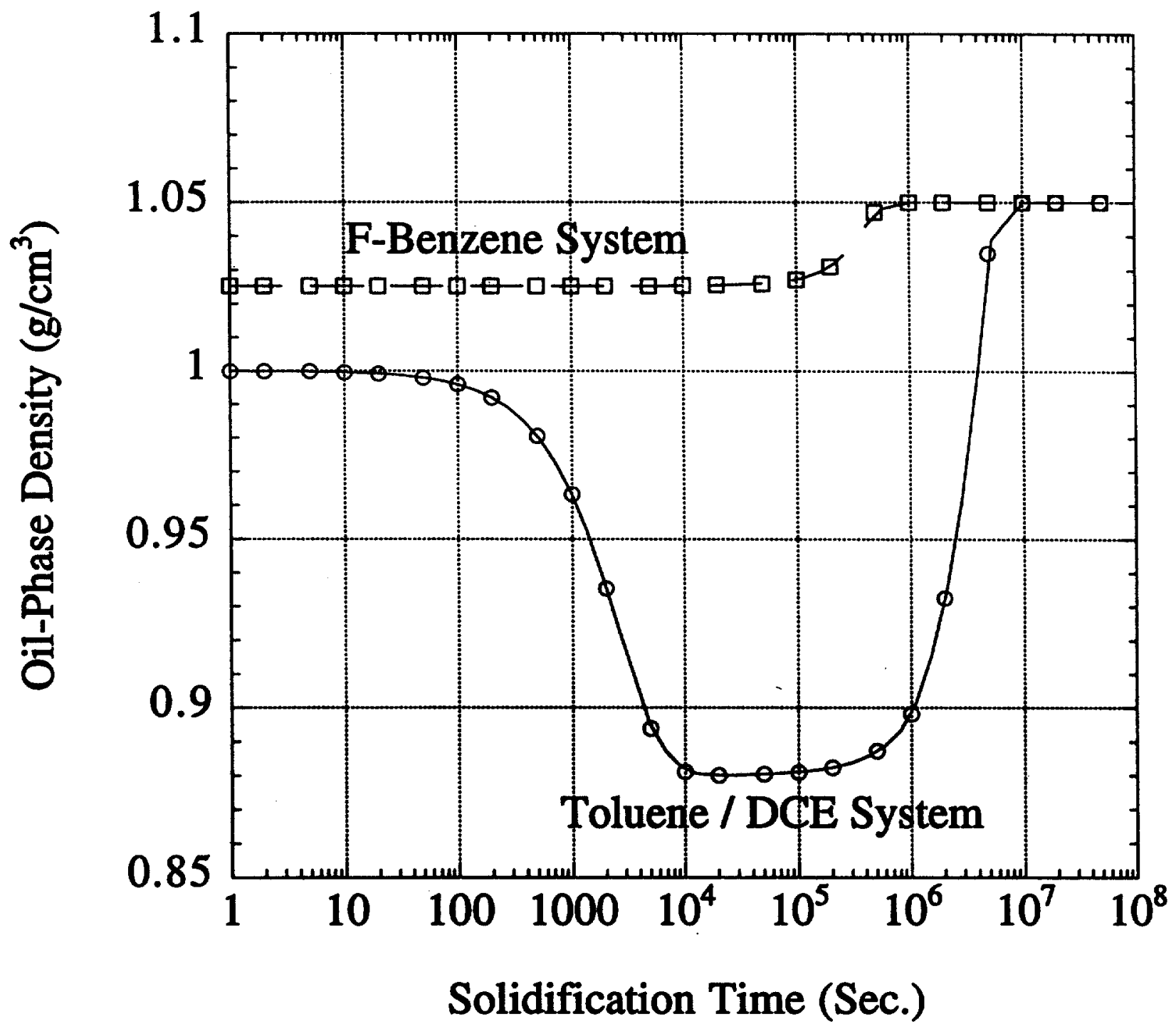


Fig. 18 - Control of T corresponding to DensityMatching due to Temperature Dependent Solvent Densities and Minor Phase Alterations

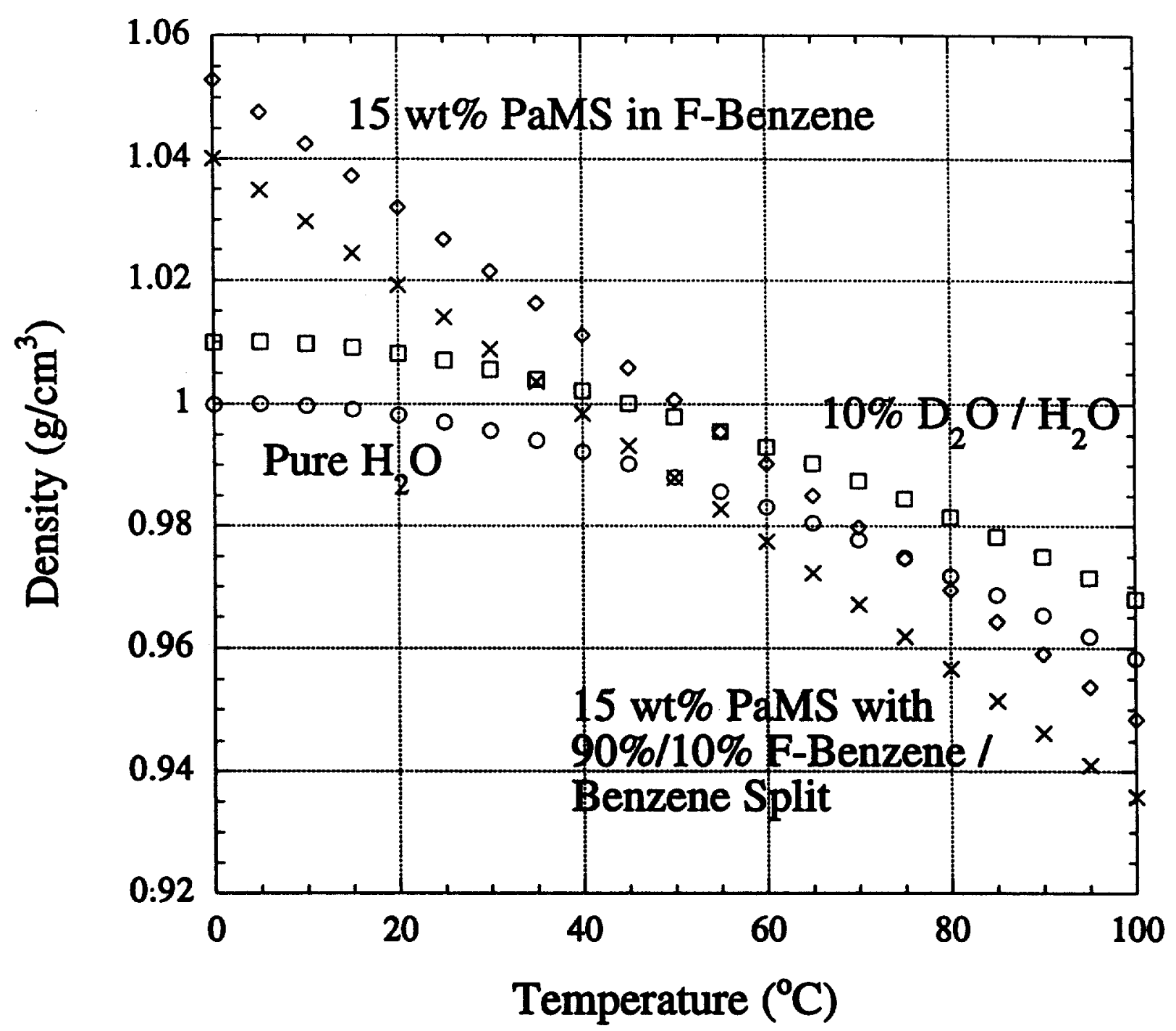


they require time consuming thermodynamic calculations. The difference in thermal expansion coefficients of the two phases results in an intersection of the fluid densities at $65^{\circ} \mathrm{C}$, hence our choice of solidification temperatures.

We have some control over the solidification temperature while still maintaining density matched conditions. We may alter it by adjusting each of the fluid phase densities (Fig. 18). We may increase the density of the core fluid by substituting a fraction of the core water with $\mathrm{D}_{2} \mathrm{O}\left(1.10 \mathrm{~g} / \mathrm{cm}^{3}\right.$ at $\left.0^{\circ} \mathrm{C}\right)$. We may decrease the initial density of the oil phase by adding a small fraction of benzene to the F-benzene; the permeation rates should be similar and the mixture should behave like a single solvent. We may increase the density of the PVA solution by adding saline solution to the bath (i.e., $2 \mathrm{wt} \% \mathrm{NaCl}$ solution). By making these adjustments, it is possible to find the solidification temperature that most effectively enhances the shell sphericity.

The expression given above for $V_{\text {core }}$ is calculated based on a sphere in an infinite medium, and it ignores wall effects as well as the condition in which the inner drop diameter is comparable to the outer diameter (where the outer phase can no longer be consider an infinite medium). In this case, the drag forces increases exponentially (Happel \& Brenner, 1965) as the diameter aspect ratio approaches unity (i.e., for thin walled structures):

$$
K=\frac{1-\left(\frac{1-\sigma}{1+\frac{2}{3} \sigma}\right) \lambda^{5}}{1-\frac{9}{4}\left(\frac{1+\frac{2}{3} \sigma}{1+\sigma}\right) \lambda+\frac{5}{2}\left(\frac{1}{1+\sigma}\right) \lambda^{3}-\frac{9}{4}\left(\frac{1-\frac{2}{3} \sigma}{1+\sigma}\right) \lambda^{5}+\left(\frac{1-\sigma}{1+\sigma}\right) \lambda^{6}}
$$

where $\sigma$ is the ratio of viscosities ( $\mu$ (outer) $/ \mu$ (inner)) and $\lambda$ is the ratio of radii $\left(r_{\text {inmer }} / r_{\text {outer }}\right)$. In the standard shell making procedure for $2 \mathrm{~mm}$ shells, we have a core to oil phase flow rate of 3 to 1 ; this corresponds to an initial $\lambda$ value of $\sim 0.88$.

During solidification this value increases until it reaches a dry shell wall aspect ratio, $\lambda$ equal to 0.98 (corresponding to $20-25 \mu \mathrm{m}$ wall thickness for a $15 \mathrm{wt} \%$ polymer solution). The correction term $\mathrm{K}$, defined as ratio of the drag in a concentric sphere to the drag in an infinite medium, would appear in the denominator of the $V_{\text {core }}$ expression, and in effect would retard the core droplet motion away from the concentric position. It is unclear how a non-trivial amount of eccentricity will differ from the concentric cases. To describe the motion / trajectory of the core fluid for a microencapsulated droplet, one needs to account for this eccentric condition. This results in the possibility of obtaining zero velocity. The eccentricity is a function of the droplet wall thickness, the degree of density mismatch, and the solution viscosity. This situation has been examined previously for viscous fluids (Sadhal, 1985). In our case, it is necessary to consider the fluid transport and drag forces with a polymer solutions than will have varying concentrations of polymer chains. This should result in both angular and radial variations.

To describe the trajectory / acceleration of the core fluid (and possibly simulate part of the solidification process), it is necessary to calculate the drag force 
of a liquid sphere moving through a second fluid (in the Stokes regime). The drag force is:

$$
\begin{aligned}
& \mathrm{F}=6 \pi \eta_{\text {oil }} \mathrm{r}_{\text {core }} \mathrm{V}_{\text {core }}(1+2 \sigma / 3) /(1+\sigma) \mathrm{K} \\
& \mathrm{F}=(\text { Stokes law drag) } \times(\text { viscos. correct.) } \times \text { (concentric sphere enhancement) }
\end{aligned}
$$

where the force is a product of Stokes law drag, a viscosity correction term for phases with differences in viscosity, and the concentric sphere correction. As the core droplet moves, it is likely that the $\lambda, K$, and the drag force will change thereby changing its velocity. The core may decelerate and find a final position or the droplet may reorient and move in another direction, i.e., random walk motion. While the core is accelerating and decelerating due to buoyant and drag forces, the oil phase viscosity is increasing due to transport of the solvent from the oil phase to the aqueous bath fluid.

\subsubsection{Comments on Droplet Solidification}

It is clear that the most important step in the microencapsulation process is the solidification step. The transformation of the oil phase in the encapsulated droplet proceeds through several stages (Fig. 19) until it becomes a dry shell. Initially it is present in semi-dilute or concentrated solution. The polymer concentration increases until it becomes a polymer gel. As further solvent is removed, it becomes a plasticized solid. Finally, it becomes a "dry" polymer film. Throughout the solidification process the properties of the oil phase change. The oil phase evolves from a material having a predominantly fluid character (viscous material) to an elastic solid material. The description / characterization means are different. The concentrated solution can be described in terms of a non-newtonian viscosity which the solid polymer film can be characterized in terms of Young's moduli, and Poisson ratios. Somewhere between the initial and final material, the surface features are defined. The transition can be described in terms of Deborah numbers, De, defined as the ratio of a characteristic relaxation time to experimental time scales for a given system. It is doubtfully the definition of surface occurs at either end point since the relaxation times are exceedingly short $(\mathrm{De}=0)$ and exceedingly long $(\mathrm{De}=\infty)$ at initial and final stages, respectively. Therefore, it is at an intermediate time that the surface features are defined $(\mathrm{De}=1)$. The time scale of surface deformations such as various mechanical perturbations, shell-shell interactions, and shell-wall interactions will be on the same order of magnitude as the restoring force (to sphericity), i.e., the minimization of interfacial area and the corresponding surface energies.

Needless to say, the manner in which the shell is solidified is important to the overall sphericity of the shell. Thus, this step has been the focus of the work so far. During solidification it is desirable to minimize the number and magnitude of deformational events imposed upon the solidifying shells. It is presumed that the shells will solidify in a spherical fashion unless they are perturbed from the spherical state (via these deformational events). This discussion will be revisited in 


\section{ENCAPSULATED DROPLET}

$\stackrel{\circ}{\otimes}$

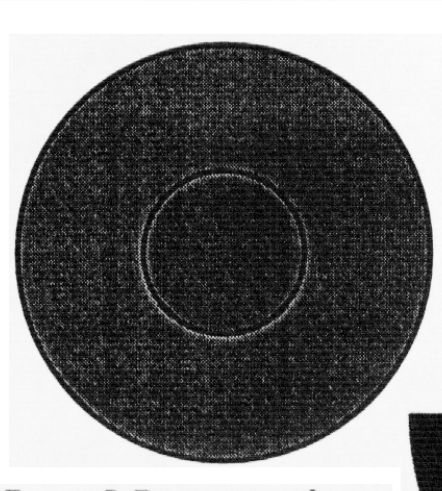

Newtonian / Non-Newtonian
Fluid $\left(\mu, \eta, \varpi_{\text {fast }}\right)$

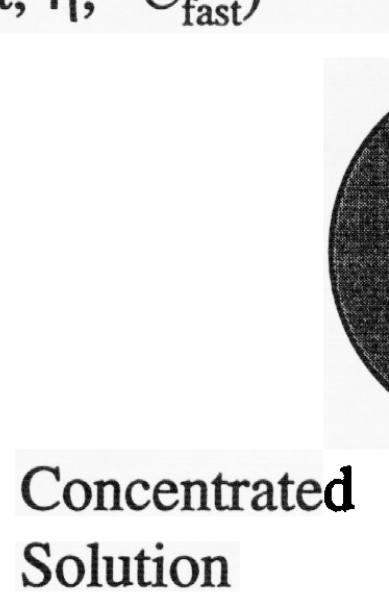

Definition of Surface (increasing relaxation times) VISCOELASTICITY
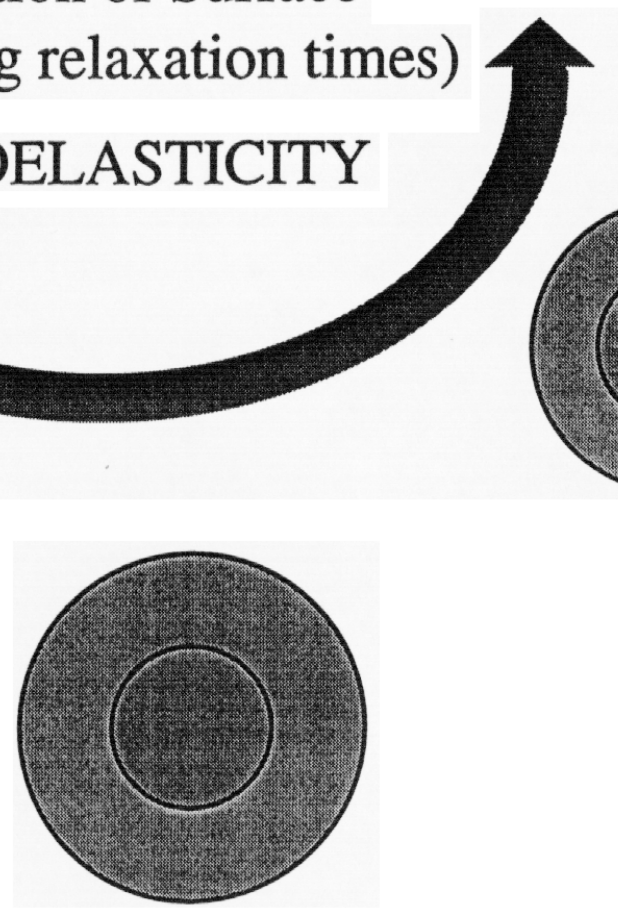

Polymer Gel
DRY SHELL

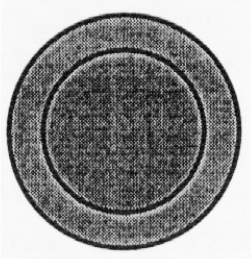

Solid Plastic Membrane (E, v)

\section{Plasticized Polymer}

$\varpi_{\text {slow }}$ )

Fig. 19: At what point is the exterior shell surface defined? The oil phase is transformed from a

fluid to a hard solid. At some intermediate value the surface features must be defined. 
later sections (see density gradient column), but for the moment we will assume this assertion to be true. We would like to maintain this emulsion / suspension so that we minimize the shell - shell and shell -wall interactions. The shells are generally heavier than water (and PVA solutions), and the shells tend to settle on the bottom of the vessel. It is undesirable to allow the shell to rest on the bottom surface since and may for flat spots from the droplet weight or they may coalesce. As it turns out the shells are nearly neutrally buoyant in the PVA bath at $65^{\circ} \mathrm{C}$. The greater problem for the shells is coalescence of the stationary shells at the bottom of the bath. This problem is exacerbated by elevated temperatures because the surface tension decreases with increasing temperatures.

Initially mechanical agitation was employed (Fig. 3). A mixing vessel from a rotary evaporator was utilized originally (essentially an elongated round-bottom flask rotating at a $45^{\circ}$ angle with respect to vertical. The resulting yield of shells was poor. The wet droplet survival rate depended on the shell composite density. The shells that tended to float at the top of the flask tended to rip apart due to the unusual shear forces present from the rotation of the flask and the buoyancy of the shells. In direct contrast, the heavy shells tended to coalescence as they generally remain stationary at the bottom of the flask. There were not any circumstance in which we would obtain any dry shells. It should be noted that of the few partially dried shells obtained in the early efforts, the walls were quite thick, $\sim 150-250 \mu \mathrm{m}$. Current wall thicknesses are an order of magnitude lower.

From then on we had examined a range of solidification vessels and various suspension schemes. We have examined rotovap configuration, $1 \mathrm{~L}$-beaker, $2 \mathrm{~L}$ beakers, the "Riebold" turntable configuration (rotating $500 \mathrm{ml}$ beaker with a small angle with respect to vertical, $\left.10-20^{\circ}\right)$, a recycle stream, a water jet, and an assortment of mechanical mixers (various blades, rotating rods, rotating eccentric rods, rotating bent rods, magnetic stir bars, etc.). Each of the various suspension means offered a potential benefit, but the bottom line was that each mode of mixing was too aggressive for the $2.0-\mathrm{mm}$ shells. It is known that the mechanical stability of the droplet and w-o-w emulsions of this type have a size dependence. It has been shown (Stone, 1990; Flumerfelt, 1972; Lagisetty, 1986) that the maximum stable droplet size and mixing speed are inverse related. By increasing the amount of the shear force / mechanical energy on a droplet, the larger sized shells tend to rupture. Smaller droplets may be stable to very high stir speed and shear rates (Fig. 20). For each droplet size, the deformation caused by the presence of a shear field has been described previously, and one may consider a critical shear force for droplet breakage as a maximum energy input imparted to the droplets (Fig. 20c).

Mechanical interactions of droplets with rigid bodies result in high impulse energy, large deformation amplitudes, and droplet attrition. The $w-o-w$ composite droplets tend to shed their internal core fluid resulting in simple oil droplets. Fluid interactions with the $w-0-w$ emulsion droplets are more forgiving. This type of energy input is more dissipative and it results in smaller local impulse energy and momentum transfer. Droplets in this case tend to agitate rather than break. This was the original reasoning behind the water recycle means of agitation; the problem with this mode was in the recycle inlet stream. The shells would adhere to the fretted glass filter and ultimately break over an extended period. 
Fig. 20a - Role of Stirring on the maximum stable Droplet Size (from Lagisetty, 1986)

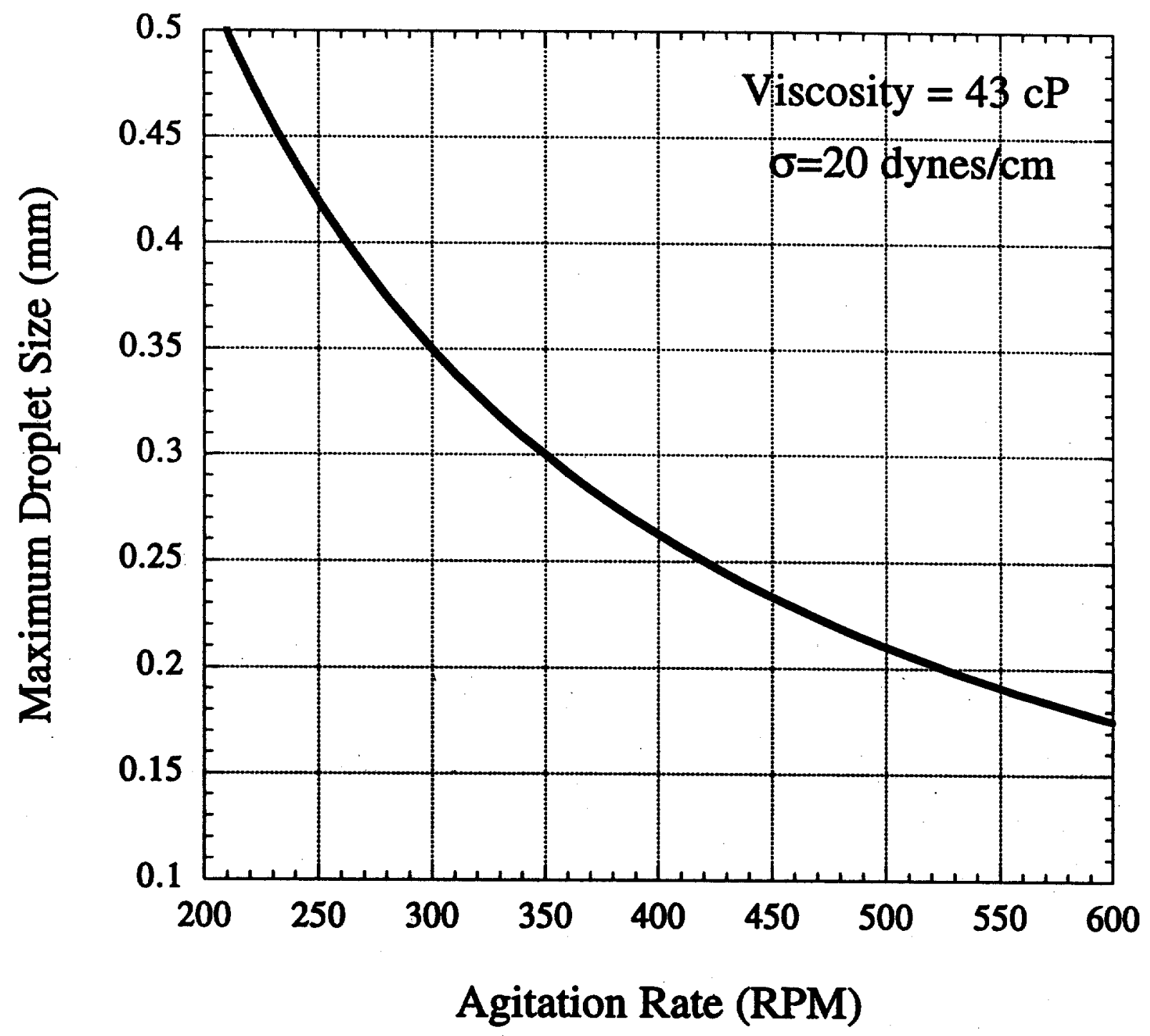


Fig. 20b - The Role of Viscosity on the Maximum Stable Droplet Size (Lagisetty, 1986)

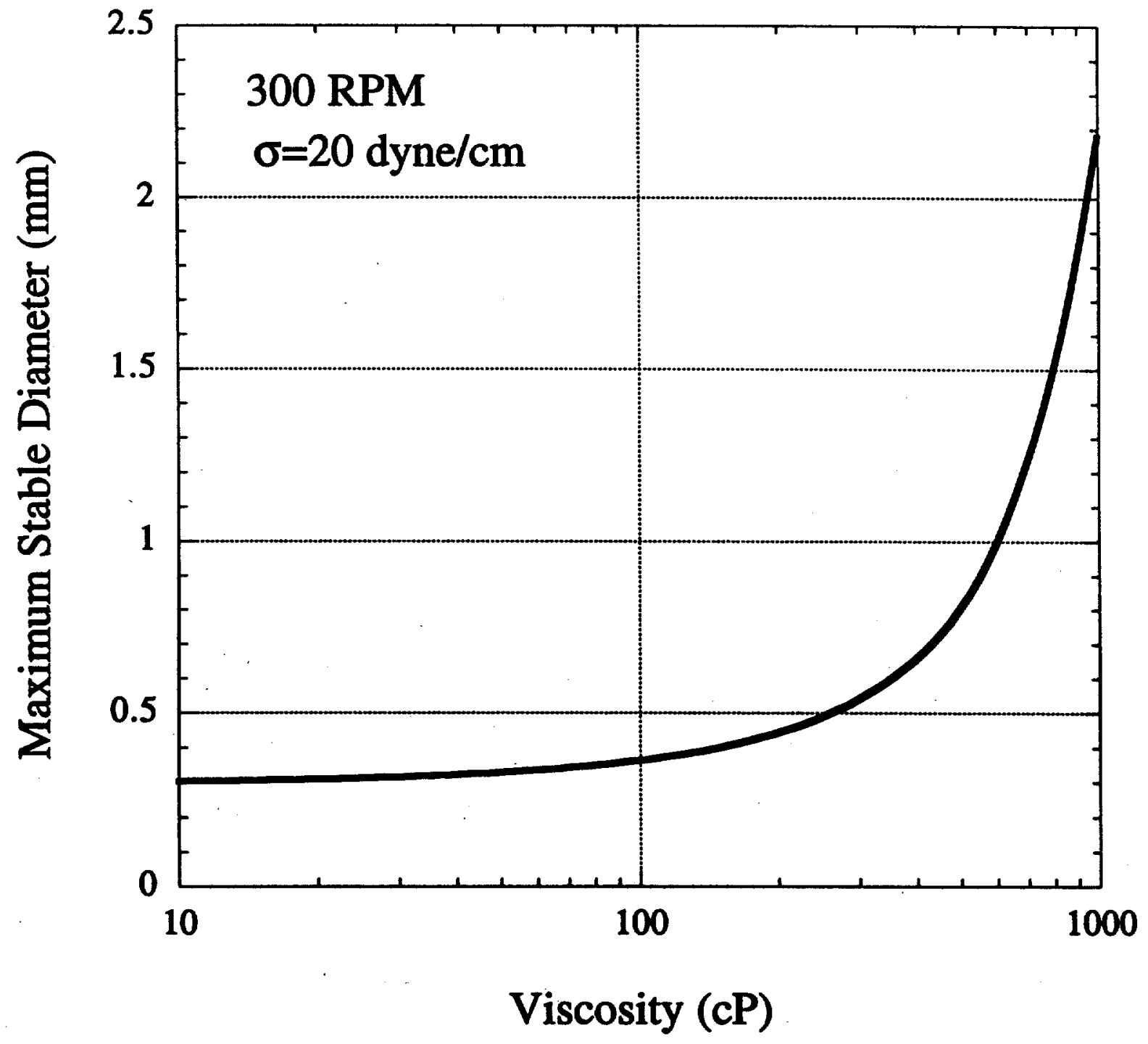



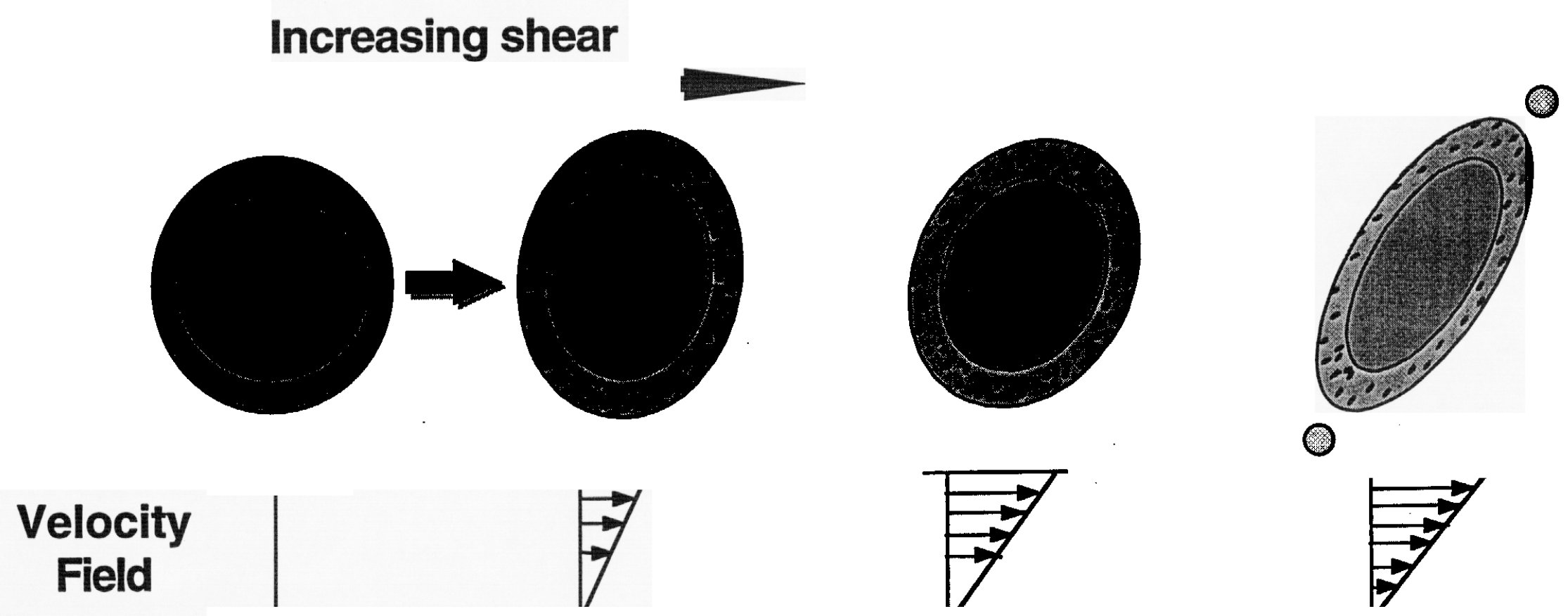

Shear forces $\left(\gamma=d V_{x} / d y\right)$

Fig. 20c: Possible deviations from sphericity by hydrodynamic forces. As the shear forces increase the level of distortion increases. If the shell / droplet can not translate, it will rotate about its center of gravity. If the shear force is increased beyond a critical shear force, satellite droplets will form (also called droplet attrition). We may ask if reversible distortions in a subcritical shear field is beneficial to the ultimate shell sphericity. 
After a few iterations, it became evident that suspension means that depended on mechanical mixing would not be practical for solidification of 2-mm shells. Shells, solidifying without mechanical mixing, settle to the bottom of the vessel. In this vessel location mass transfer is slow and the heavier solvents tend to accumulate at the bottom. Bad things happen to "sunken" shells. They tend to flatten (due to their effective weight, $g \Delta \rho \mathrm{V}$ ) or coalesce. To circumvent these problems, we found a way to enhance the buoyancy of the shells. We simply add $40 \mathrm{ml}$ increments of 2 or $5 \mathrm{wt} \% \mathrm{NaCl}$ solution to the $1 \mathrm{~L}$ beakers containing the shells. Typically starting volume of PVA fluid is approximately $500 \mathrm{ml}$ (This value varies with stripping rate conditions and shell collection times). When sufficient saline solution is added, the shells float in the PVA bath. More specifically the nearlyneutrally buoyant shells do convect.

The solidification vessel is submerged in a $65^{\circ} \mathrm{C}$ water bath. Initially the fluid is at room temperature $\left(\sim 26^{\circ} \mathrm{C}\right)$. Heat is transferred through a convective heat transfer coefficient of the water bath to the exterior glass, through a conduction mechanism of the glass, and heat transfer coefficient of the glass interior surface to the PVA fluid. One liter of water will reach $62{ }^{\circ} \mathrm{C}$ in approximately $20^{\circ} \mathrm{C}$. This converts to an overall heat transfer coefficient of $117 \mathrm{Watts} / \mathrm{m}^{2 *} \mathrm{~K}$. Once the bath reaches a state-state, there still is a small thermal gradient present in the fluid contained within the beaker. Since the beaker is heated by the exterior glass surfaces and cooled by the top surface, the shell convect by rising near the outer walls and fall close to the centerline of the fluid. (This is exactly analogous to the convection current present in a pot of boiling water on the stovetop). It is this mechanism that agitates the droplets, keeps them from coalescing, and enhances the mass transfer of solvent from droplet to outer PVA bath fluid. The amount of thermal free convection can be described in dimensionless units by the Rayleigh and the Grashof number. There is probably no more than a couple of the degrees Celsius temperature difference across the entire vessel, but this appears to be sufficient to cause the shells to circulate in the beaker. The thermal convection is enhanced by the temperature dependent densities of the fluids involved. Periodically, it is necessary to add additional increments of saline solution to the bath to be able to maintain a shell suspension since the lighter F-benzene is leaving the shell leaving behind the heavier P $\alpha \mathrm{MS}$ polymer shell wall. The shell density increases and the shells tend to settle the bottom of the vessel again.

Estimates of the maximum droplet speed is in the range of $1 \mathrm{~cm} / \mathrm{sec}$. To test this property and to examine the shell properties obtained, we increased the beaker size from a $1 \mathrm{~L}$ ( $105 \mathrm{~mm}$ diam. $\times 150 \mathrm{~mm}$ tall) to a $2 \mathrm{~L}$ beaker (112 mm diam. $\times 255 \mathrm{~mm}$ tall). Qualitatively, it was easy to observe the differences in maximum droplet speed in this thermal gradient. The shell speed may have been as high as $5 \mathrm{~cm} / \mathrm{sec}$. The resulting "dry" shells from the $2 \mathrm{~L}$ vessel were noticeably more elongated (average MOOR $=143.5 \mu \mathrm{m}$ ) than the shells from the 1L-vessel (average MOOR $=38.8 \mu \mathrm{m}$ ) for $118 \mathrm{k}$ P $\propto \mathrm{MS}$.

\subsubsection{Role of poly(vinyl alcohol)}

We also examined the role of poly(vinyl alcohol), PVA. It would be improper to characterize the functionality of PVA as a surfactant since it does not inherently 
act upon the interfacial surface of the $w-0-w$ emulsion. PVA acts a emulsion stabilizer. It is soluble in the aqueous phase (not the oil phase). It has its equilibrium configuration in solution (at a particular temperature). As two droplets approach each other in solution, the PVA chains in solution become compressed beyond their desired equilibrium configuration. This results in large decreases in the amount of system entropy. Therefore they provide stabilization from intimate contact. This process is enhanced by the retarded movement of the polymer chains in the confined geometries. These processes inhibit the contact necessary for the hydrodynamic flow of the oil phases of the two droplets needed for coalescence.

Furthermore, poly(vinyl alcohol) can not be synthesized directly (since vinyl alcohol will not polymerize). All commercially available PVA is synthesized by reaction with poly(vinyl acetate), i.e., either hydrolysis, saponification, transesterification, or aminolysis (Finch, 1992). The resulting polymer is complicated by this two-stage process, and it is a random copolymer of the vinyl alcohol and the vinyl acetate repeat units. The PVA we have used throughout the course of the work has been $88 \%$ hydrolyzed. There are differences in solubility in $\mathrm{H}_{2} \mathrm{O}$; the PVA with a higher percent hydrolyzed has a lower degree of solubility. This seems counterintuitive, and may be due to the crystallity present in highly hydrolyzed PVA samples.

Experimentally we examined a range of PVA concentrations (0-10 wt\% PVA) and its effect on the emulsion stability and the resulting shell quality. At high PVA concentrations we noted some degree of emulsification of the droplets into smaller smaller droplets. This was probably to the residual acetate content in the PVA and its limited solubility in the oil phase at high concentrations, i.e., there were local pockets of hydrophobic clusters of the vinyl acetate repeat units. (This assertion may readily be tested by measuring the interfacial tension as a function of aqueous phase PVA content; some efforts to this end are currently underway; initial results indicate the interfacial tension is reduced by the presence of the aqueous phase PVA). In the absence of PVA, the droplets coalesced (within an hour or two). Despite the early doubts of PVA's effectiveness, this experiment proves the need for an emulsion stabilizer. As to the question of how much PVA is needed, the answer is not quite as clear cut. Qualitatively, one only needs a sufficient amount to stabilize the emulsion; this may be performed experimentally. Quantitatively, one much consider a number of factors including molecular weight of the PVA (and its distribution), \% hydrolyzed, the critical overlap concentration (Fujita, 1990; Flory, 1954; Cowie, 1991), and the solution temperature. In terms of the emulsion stablity, it appears as though $0.5 \mathrm{wt} \%$ PVA is sufficient for stabilization. There may be secondary reasons for adding additional amounts such as increasing the solution viscosity (which may enhance the robustness of the droplets), but we have not yet pursued this direction experimentally.

There is some evidence that there is an upper limit to the number density of $w-o-w$ droplets that can be present in a given vessel. The following is only semiquantitative. For the most part, we are collecting shells in 1L-beakers. We can collect shells for various time intervals from 1-9 min. at a particular PVA flow ( 50 $\mathrm{ml} / \mathrm{min}$ ). We initially start with approximately $200-300 \mathrm{ml}$ of PVA fluid. This leaves room for PVA phase density adjustments by $\mathrm{NaCl}$ solution additions. It was 
found that there was a maximum number density of droplets that could survive. Droplets numbering in excess of $\sim 300$ would break. Efforts in adding more droplets resulted only in increases in the number of shells broken (not the number of shell survivors). Batches with fewer shells can be readily made, e.g., a batch with $\sim 100$ shells were made, but there is no advantage in doing so.

\subsection{DISCUSSION OF POLYMER SHELLS (Factors affecting shell sphericity)}

\subsubsection{Shell Characterization}

Shells are characterized by various means including RACI, unitron, and sphere mapping. Use of each technique becomes a trade-off between speed, accuracy, level of detail obtained, and sample requirements (sphericity and surface cleanliness, surface debris). The Unitron can be used on any of the shells. It measures the diameter in two directions $\left(D_{X}\right.$ and $\left.D_{Y}\right)$. For a typical batch of shells, we make 30 measurements, 10 shells with 3 views each (with $a D_{X}$ and $D_{Y}$ pairing at each view). Between views on a shell, we reorient the shell by rotation in a circular glass dish /slide. It would be desirable to get three random views of a given shell. There is no guarantee that we do in fact get three random views. It is likely that the degree of randomness is dependent on the degree of sphericity. The more out of round a shell is, the more likely it is to have a preferred orientation (e.g., in the case of an M\&M (without peanuts) or in the case of a football). Unitron characterization of M\&M-like shells would incorrectly find that the shells are round at the three "random " orientations despite being grossly out of round. This is a major limitation of the RACI and unitiron techniques. Luckily, the shells are not so far out of round to dramatically affect the center of gravity so as to be a big concern. This would require shells that are $\sim>50 \%$ out of round (i.e., a distortion that approximately equals the radius of the shells). Nonetheless, a maximum-out-ofround, MOOR, is determined by the largest difference obtained from the $6 \mathrm{D}_{\mathrm{x}}$ and $D_{Y}$ measurements made for each shell. Minimum, maximum, and median MOOR values are obtained for batch of ten shells (representing the best, worst, and representative shells, respectively, from the test sample extracted from the total shell population from a particular experiment).

One the advantages of RACI (over the Unitron measure) is that one obtains a full circumferential view (albeit, in one single direction, Fig. 21). It would be desirable to have three orthogonal views of the same shell at the same time. The unitron will never be able to do this. At this moment RACI can not do this either, but it may be possible with not-so minor modifications to the instrument. For full shell characterization it is necessary to get three orthogonal views simultaneously. This is possible to do with the sphere mappper, but it does have a strict sample requirement (no more than $8 \mu \mathrm{m}$ out of round). To obtain a shell free from debris, it may be necessary to work in clean room environment; dust, fibers, and hairs all contaminant the shells thereby complicating the sphere mapping operation. Viable NIF targets will have to be more spherical than $8 \mu \mathrm{m}$, but it is necessary to have the ability to make measurements on shells with a lower degree of sphericity in order to evaluate the various parameters to be able to understand the conditions needed to obtain the proper sphericity. 


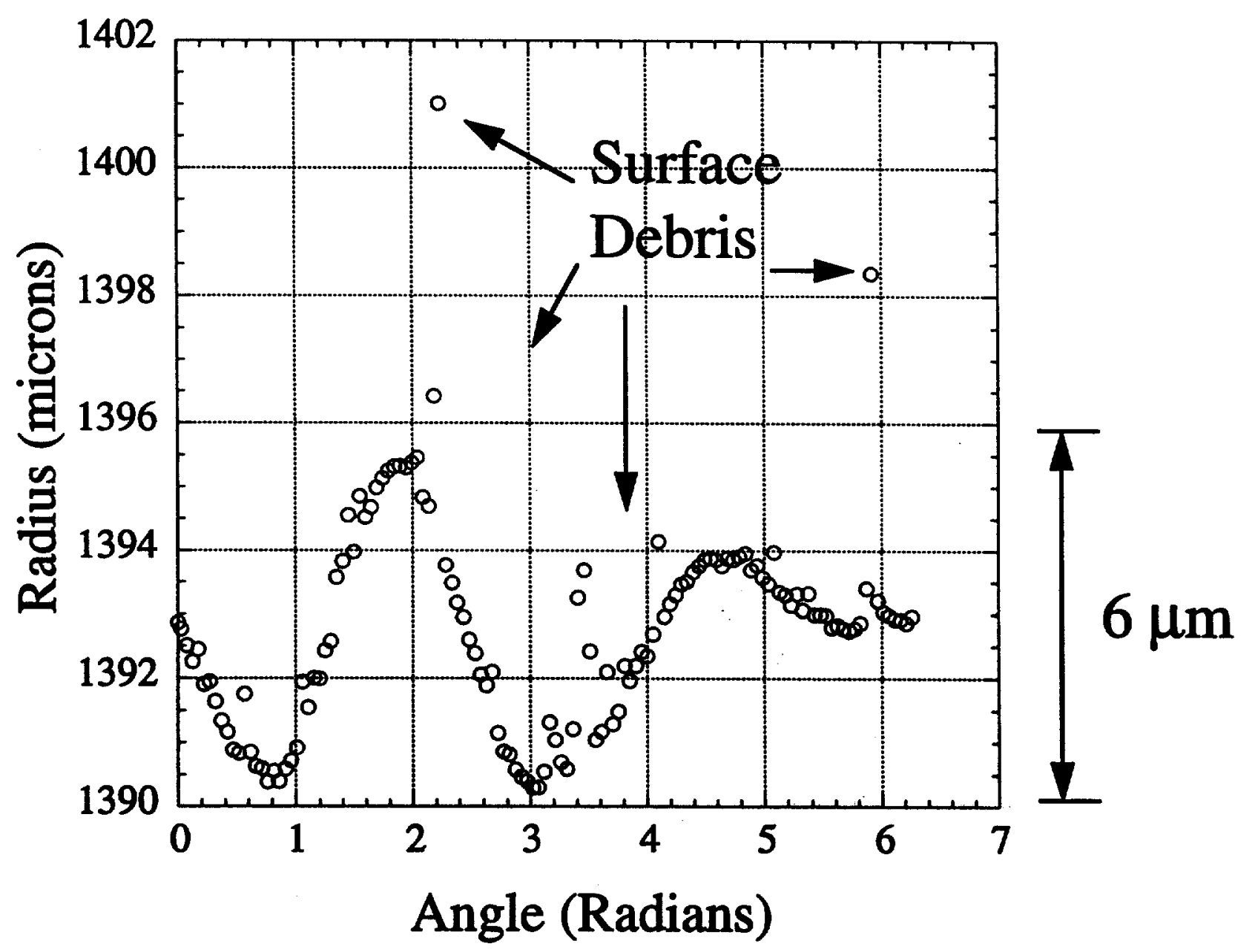

Fig. 21: Several shells have been examined by rapid aspherical characterization (RACI) in which the circumference of a shell is observedin one view. Ideal characterization would include analysis in three orthogonal directions. This techinques is susceptible to problems with surface debris. 
The first shells to be prepared and hence the first shells to be characterized were PS shells. Initially polystyrene was used because it was cheaper than the high molecular weight P $\alpha$ MS. It was also used by Osaka University in making large nearly spherical shells.

\subsubsection{Role of Polymer Repeat Unit Structure on Sphericity.}

Shortly after successfully recovering several solid PS shell batches, it was desirable to transition from making PS shells to making PoMS shells (as was consistent with original goal). As expected at the outset, PS would not be useful in the decomposable mandrel approach since the PS pyrolyzes at similar temperature to plasma polymer. P $\alpha \mathrm{MS}$ on the other hand decomposes $50-80^{\circ} \mathrm{C}$ below that of PS. Hence, it is possible to depolymerize P $\alpha \mathrm{MS}$ before the plasma polymer degrades.

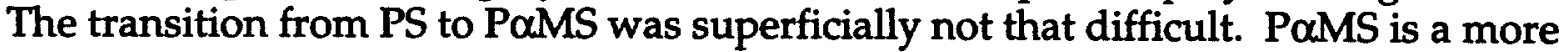
dense polymer than PS and higher a greater $\Delta \rho$ with the aqueous phases. Therefore, the solidification process is a bit more complicated (and possibly a lower percentage of shells survive). A bigger problem than the $\Delta \rho$ is the sphericity of the shells made with P $\alpha$ MS is unexpectedly quite different from the shells made with PS; the MOOR for P $\alpha$ MS shells $(20-120 \mu \mathrm{m})$ is greater than equivalently prepared PS shells $(3-20 \mu \mathrm{m})$. The PoMS shells were visibly out-of-round (with the unaided eye). Due to the similarity in repeat units (Fig. 22) and chemical nature, one would expect similar behavior. The cause was unclear, but warranted further investigated for two reasons, a) the P $\alpha M S$ shells were more out of round than the PS (had it gone the other way we would not have cared), b) understanding how and why the two polymers cause dramatic differences in sphericity offers the opportunity of understanding, in general, what causes the shells to deviate from sphericity.

After repeating the experiment a couple of times and corroborating the initial results, it was decided that examining a third styrenic polymer would be useful, namely, poly(4-methyl styrene), P4MS or alternately called poly(p-methyl styrene), PPMS. The density of the P4MS $\left(1.03 \mathrm{~g} / \mathrm{cm}^{3} 25^{\circ} \mathrm{C}\right.$ ) is lower than PS (usually accepted to be in the range of $1.05 \mathrm{~g} / \mathrm{cm}^{3}$ at $25^{\circ} \mathrm{C}$ ) and PoMS (measured previously to be $1.07 \mathrm{~g} / \mathrm{cm}^{3}$ at $25^{\circ} \mathrm{C}$ ). The differences in styrenic polymer densities can be attributed to differences in polymer chain packing effectiveness in bulk samples. The 4-methyl group provides some level of steric repulsion while the $\alpha$-methyl group increases the packing effectiveness. The degree of sphericity obtained with P4MS is greater than either of the other two polymers (3-11 $\mu \mathrm{m}$ MOOR). Unfortunately, P4MS is unsuitable for the decomposable mandrel approach as is PS (due to similar pyrolysis behavior to PS). This experiment was only intended as an academic exercise and to better understand the solidification processes. One possible property that could be responsible for the difference in styrenic polymer shell sphericity is glass transition temperature, $\mathrm{T}_{g^{\prime}}\left(118 \mathrm{k} \mathrm{M} \mathrm{w}_{\mathrm{w}} \mathrm{P} \alpha \mathrm{MS}\right.$ is $180^{\circ} \mathrm{C}, 90 \mathrm{k}$ PS is $100^{\circ} \mathrm{C}$, and $35 \mathrm{k} \mathrm{P4MS}$ is $106^{\circ} \mathrm{C}$ ). Both the shells made with PS and $118 \mathrm{k} \mathrm{Mw}$ PoMS have a cloudy wall appearance due to water supersaturation and subsequent phase separation as the solvent dissipates. The P4MS shells have an opaque white appearance due presumably to the formation a large number of micron sized particles / vacuoles within the wall causing light scattering and the lack of transparancy. 


\section{$\underline{\text { PS }}$}

岗

\section{$\underline{\mathbf{P} \alpha M S}$}

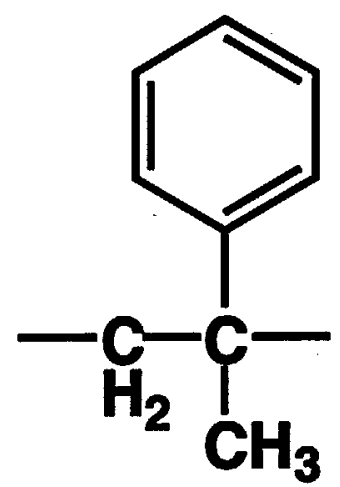

$\mathrm{T}_{\mathrm{g}}=180 \circ \mathrm{C}$

$\rho=1.07 \mathrm{~g} / \mathrm{cm}^{3}$
PPMS

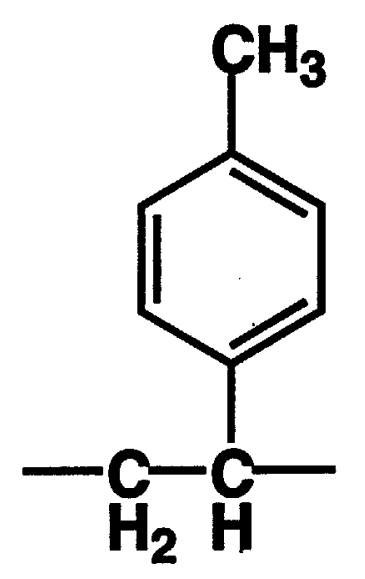

$T_{g}=106 \circ C$

$\rho=1.03 \mathrm{~g} / \mathrm{cm}^{3}$

Fig. 22: Comparison of Styrenic Repeat-Units for three polymers, polystyrene, PS, poly( $\alpha$-methylstyrene, P $\alpha M S$, and poly(p-methylstyrene), PPMS and their respective high molecular weight polymer glass transition temperature, $T_{g}$, 


\subsubsection{Role of P $\alpha M S$ Molecular Weight (E Polydispersity on Sphericty)}

It has also been observed that the shell sphericity is related to the P $\alpha M S$ molecular weight, and possibly more generally in terms of any given polymer molecular weight. The primary reason for examining shells made with different $P \alpha M S$ molecular weight is based on the commercial availability and cost. Making P $\alpha$ MS by free radical means yields a bimodal distribution of molecular weights. The average molecular weight tends to be rather low (under $40,000 \mathrm{~g} / \mathrm{mol}$ ). The final free radical P $\alpha \mathrm{MS}$ is rather cheap $(\sim 30 / \mathrm{kg})$ whereas a narrow distribution (anionically synthesized) P $\alpha \mathrm{MS}$ is rather expensive $(\sim 25-50 / \mathrm{g})$. Hence, shell production with the bimodal P $\alpha$ MS or PS is warranted when the appropriate information can be extracted. There are several P $\alpha \mathrm{MS}$ products available ranging in molecular weight and $\mathrm{T}_{\mathrm{g}}$. The ones used to make shells are $118 \mathrm{k}$ (monodisperse, $\mathrm{T}_{\mathrm{g}}$ $=180^{\circ} \mathrm{C}$ ), 26k (bimodal, $\left.\mathrm{T}_{\mathrm{g}}=49^{\circ} \mathrm{C}\right), 11 \mathrm{k}$ (bimodal, $\mathrm{T}_{\mathrm{g}}=49^{\circ} \mathrm{C}$ ), and $6 \mathrm{k}(\mathrm{PI}=\sim 2)$. The shells obtained were found to differ in shell wall clarity and shell sphericity. The $118 \mathrm{k}$ PaMS shells tended to be cloudy while the $26 \mathrm{k}$ and $11 \mathrm{k}$ PaMS shells tended to be transparent. The differences in the sphericity were also dramatic (see Table 2). The high molecular weight P $\alpha$ MS yielded high MOOR values $(20-120 \mu \mathrm{m})$ while the low molecular samples, $26 \mathrm{k}$ and $11 \mathrm{k}$, offered lower MOOR values (3-70 $\mu \mathrm{m}$ and 3-50 $\mu \mathrm{m}$, respectively). Encapsulation problems were observed for the lowest molecular weight PoMS and OOR values are consequently unavailable.

Further experimentation to this end is being attempted with several narrow molecular standards $\left(\mathrm{M}_{\mathrm{w}}=12 \mathrm{k}, 31.4 \mathrm{k}, 120 \mathrm{k}, 395 \mathrm{k}, 800 \mathrm{k}, 1040 \mathrm{k}\right.$ and $\left.\mathrm{PI}<1.18\right)$. Characterization of each is underway; the results of which are summarized in Table 3. It is possible to consider this series of polymers in a couple of different ways, according to degree of polymerization (DP), radius of gyration (S), and the end-toend distance. From the PoMS repeat unit molecular weight of $116 \mathrm{~g} / \mathrm{mole}$, it can be determined that the DP (number of repeat units / polymer chain) for the various PoMS standards are 104, 271, 1034, 3094, 6000, 8970, respectively. Using a PS's characteristic ratio, $C R$, of 10 , one can estimate the chain dimensions in solution. The $C R$ is defined as the ratio of the square of the end-to-end distance to the number of bonds and the square of the chain length $\left(\mathrm{nl}^{2}\right)$. It is a measure of the chain stiffness in dilute solutions. In a theta solvent, the end-to-end distances of the nearly monodisperse polymers are $2.61,4.21,8.22,14.2,19.8$, and $24.2 \mathrm{~nm}$, respectively. For a typical shell wall in the range of $20-25 \mu \mathrm{m}$, this means the wall is comprised of at least $10^{3}$ chains from the interior to exterior surface.

\subsubsection{Relationship of Polymer Solubility to Shell Sphericity}

During the course of the experimentation with various polymers having different repeat-units and molecular weights, it was also observed that polymers with a higher degree of solubility (in F-benzene) tended to give dry shells with a higher degree of sphericity. This appeared to be the case for the styrenic family of polymer; both PS and P4MS had good solubility and good sphericity relative to the moderate 118k weight P $\alpha$ MS solubility and its corresponding poor sphericity. Similarly, the lower molecular P $\alpha M S$ (26k and 11k) were very soluble in F-benzene 
Table 2: Solution / properties vs. Sphericity

\begin{tabular}{|l|c|c|c|c|c|c|}
\hline \multicolumn{5}{|c|}{ Polymer Property } & \multicolumn{2}{c|}{ Shell Property } \\
\hline Polymer & $\mathbf{M}_{w}$ & Modality & $\begin{array}{c}\text { F-Benzene } \\
\text { Solubility }\end{array}$ & $\begin{array}{c}\text { Polymer } \\
\mathrm{T}_{\mathrm{z}}\end{array}$ & $\begin{array}{c}\text { Shell } \\
\text { Wall } \\
\text { Properties }\end{array}$ & $\begin{array}{c}\text { Shell } \\
\text { Sphericity } \\
\text { (MOOR) }\end{array}$ \\
\hline PS & $90 \mathrm{k}$ & Monodis. & good & $100^{\circ} \mathrm{C}$ & cloudy & $3-20 \mu \mathrm{m}$ \\
\hline PPMS & $72 \mathrm{k}$ & PI $=2$ & good & $106^{\circ} \mathrm{C}$ & opaque & $3-11 \mu \mathrm{m}$ \\
\hline PQMS & $118 \mathrm{k}$ & Monodis. & fair & $180^{\circ} \mathrm{C}$ & cloudy & $20-120 \mu \mathrm{m}$ \\
& $26 \mathrm{k}$ & Bimodal & excellent & $49^{\circ} \mathrm{C}$ & clear & $3-70 \mu \mathrm{m}$ \\
& $11 \mathrm{k}$ & Bimodal & excellent & $49^{\circ} \mathrm{C}$ & clear & $3-50 \mu \mathrm{m}$ \\
\hline
\end{tabular}




\section{Table 3 - Comparison of P $\alpha$ MS Materials used for Shells .}

\begin{tabular}{|c|c|c|c|c|c|c|c|c|c|c|}
\hline $\begin{array}{l}\text { Avg. Mole. } \\
\text { Weight } \\
\text { (M) }\end{array}$ & Supplier & $\stackrel{\mathrm{PI}}{\left(\mathrm{M}^{\prime} / \mathrm{M}_{2}\right)}$ & $\overline{D P}$ & $\begin{array}{l}\text { end-to- } \\
\text { end dist. } \\
(\mathrm{nm})\end{array}$ & $\begin{array}{c}\mathrm{T}_{\mathrm{s}} \\
\text { (Onset) }^{\circ} \mathrm{C}\end{array}$ & $\begin{array}{c}\mathrm{T}_{\mathrm{g}} \\
\left(1 / 2 \Delta \mathrm{c}_{\mathrm{p}}\right. \\
{ }^{\circ} \mathrm{C}\end{array}$ & $\begin{array}{l}\text { TGA } \\
\text { (Onset) } \\
{ }^{\circ} \mathrm{C}\end{array}$ & $\begin{array}{c}\text { Solubility } \\
\text { (in F-benz.) }\end{array}$ & $\begin{array}{c}\text { Vacuoles } \\
\text { (wall clarity) }\end{array}$ & $\begin{array}{l}\text { Shell Moor } \\
(\mu \mathrm{m})\end{array}$ \\
\hline $118 \mathrm{k}$ & $\mathrm{SP}^{2}$ & 1.08 & & & -180 & & & moderate & cloudy & $20-120$ \\
\hline $26 \mathrm{k}$ & $\mathbf{S P}^{2}$ & Bimodal & & & 49.5 & & & very good & clear & $3-30$ \\
\hline $11 \mathrm{k}$ & $\mathrm{SP}^{2}$ & Bimodal & & & $<49$ & & & very good & clear & $3-15$ \\
\hline $9 \mathrm{k}$ & Aldrich & $>2.0$ & & & $?<<49$ & & & excellent & $n / 2$ & no shells \\
\hline $6 k$ & Aldrich & $>2.0$ & & & $?<<49$ & & & excellent & $n / a$ & no shells \\
\hline $12 k$ & $\mathbf{S P}^{2}$ & 1.18 & 104 & 2.61 & & & & & & \\
\hline $31.4 \mathrm{k}$ & $\mathbf{S P}^{2}$ & 1.11 & 271 & 4.21 & 164 & 166.8 & 363.2 & & & \\
\hline $121 \mathrm{k}$ & $\mathbf{S P}^{2}$ & 1.10 & 1034 & 8.22 & & & & & & \\
\hline $395 \mathrm{k}$ & $\mathbf{S P}^{2}$ & 1.19 & 3094 & 14.2 & & & & & & \\
\hline $696 \mathrm{k}$ & $\mathbf{S P}^{2}$ & 1.08 & 6000 & 19.8 & 181 & 183.2 & 346.1 & & & \\
\hline $1041 \mathrm{k}$ & $\mathbf{S P}^{2}$ & 1.16 & 8970 & 24.2 & 176 & 178.0 & 339.6 & & & \\
\hline
\end{tabular}

As $\mathrm{M}_{\text {, increases: }}$
a) solubility usually decreases (need data on monodisperse samples)
b) $T$, increases (to a smaller amount as the chain ends become rare)
c) TGA T(onset) decreases
d) shell MOOR increases (qualitatively true from prior results). 
and resulting in a high degree of sphericity relative to the $118 \mathrm{k}$ P $\alpha \mathrm{MS}$. This may be partly due to the polydispersity, modality, and lower $T_{g}$ 's.

It is possible to change solubility by changing a) the polymer, b) molecular weight of a given polymer, $c$ ) the choice of solvent, and d) solidification temperature. Options c) and d) are the most difficult to deal with since several physical phenomena are coupled during solidification such as solubility in the aqueous phase and the solvent vapor pressure. Nonetheless, it is evident from the previous results that the solution properties are of prime importance to the overall sphericity of the shells produced.

A construct has already been developed to handle the solubility of polymers from a theoretical standpoint, and this analysis is helpful from a qualitative sense in understanding the solution behavior of various polymers. Polymers dissolve when they have a negative Gibbs free energy of mixing, $\Delta G^{M}$. It has both entropic (combinatorial) and enthapic (contact dissimilarity) contributions. For a thermodynamic description of a polymer solution one can use the following expression:

$$
\Delta G^{M}=k T\left[N_{1} \ln \phi_{1}+N_{2} \ln \phi_{2}+N_{1} \phi_{2} \chi_{1}\right]
$$

where $N_{1}$ and $N_{2}$ are is the number of solvent and polymer molecules, respectively, $\phi_{1}$, and $\phi_{2}$ are the volume fractions of solvent and polymer, respectively, and $\chi_{1}$ is the Flory-Huggins coefficient for polymer-solvent interactions which is a function of $T$, concentration, and polymer molecular weight. A poor solvent would have a $\chi_{1} \sim 0.5$. The solvating power increases as $\chi_{1}$ decreases (below 0.5). At $\chi_{1}=0.5$ the polymer solution is at its theta or Flory point / temperature which corresponds to an ideal solution and unperturbed polymer coils. Generally, $\chi_{1}$ has the following temperature dependence (with increased solubility with increases in temperature):

$$
\chi_{1}=a+b / T
$$

Above $T_{\theta}\left(\chi_{1}=0.5\right)$, the polymer chains are extended or expanded coils. Below $T_{\theta}$ the chains collapse and phase separation is observed $\left(\chi_{1, c}=\right.$ interation parameter at critical conditions). $\chi_{1, c}$ is molecular weight dependent according to the following expression:

$$
x_{1, c}=1 / 2+1 / x_{n}^{1 / 2}+(1 / 2) x_{n}
$$

where $x_{n}$ is the degree of polymerization. $\chi_{1, c}$ equals 0.5 as $x_{n}$ approaches infinity. It also can be said that $\chi_{1, c}$ increases as molecular weight decreases (i.e., for the same polymer-solvent pairing the lower the molecular weight the better the solvent).

Another means of assessing the polymer chain configuration in a solvent is through the Mark-Houwink relationship:

$$
\begin{aligned}
& {[\eta]=\mathrm{kM}_{\mathrm{w}}{ }^{\alpha}} \\
& {[\eta]=\mathrm{k}_{\theta} \mathrm{M}_{\mathrm{w}}{ }^{\mathrm{\theta}} \text { (at } \theta \text {-conditions) }}
\end{aligned}
$$

where $k$ and $k_{\theta}$ are coefficients and $\alpha$ is an exponent that represents the degree of chain expansion in solution, and [ $\eta]$ is the intrinsic viscosity given for a polymer at infinite dilution. An $\alpha$-value equal to 0.5 corresponds to a random / gaussian coil configuration. The polymer chains / coils become more extended as $\alpha$ increases. Of course, the chain configuration in solution affects $\eta$. The Mark-Houwink exponents for PoMS, PS, and, P4MS in toluene at $30^{\circ} \mathrm{C}$ are $0.71,0.725$, and 0.74 , respectively. While it would be difficult to assign too much significance to differences of this 
magnitude, the values do suggest that P $\alpha$ MS has to lowest solubility of the three polymers and perhaps may "phase separate" earlier than the others.

One possible causal explanation for the relationship between solubility and shell sphericity is that the polymer with a lower degree of solubility undergoes phase separation earlier than the more soluble counterparts. This possibly results in the evolution of more mechanical stress in the films that phase separate early in the process. The stress, in turn, may drive the shell out of a spherical configuration.

\subsubsection{Changes in Shell Sphericity with Shell Size.}

The driving force for sphericity, interfacial tension, increases as the shell size decreases or as the radius of curvature decreases. It is important to make these comparisons to be able to examine how difficult is it to prepare NIF size targets via microencapsulation. For most polymer systems, the MOOR increases as the size of the droplet / shell increases (Fig. 23). The 118k P $\alpha \mathrm{MS}$ shows the largest increase in median MOOR for the polymers and shell sizes examined. Both the median MOOR values for the 26k P $\alpha \mathrm{MS}$ and the 90k PS shells were surprisingly size invariant well above the $2000 \mu \mathrm{m}$ size range (and especially beyond the size where the median MOOR for 118k PaMS increases dramatically). The numbers obtained here for 118k P $\alpha$ MS are consistent with the MOOR values reported by General Atomics (McQuillan, 1996) for 400k PoMS (Fig. 24). GA's MOOR numbers, perhaps, are slighly higher than the number obtain for the $118 \mathrm{k}$ P $\alpha \mathrm{MS}$. If true, this would be consistent with the experimental trend of higher sphericity from lower molecular polymers (for P $\alpha M S$ ).

\subsubsection{Methacrylate-Based Polymer}

The reasons for trying a non-styrene based polymer is three-fold. It is known that the methacrylate-based polymers have a greater affinity toward water, and that this may eliminate the formation of vacuoles within the shell wall by lowering the degree of supersaturation. Secondly, it was another system to examine the trend of sphericity with shell size (in an attempt to gain more information to be able to establish a causal relationship between a) polymer and shell shericity, and b) polymer solubility and shell shericity). Thirdly, methacrylate based polymers are also attractive because they have glass transition temperatures in the neighborhood of the solidification temperature $\left(65^{\circ} \mathrm{C}\right)$. Atactic poly(isobutyl methacrylate), PiBMA, has a $T_{B}=54^{\circ} \mathrm{C}$, poor to moderate solubility, and high OOR values (Table 4). Poly(ethyl methacrylate), PEMA, has $\mathrm{T}_{\mathrm{g}}=65^{\circ} \mathrm{C}$, poor to moderate solubility, and high OOR values (Table 5). Poly(methyl methacrylate), $\mathrm{PMMA}$, has a $\mathrm{T}_{\mathrm{g}}=105^{\circ} \mathrm{C}$, but polymer solutions made from it were difficult to encapsulate due to the low polymer molecular weight ( 20k). Higher molecular weight PMMA has been obtained, but it has not yet been tested. Additionally, the vacuole problem has not been solved with the methacrylate polymers; however, the number and size of vacuoles has been largely reduced by other means (aqueous phase salinity and / or P $\alpha \mathrm{MS}$ molecular weight).

One possible thought upon examining the P $\alpha \mathrm{MS}$ molecular weight dependence on sphericity (and knowing the $T_{g}$ dependence) is that having a $T_{g}$ in the neighborhood of the solidification temperature is necessary for a high degree of 


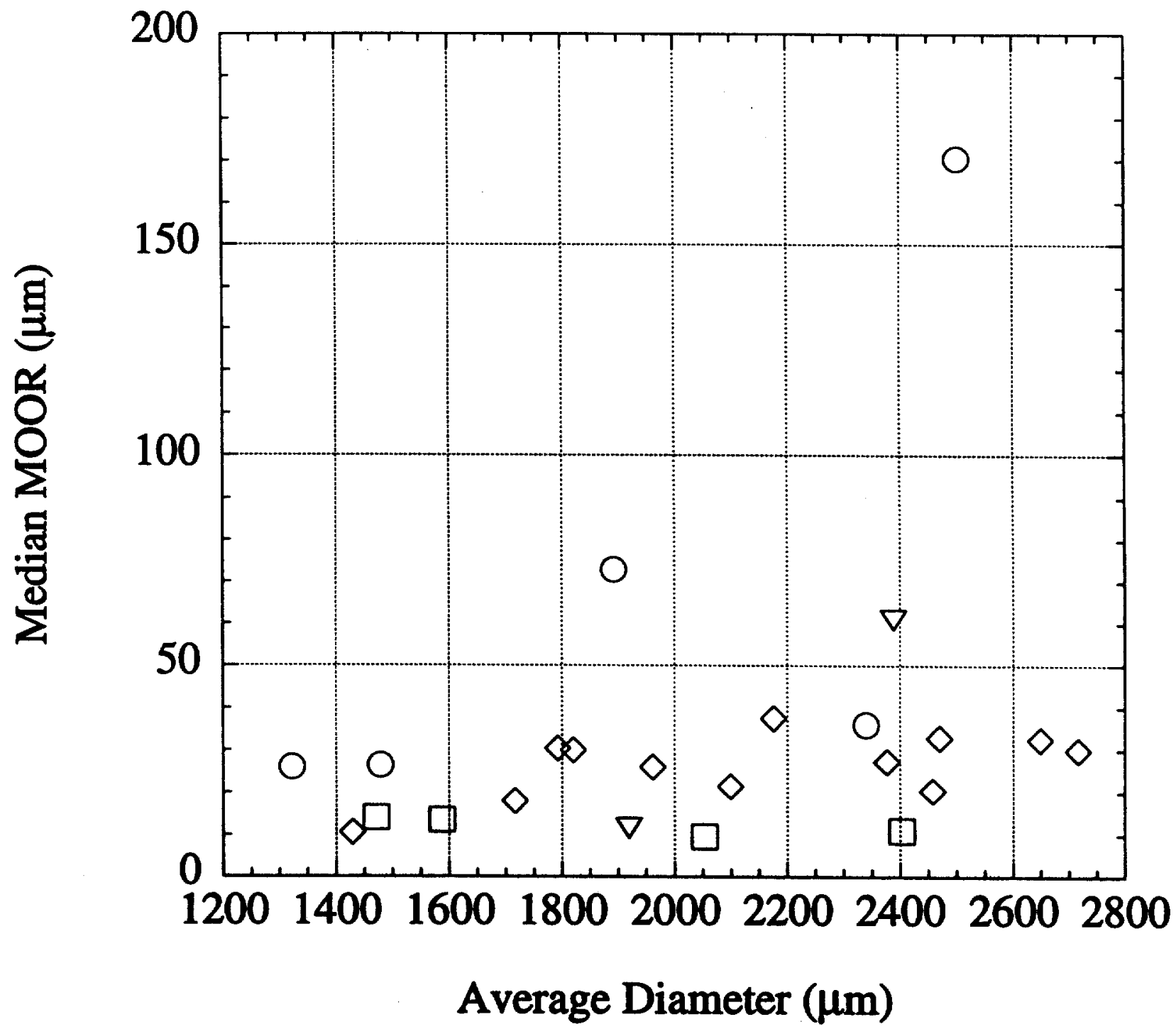

Fig. 23: The variation of median shell maximum-out -of-round (MOOR) values (in $\mu \mathrm{m})$ as a function of shell batch average diameter $(\mu \mathrm{m})$ for $90 \mathrm{k} \mathrm{MW}$ polystyrene (square); $11 \mathrm{k}$ bimodal MW PoMS (inverted triangles); 26k bimodal MW PolMS (diamonds); 118k monodisperse MW P $\alpha M S$ (circles); Median MOOR values are determined from optical characterization of ten random samples from each batch. 


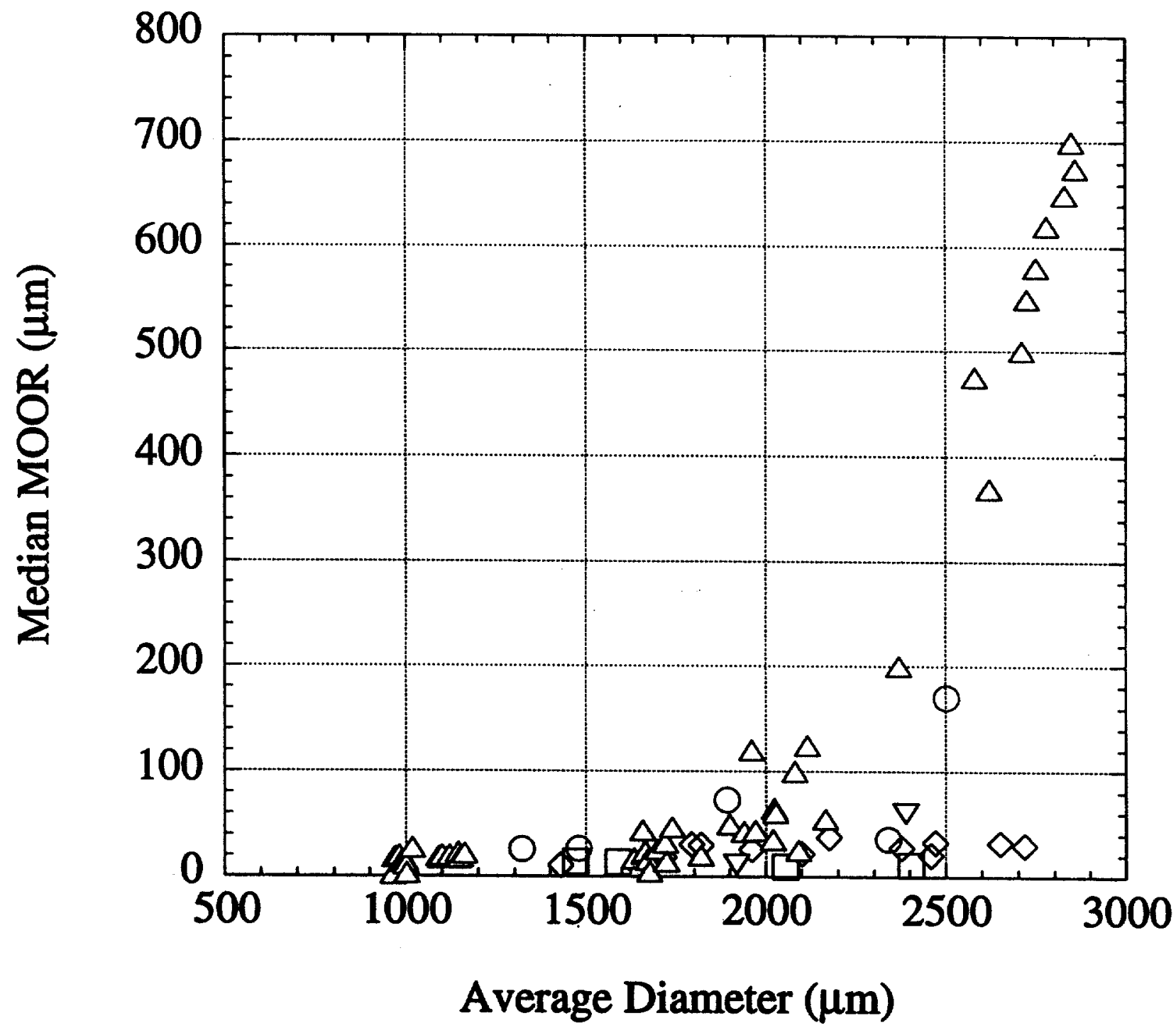

Fig. 24: The variation of median shell maximum-out -of-round (MOOR) values (in $\mu \mathrm{m})$ as a function of shell batch average diameter $(\mu \mathrm{m})$ for $90 \mathrm{k} \mathrm{MW}$ polystyrene (square); 11k bimodal MW PoMS (inverted triangles); 26k bimodal MW PolMS (diamonds); 118k monodisperse MW PoMS (circles); General Atomics 395k monodisperse MW PoMS (triangles). Median MOOR values are determined from optical characterization of ten random samples from each batch. 


\section{Table 4: Shell Properties from poly(isobutyl methacrylate).}

\begin{tabular}{|l|r|r|r|r|}
\hline $\begin{array}{l}\text { PVA Flow Rate } \\
\text { (ml/min) }\end{array}$ & 30 & 55.5 & 140 & 187 \\
\hline Median Diam. & 2159.5 & 2016 & 1558.5 & 1347.3 \\
\hline Std. Dev. & 51.02 & 37.83 & 46.71 & 43.49 \\
\hline Median MooR & 20.5 & 113 & 26.5 & 19 \\
\hline Min. MooR & 5 & 9 & 6 & 7 \\
\hline Max MooR & 146 & 193 & 53 & 64 \\
\hline
\end{tabular}

PiBMA characteristics: $\mathrm{T}_{\mathrm{z}}=54^{\circ} \mathrm{C}, \mathrm{M}_{\mathrm{w}}=340^{\circ} \mathrm{C}$.

The core fluid contains $0.4 \mathrm{wt} \%$ propylene glycol with the balance being deionized water.

Median MOOR is $\sim 20 \mu \mathrm{m}$

Best shells are 5-7 $\mu \mathrm{m}$ out-of-round. 


\section{Table 5: Shell properties made from Poly(ethyl methacrylate)}

\begin{tabular}{|l|r|r|r|r|r|r|}
\hline $\begin{array}{l}\text { PVA Flow Rate } \\
\text { (m1/min) }\end{array}$ & 30 & 30 & 55.5 & 55.5 & 140 & 140 \\
\hline Med. Diam. & 2446.5 & 2411.5 & 2043.8 & 2084 & 1739.8 & 1697.5 \\
\hline Std. Dev. & 82.29 & 62.43 & 133.52 & 64.28 & 63.94 & 58.28 \\
\hline Med. Moor2 & 49.5 & 54.5 & 23 & 22.5 & 20 & 26.5 \\
\hline Min MOOR2 & 22 & 29 & 11 & 6 & 10 & 10 \\
\hline Max MOOr2 & 166 & 287 & 62 & 60 & 35 & 86 \\
\hline
\end{tabular}

Starting polymer content in the oil phase is $15 \mathrm{wt} \%$.

PEMA characteristics are: $T=65^{\circ} \mathrm{C}, \mathrm{M}_{\mathrm{w}}=320 \mathrm{k}$

The core fluid contains $0.4 \mathrm{wt} \%$ propylene glycol with the balance being deionized water.

The median MooR is $\sim 20 \mu \mathrm{m}$.

The best shells are 6-10 $\mu \mathrm{m}$ ooR.

Good batch-to-batch repeatability observed. 
shell sphericity. Having the opportunity to test shell properties with polymers having the glass transitions below, at, and above the solidification temperature had appeared to be an interesting test. The results seem to show that it takes more than low polymer $\mathrm{T}_{\mathrm{g}}$ to get highly spherical shells. The statement is corroborated by the fact that the most spherical shells obtained thus far have been from PS and P4MS (having $\mathrm{T}_{\mathrm{B}}=100^{\circ} \mathrm{C}$ and $106^{\circ} \mathrm{C}$, respectively).

\subsubsection{Shell Annealing}

It has been thought to be possible to enhance the sphericity of a shell by postsolidification treatment / annealing. One set of experiments has been completed in which PS shells were made in the standard fashion at $65^{\circ} \mathrm{C}$ and solidified overnight at $65^{\circ} \mathrm{C}$. Half of the batches were subsequently heated to $90^{\circ} \mathrm{C}$ for another $24 \mathrm{hrs}$. The sphericity of the annealed and unannealed shells were compared with the hope that sphecity of the shells would be improved. As Table 6 shows, this was not shown to be the case with overwhelming evidence. This line of testing is worth repeating.

\subsubsection{Core Fluid Alterations}

There are three possible reasons for wanting to change the core fluid, 1) changing the density, 2) affecting the interfacial tension, or 3) altering the osmostic pressure across the forming membrane. A change in denisty can be effected with either additions of $\mathrm{NaCl}$ or $\mathrm{D}_{2} \mathrm{O}$ to the core fluid. One may affect the interfacial tension by adding $\mathrm{NaCl}$ or propylene glycol (and possibly PVA). The osmotic pressure can be altered by changing the $\mathrm{NaCl}$ concentration in the core fluid. Several of these possibilities are been considered and implemented experimentally.

\subsubsection{Interfacial Tension}

The main driving force for sphericity is interfacial tension. However, we have very little tangible information on the actual experimental values. Some analysis has been completed on selected interfaces (Table 7). The measurements were performed externally on a drop volume tensiometer. In this method, the interfacial tension is determined by the balance of the buoyant force and the adherend force (to the orifice). From this it is possible to back out the interfacial tension (averaged for ten's of drops). Measurements were made with a dispersed (droplet fluid) flow rate of $5 \mathrm{ml} / \mathrm{hr}$. Depending on the fluids and the particulars of the interface, this measured value will be different than an equilbrium value (obtained most easily at slowest flow rates). The drop volume tensiometer is capable of flow rates from $0.001 \mathrm{ml} / \mathrm{hr}$ to $47 \mathrm{ml} / \mathrm{hr}$. The measured interfacial tension values obtained at the faster flow rates are higher than the ones at slower flow rates. Fast flow rates result in fast interface formation and relatively little time for the necessary species to diffusion to the surface. Solutions with large species are the ones that require long rearrangement times at the interface, and they are most affected by this rate dependent measurement. For the samples reported in Table 7, the flow rate dependence has not been determined. It is likely these values are different than the equilibrium values. It is not a difficult measurement to

performed, but it does take time. A second measurement on each fluid pairing has 


\section{Table 6: Shell Sphericity Enhancement by post- solidification annealing step.}

\begin{tabular}{|l|r|r|r|r|r|r|}
\hline $\mathrm{T}_{\text {solidificiation, }}\left({ }^{\circ} \mathrm{C}\right)$ & 65 & $65 \& 90$ & 65 & $65 \& 90$ & 65 & $65 \& 90$ \\
\hline $\begin{array}{l}\text { Median } \\
\text { Diameter }\end{array}$ & 2402.5 & 2460.5 & 2133.5 & 2118.25 & 1680.5 & 1703 \\
\hline $\begin{array}{l}\text { Standard } \\
\text { Deviation }\end{array}$ & 106.64 & 167.95 & 85.77 & 46.05 & 41.21 & 102.40 \\
\hline $\begin{array}{l}\text { Median MooR, } \\
\mu \mathrm{m}\end{array}$ & 24 & 33 & 55.5 & 42.5 & 31 & 16.5 \\
\hline $\begin{array}{l}\text { Minimum } \\
\text { MooR, } \mu \mathrm{m}\end{array}$ & 12 & 15 & 18 & 20 & 11 & 8 \\
\hline $\begin{array}{l}\text { Maximum } \\
\text { MooR, } \mu \mathrm{m}\end{array}$ & 32 & 195 & 78 & 83 & 93 & 32 \\
\hline
\end{tabular}

Polymer characteristics: Poly(styrene),PS; $\mathrm{T}_{\mathrm{z}}=100^{\circ} \mathrm{C}, \mathrm{M}_{\mathrm{w}}=340 \mathrm{k}$.

The core fluid contains $0.4 \mathrm{wt} \%$ propylene glycol with the balance being deionized water.

Possible "post-solidification" heat treatment to remove stress (and out-ofroundess).

This heat treatment may have had a beneficial effect on the median MOOR values.

The MOOR values for $65^{\circ} \mathrm{C}$ shells are higher than expected. The data were collected on a "troublesome" run. It is worth another attempt. 


\section{Table 7: Kruss Interfacial Tension Measurements}

\begin{tabular}{|c|c|c|c|c|c|}
\hline Aqueous Phase & Oil Phase & $\begin{array}{l}\rho \text { (aqueous) } \\
\mathrm{g} / \mathrm{cm}^{3}\end{array}$ & $\begin{array}{l}\rho \text { (oil) } \\
\mathrm{g} / \mathrm{cm}^{3}\end{array}$ & $\begin{array}{c}\text { Average } \\
\text { Interfacial } \\
\text { Tension } \\
(\text { dyne/cm) }\end{array}$ & $\begin{array}{c}\text { Standard } \\
\text { Deviation }\end{array}$ \\
\hline Water & Benzene & 0.9943 & 0.8571 & $\begin{array}{l}42.08 \\
42.10 \\
\end{array}$ & $\begin{array}{l}0.07 \\
0.14 \\
\end{array}$ \\
\hline Water & F-Benzene & 0.9930 & 0.9985 & $\begin{array}{c}10.34 \\
9.11 \\
\end{array}$ & $\begin{array}{l}0.05 \\
0.06 \\
\end{array}$ \\
\hline $\begin{array}{c}\text { Water } \\
\text { 2wt\% PVA }\end{array}$ & F-Benzene & 0.9946 & 0.9960 & $\begin{array}{l}0.50 \\
0.47 \\
\end{array}$ & $\begin{array}{l}0.01 \\
0.01 \\
\end{array}$ \\
\hline $\begin{array}{c}\text { Water } \\
\text { 2wt\% PVA }\end{array}$ & $\begin{array}{c}\text { F-Benzene } \\
\text { 15. wt\% 118k } \\
\text { PolMS }\end{array}$ & 0.9954 & 1.0220 & $\begin{array}{l}6.04 \\
5.56\end{array}$ & $\begin{array}{l}0.03 \\
0.07\end{array}$ \\
\hline $\begin{array}{c}\text { water } \\
2 \text { wt\% PVA }\end{array}$ & $\begin{array}{l}\text { F-Benzene } \\
15 \text { wt\% PS }\end{array}$ & 0.9965 & 0.8911 & $\begin{array}{l}8.88 \\
8.63 \\
\end{array}$ & $\begin{array}{l}0.07 \\
0.08\end{array}$ \\
\hline $\begin{array}{c}\text { water } \\
0.4 \text { wt } \% 1,2- \\
\text { propanediol }\end{array}$ & $\begin{array}{c}\text { F-Benzene } \\
15 \text { wt\% 118k } \\
\text { PoMS }\end{array}$ & 0.9957 & 1.0230 & $\begin{array}{l}23.4 \\
7.14\end{array}$ & $\begin{array}{c}0.2 \\
0.04\end{array}$ \\
\hline $\begin{array}{c}\text { water } \\
5 \mathrm{wt} \% \mathrm{NaCl}\end{array}$ & F-Benzene & 1.0270 & 0.9907 & $\begin{array}{l}124.70 \\
96.29\end{array}$ & $\begin{array}{l}0.47 \\
0.67\end{array}$ \\
\hline
\end{tabular}

Measurements obtained at room temperature by drop volume tensiometer technique.

Dispersed phase flow rate is equal to $5 \mathrm{ml} / \mathrm{hr}(0.001-47 \mathrm{ml} / \mathrm{hr}$ flow are available). This is not an equilbrium measurement as is frequently reported

Average interfacial tension values are averages of five readings.

Second set of interfacial data are repeated $24 \mathrm{hrs}$. after initial readings.

Large range of interfacial tensions 
been made after 24 hours (line \#2 of each entry in Table 7), and these should be compared to the intial values (line \#1 of each entry in Table 7). Other methods of interfacial tension measurement such as DuNouy ring and Wilhemy plate methods had been considered, but the drop volume method had been choosen based on its performance in the neighborhood of density matched conditions.

The observed interfacial tension for the benzene / water interface is 42 dyne $/ \mathrm{cm}$ (or $10^{-3} \mathrm{~N} / \mathrm{m}$ or $\mathrm{mN} / \mathrm{m}$ ). This value is expectedly higher than the equilibrium value of $35 \mathrm{dyne} / \mathrm{cm}$ reported in the literature (Adamson, 1990). If we replace benzene with F-benzene the interfacial tension drops to $\sim 10$ dyne $/ \mathrm{cm}$. When PVA is added the interfacial tension drops by 50 -fold $(\sim 0.5$ dyne $/ \mathrm{cm})$. This was clearly unexpectedly low since PVA was not believed to act at the water-oil interface. If 15 $w t \% P \alpha M S$ is added to the oil phase the interfacial tension increases to $\sim 6 \mathrm{dyne} / \mathrm{cm}$, and addition of $15 \mathrm{wt} \%$ PS to F-benzene gives interfacial tension values in the range of 9 dyne $/ \mathrm{cm}$. It is doubtful that this slight difference in interfacial tension could account for the substantial difference in sphericity, and there must be an alternate cause of this behavior. Against our intuition, the interfacial tension increased with propylene glycol content. If this were in fact true, this would explain the trend observed in Table 8. The mechanism may be more complicated and it may involve the competitive interfacial adsorption of propylene glycol and poly(vinyl alcohol). Lastly, additions of $\mathrm{NaCl}$ to the aqueous had a marked effect on the interfacial tenison. The value of $125 \mathrm{dyne} / \mathrm{cm}$ is 10 -fold higher than the measured tension for the F-benzene / water interface. It is not prudent to try to conclude too much with these data given their preliminary nature and the likelihood of species interactions at the interfaces. What is clear is the large range of measured interfacial tensions ( 0.5 to 125 dyne $/ \mathrm{cm}$ ) that were observed. This level of fluctuation could grossly impact the overall sphericity of the shells obtained. More work in this area is needed.

\subsubsection{Propylene Glycol additions to the core Fluid}

In an effort to density match the three fluid phases involved, several core fluids were examined. At this moment in time, it is believed that we ultimately will want the core fluid as clean as possible. (Clean meaning free from particulate matter or any materials that with carbonize during the PoMS pyrolysis step). During the initial shell making efforts, green food dye was used in the core fluid ( $0.4 \mathrm{wt} \%$ dye) to enhance the visibility of the core fluid and the encapsulation process. After "standard" shell making conditions were identified, the green dye was removed. It has been our impression that there are subtle (yet unproven) differences in the droplet robustness and shell sphericity. The primary solvent used in the food dye is propylene glycol (1,2-propanediol). We have made shells with $0.4 \mathrm{wt} \%$ propylene glycol as well. There appears to be some benefits for its use. Table 8 shows the differences in shell sphericity at a constant shell size (and 118k PaMS) with increases in the amount of propylene glycol in the core fluid (0-5.0 $\mathrm{wt} \%$ propylene glycol). The trend is obvious, a decrease in both median and average OOR values. The most readily accepted explanation for the difference in sphericity is that the interfacial tension is affected by the presence of proylene glycol in the core fluid. . We are in the process of measuring the interfacial tension of several solution pairings, and hopefully these changes will be measured. There is some initial evidence that the 
Table 8: Role of Proylene Glycol content (in the core fluid) on Shell Sphericity

\begin{tabular}{|l|r|r|r|r|r|}
\hline wt\% Glycol & 0.0 & 0.1 & 0.2 & 0.4 & 5.0 \\
\hline Median & 2357 & 2334 & 2333 & 2340 & \\
Diameter, $\mu \mathrm{m}$ & & & & & \\
\hline Std. Dev., $\mu \mathrm{m}$ & 71.5 & 51.9 & 44.2 & 27.2 & \\
\hline Min MooR, $\mu \mathrm{m}$ & 30 & 36 & 24 & 28 & \\
\hline Max. MooR, $\mu \mathrm{m}$ & 329 & 197 & 139 & 123 & \\
\hline Med. MooR, $\mu \mathrm{m}$ & 129 & 93 & 101 & 36 & \\
\hline
\end{tabular}

Shell properties are function of core fluid make-up.

The average MOOR, maximum MOOR, and the diameter standard deviation decrease as the propylene glycol content increases. This is not expected. 
interfacial tension does, in fact, increases with increasing propylene glycol concentrations. This possibly could be due to the displacement of the PVA chains from the interface; the presence of PVA at the interface appears to reduce the interfacial tension. Species interaction and synergy at the droplet interface are underway, and this certainly highlights the need a more detailed interfacial tension study.

\subsubsection{3. $\mathrm{D}_{2} \mathrm{O}$ in core fluid.}

A series of experiments were performed to test what a core offset would do to the overall shell sphericity, i.e., potentially linking concentricity and sphericity. This was completed with additions of $\mathrm{D}_{2} \mathrm{O}$ to the core fluid (ranging from $0-50 \mathrm{wt} \% \mathrm{D}_{2} \mathrm{O}$ in the core fluid). While this was a good experiment on paper, its implementation was problematic. It was difficult to keep the core fluid within the oil phase thereby reducing the overall shell yield to nearly zero (for batches with $\mathrm{D}_{2} \mathrm{O}$ contents in excess of $2 \mathrm{wt} \% \mathrm{D}_{2} \mathrm{O}$. It is not clear why the compound droplet survival rate was so low. The density differences between the oil phase and the core fluid is actually much smaller throughout the solidification process with the $\mathrm{D}_{2} \mathrm{O}$ present than in its absence. (see Fig. 25). This seems to suggest that there is a problem in having a heavy core fluid $\left(\rho>\rho\left(\mathrm{H}_{2} \mathrm{O}\right)\right)$ and to a lesser problem of having a lighter core.

\subsubsection{4. $\mathrm{NaCl}$ in core fluid}

This trend is corroborated by examining the droplet survival for droplet made with $\mathrm{NaCl}$ added to the core fluid ranging from $0-10 \mathrm{wt} \% \mathrm{NaCl}$. All of the shells other than ones with the $1 \mathrm{wt} \% \mathrm{NaCl}$ solution broke open. There is a second potential benefit of putting $\mathrm{NaCl}$ in the core fluid besides the density adjustment. The benefits are in terms of vacuole formation. It has been pointed out by General Atomics (McQuillan, personal communication, 1997) that by adding salt to the exterior aqueous / PVA fluid it is possible to remove most the vacuoles forming in the shell walls (due the water supersaturation and consequential phase separation during solidification). The elimination of the vacuoles in based on osmotic pressure arguments and the ability of the salt solutions to "draw out" the water than may be present in the oil phase. In other words, the salt addition changes the partition coefficient for the water / oil interface.

Based on this argument, it would seem advantageous from an academic standpoint to examine the effect of adding $\mathrm{NaCl}$ to the core fluid as well as the external fluid. This would seem to provide an environment in which it would not be desirable for water molecules to be present in the oil phase since that would be the highest energy state (and it would be much lower in either of the water phases). Moreover, the interest in using $\mathrm{NaCl}$ in the core fluid has an addition benefit. One could speculate on the possible forces that drive the shell / composite droplet out of a spherical configuration; osmotic pressure is one of the possibilities. We are already using $\mathrm{NaCl}$ in the PVA fluid. There is an associated osmotic pressure with it; water is being drawn out of the core fluid to solvate the salt solution (through the forming polymer membrane). Across the droplet / shell there must be a higher pressure on the inside relative to the outside of the shell. It is possible that the force 
Fig. 25a - Problems with heavy core-fluid densities using $\mathrm{D}_{2} \mathrm{O}$ resulting in core shedding at room temperature.

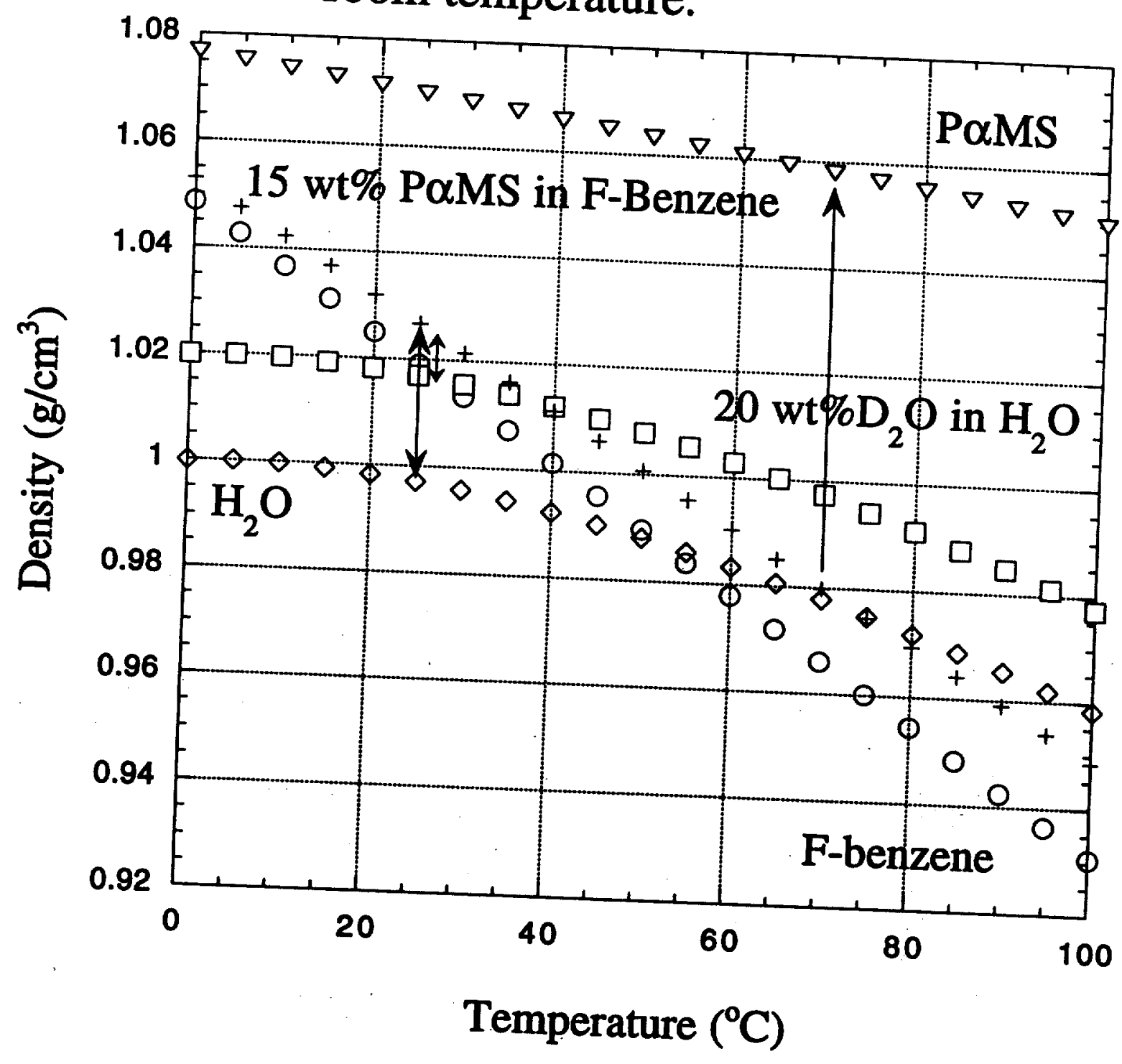


Fig. 25b - Problems with heavy core-fluid densities using $\mathrm{NaCl}$ additions to core resulting in core shedding at room temperature.

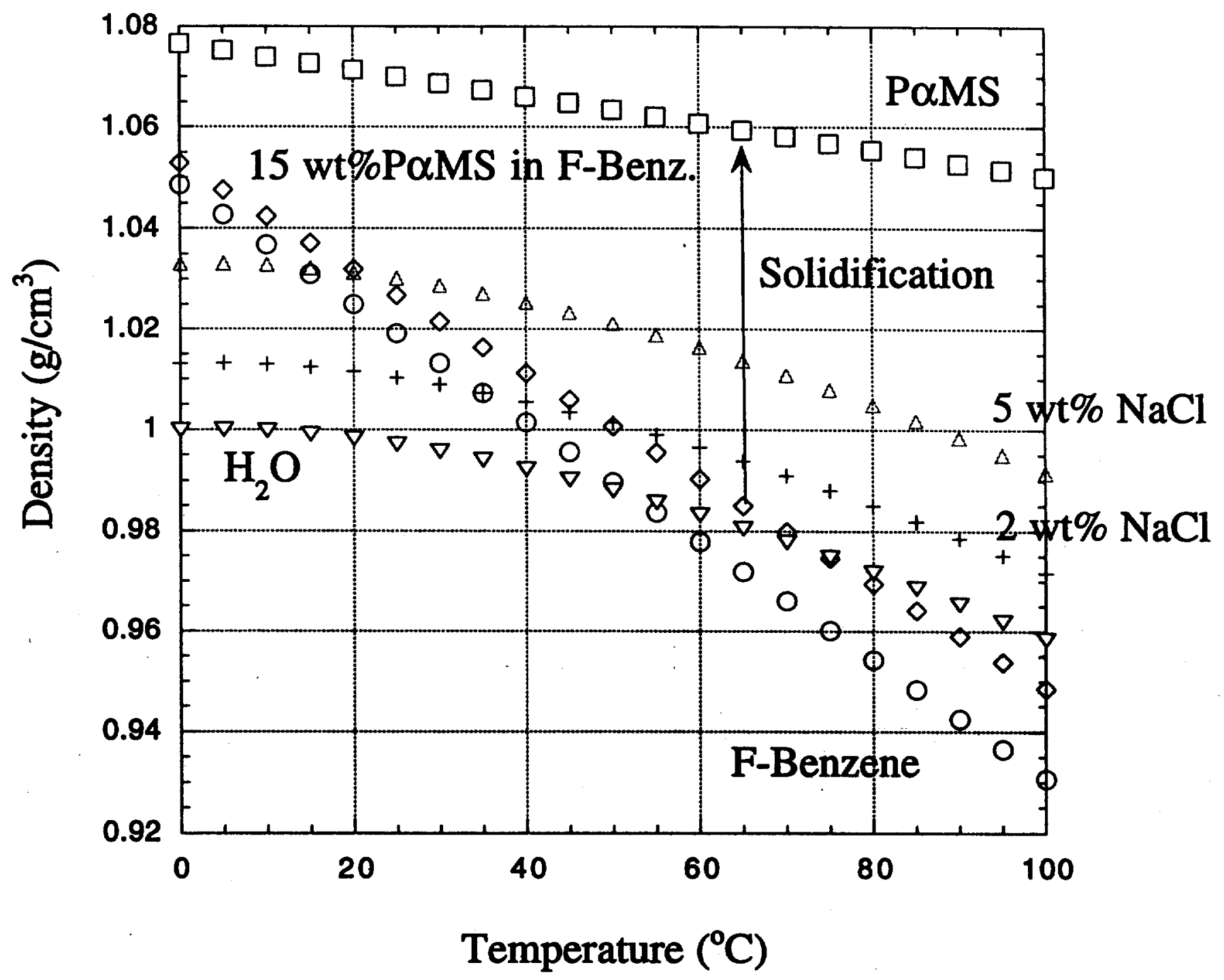


has a tendency to distort the shells. By adding $\mathrm{NaCl}$ to the core fluid, the osmotic pressure should be minimized.

\subsubsection{Role of Solvent Transport}

Understanding the solvent transport is important. It has been suggested by General Atomics that the rate of solvent transport affects the overall shell sphericity. Barry McQuillan has found that the sphericity increases as the solidification time increases. For this reason and to retard solvent transport, General Atomics presaturates the aqueous phase with organic solvent. For solvent to leave the droplet, some F-benzene must evaporate off of the top surface. A second approach has been implemented such that the shells are collected and kept at ice bath temperatures for an hour then the system temperature is slowly raised to $60^{\circ} \mathrm{C}$. These shells tend to be less out-of-round than the higher temperature ones. Some attempts have been made to reproduce these efforts (see Table 9). Under the conditions we examined, we found it difficult to observe any differences in shell sphericity with and without pre-saturation of the aqueous, and with and without a high level of reflux at the top of the vessel. This is not to say that these effects do not exist, but rather that we did not observe them under the conditions we were testing. Differences in the execution of the experiment exist; they are predominantly related to the use of mixing and the size of the shell examined. The results observed by General Atomics were obtained for smaller shells (less than $1500 \mu \mathrm{m}$ ) while the shells were being mixed at $100 \mathrm{rpm}$. The test performed here were done on larger shells $(2.3$ to $2.6 \mathrm{~mm}$ ) without the use of any mixing. It is worth attempting again given the clarity of the results obtained at General Atomics.

\subsubsection{Effect of Mixing During Solidification on Shell Sphericity}

It is not clear at this point whether mixing /agitation during solidfication is helpful or harmful to the shell's sphericity. It is possible that Taylor Wang's (1995) theory on oscillatory enhancement of concentricity is observed; this would possibly link concentricity to the shell's degree of sphericity. The choice of blades is important to the power dissipated by fluid and consequently the amount mixing achieved (Sterbacek, 1965; Uhl, 1966; 1967; 1986; Nagata, 1975). Blade length, blade angle, blade pitch, and number of blades around shaft, rotation direction (CW vs. CCW), vessel geometry, and the location of the blades with respect to the vessel are important variables. It is also important to limit the amount of droplet breakage during solidification. Broken droplets will float on the top of the beaker, and they will ensnare healthy droplets in the vicinity. Thus, it is necesary to remove the broken shells as soon as it forms a film. Generally, this is only important for the first hour or so. After this time little shell breakage occurs. Provided this does not occur

and the levels of mixing are subcritical, the question remains: Is mixing beneficial to the concentricity of the two droplets?

We have observed some conflicting experimental data with respect to this question. The role of agitation during solidification (Table 10 and Fig. 26) falls somewhere between beneficial to no effect to deleterious. Fig. 26 clearly shows the increase of OOR values as the RPM of the stirring blade is increased. Other batches of shells indicate that some level of stirring decreases the MOOR values. We have 
Table 9: Role of F-benzene Transport on Shell Sphericity

\begin{tabular}{|l|c|r|r|r|r|r|r|r|}
\hline $\begin{array}{l}\text { F-Benzene } \\
\text { Presaturation }\end{array}$ & no & no & yes & yes & no & yes & yes & yes \\
\hline $\begin{array}{l}\text { Wt\% Propylene } \\
\text { Glycol to Core }\end{array}$ & 0 & 0 & 0 & 0 & 0.4 & 0.4 & 0.4 & 0.4 \\
\hline $\begin{array}{l}\text { Wt\% Glycol to } \\
\text { PVA }\end{array}$ & 0 & 0.8 & 0 & 0.8 & 0 & 0 & 0 & 0 \\
\hline Avg. Diam., $\mu \mathrm{m}$ & 2371 & 2178 & 2221 & 2186 & 2281 & 2279 & 2247 & 2273 \\
\hline med MOOR & 582 & 146 & 146 & 96 & 124 & 323 & 140 & 204 \\
\hline min moor & 270 & 60 & 46 & 46 & 76 & 148 & 70 & 28 \\
\hline max moor & 1142 & 234 & 368 & 266 & 178 & 682 & 396 & 288 \\
\hline
\end{tabular}

No obvious shericity enhancement with F-Benzene pres-saturation of the PVA fluid.

Adding propylene glycol to the PVA fluid appears to be beneficial. 
Table 10 - Effect of Agitation (during solidificiaton) on Shell Sphericity
A)

\begin{tabular}{|l|r|r|r|}
\hline Stir rate (RPM) & 0 & 16.7 & 22.3 \\
\hline Med. Diam. $\mu \mathrm{m}$ & 2204 & 2231 & 2240.5 \\
\hline Med. Moor, $\mu \mathrm{m}$ & 59 & 120.5 & 169 \\
\hline Min MOOR, $\mu \mathrm{m}$ & 19 & 44 & 67 \\
\hline Max MOOr, $\mu \mathrm{m}$ & 186 & 239 & 281 \\
\hline
\end{tabular}

* 15wt \% 118k PaMS; 0.4 wt\% Propylene glycol in core.

* The minimum, the medium, and the maximum MOOR increased with increasing agitation rates.

B)

\begin{tabular}{|l|r|r|r|r|r|}
\hline Avg. Diam., $\mu \mathrm{m}$ & 2176 & 1961 & 1793 & 1717 & 2184 \\
\hline Stir rate (RPM) & 0 & 0 & 0 & 0 & 16.5 \\
\hline Med. MOOR, $\mu \mathrm{m}$ & 37.5 & 26 & 30.5 & 18 & 19.5 \\
\hline Min MOOR, $\mu \mathrm{m}$ & 12 & 13 & 12 & 13 & 10 \\
\hline Max MOOR, $\mu \mathrm{m}$ & 79 & 72 & 96 & 54 & 53 \\
\hline
\end{tabular}

* 20 wt\% 26k PaMS; 0.4 wt\% propylene glycol in core * The minimum, the medium, and the maximum MOOR decreased with an agitation rate of 16.5
RPM.

C)

\begin{tabular}{|l|l|l|l|}
\hline Avg. Diam., $\mu \mathrm{m}$ & 1892 & 1816 & 1875 \\
\hline Stir rate (RPM) & 0 & 24 & 24 (after 1 hour delay) \\
\hline Med. MOOR, $\mu \mathrm{m}$ & 38.8 & 27 & 28.1 \\
\hline Min MOOR, $\mu \mathrm{m}$ & 9 & 3 & 9 \\
\hline Max MOOR, $\mu \mathrm{m}$ & & & \\
\hline
\end{tabular}

* 15 wt\% 118k PaMS, 0.4 wt\% propylene glycol in core

* The medium MOOR decreased with stirring. The role of mixing on the best shell is 


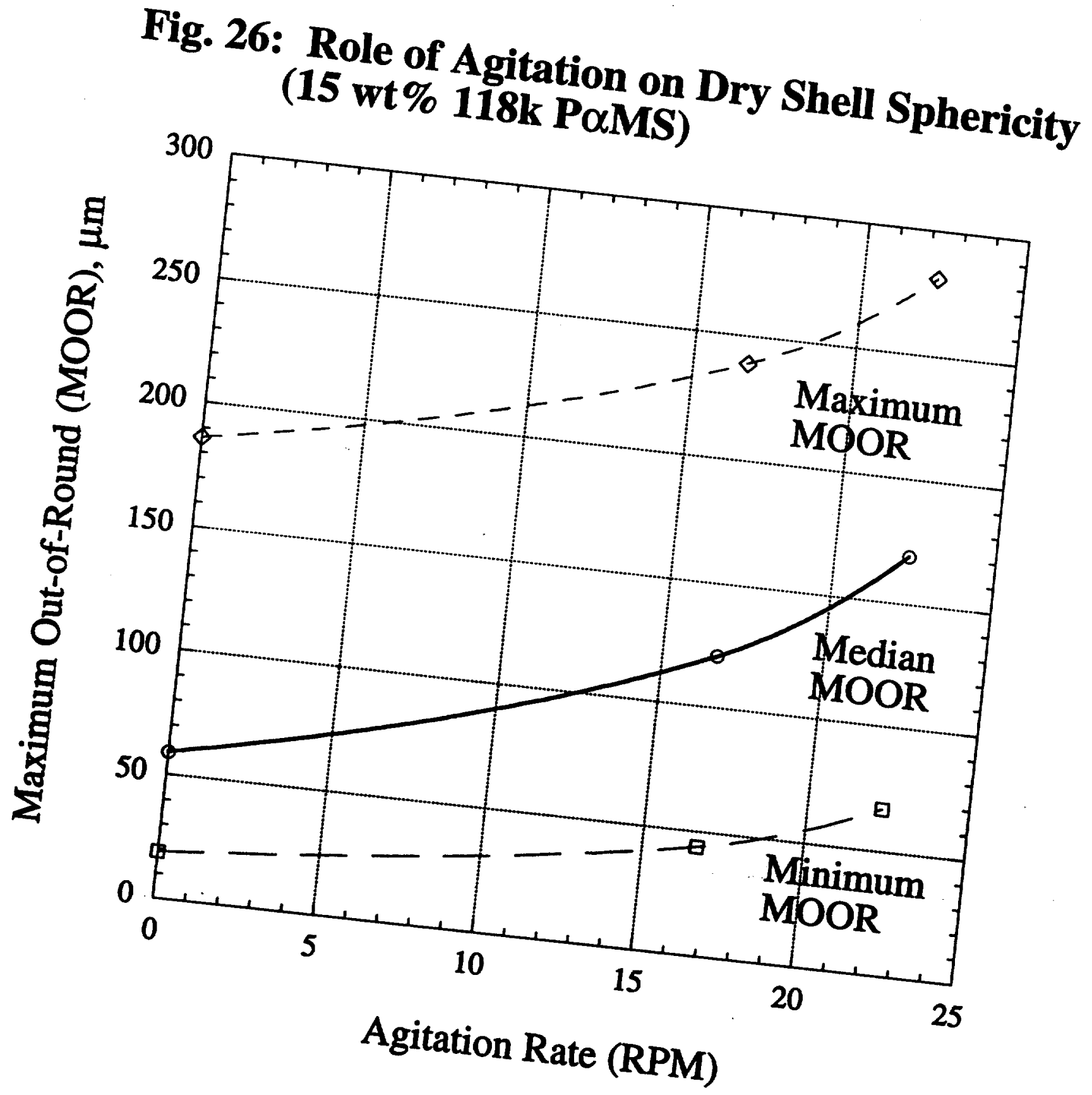


also found for the 2-mm shells there is very little margin of error between the energy input for shell suspension through mechanical means and the energy required for shell attrition, i.e., the speed required to suspend the shells is very close to critical shear stress of the $\mathrm{w}-\mathrm{O}-\mathrm{w}$ emulsion droplets. It is likely that the peak stress near the blade is substantially higher the average shear stress of the surrounding bath fluid. Therefore, the specifics of the shell - blade interactions are important (especially in the location of the shell with respect to blade). The location of the shells may be altered somewhat by the use of saline solutions. The specifics of shell-blade interactions are dictated by the type of mixing performed (Uhl, 1966; 1967; 1986; Sterbackek, 1965; Nagata, 1975). Again, it is necessary to perform more well defined, controlled experiments. Due to the number of variables involved with degree of agitation and the peak shear rates, it is not only difficult to get consistent internal results, but it is also difficult to compare the results from group to group (unless all conditions are equivalent).

\subsubsection{Connection between Sphericity and Concentricity}

Recently, General Atomics found a correlation between shell sphericity and shell concentricity / wall uniformity. The shells with the highest degree of sphericity were the ones with the most uniform walls. This has been attributed to an oscillatory centering mechanism provided by pressure oscillations of the mixing blades. It is doubtful that simply by virtue of being non-concentric that the shell would be non-spherical; most likely the fluid will redistribute to minimize the energy of system effecting a balance of capillary forces, bouyant forces, osmotic forces, interfacial energies, and ones based on chemical potential. These properties, forces, energies are subject to change based on temperature fluctations, reorienation, density changes, viscosity changes, and concentration fluctuations. Of course there are situations where, for instance, there is a large density mismatch between phases. The core will be ejected. We would like to avoid this. This can be achieved by $\Delta \rho$ minimization. Density matching can not be maintained throughout the entire process, therefore, an external means might be used for core containment and positioning. The solidification of a non-concentric droplet (Fig. 26b), a shell with thin and thick region of the shell wall / fluid, will have regions in the shell that dry quickly and those that dry slowly. The fast drying regions may start to bend due to compressive stresses. The non-uniform drying results in distorted shapes. The polymer membrane is stressed (Ward, 1983; Wasley, 1983) yielding a non-spherical / non-uniform curvature. This is likely to be both drying rate and polymer molecular weight dependent (Perhaps, the level of mechanical stress developed in the film is dependent on the chain entanglement density and the radius of gyration of the polymer chains; there is some qualitative evidence to this effect presented in the P\&MS molecular weight section (see Case-Hardening Instability literature).

One possible means of enhancing the containment is by using oscillatory behavior such as acoustically driven deformations (Saffren, 1981; Lee, 1981). This is an attractive method because it is explicitly controlled. We choose the amplitude, frequency, cycle loading, phase match / mis-matching, number of vibration nodes created on the droplet surface, resonances, chamber geometry, etc. We have some control over the energy deposited at an interface via acoustical impedance mismatch 

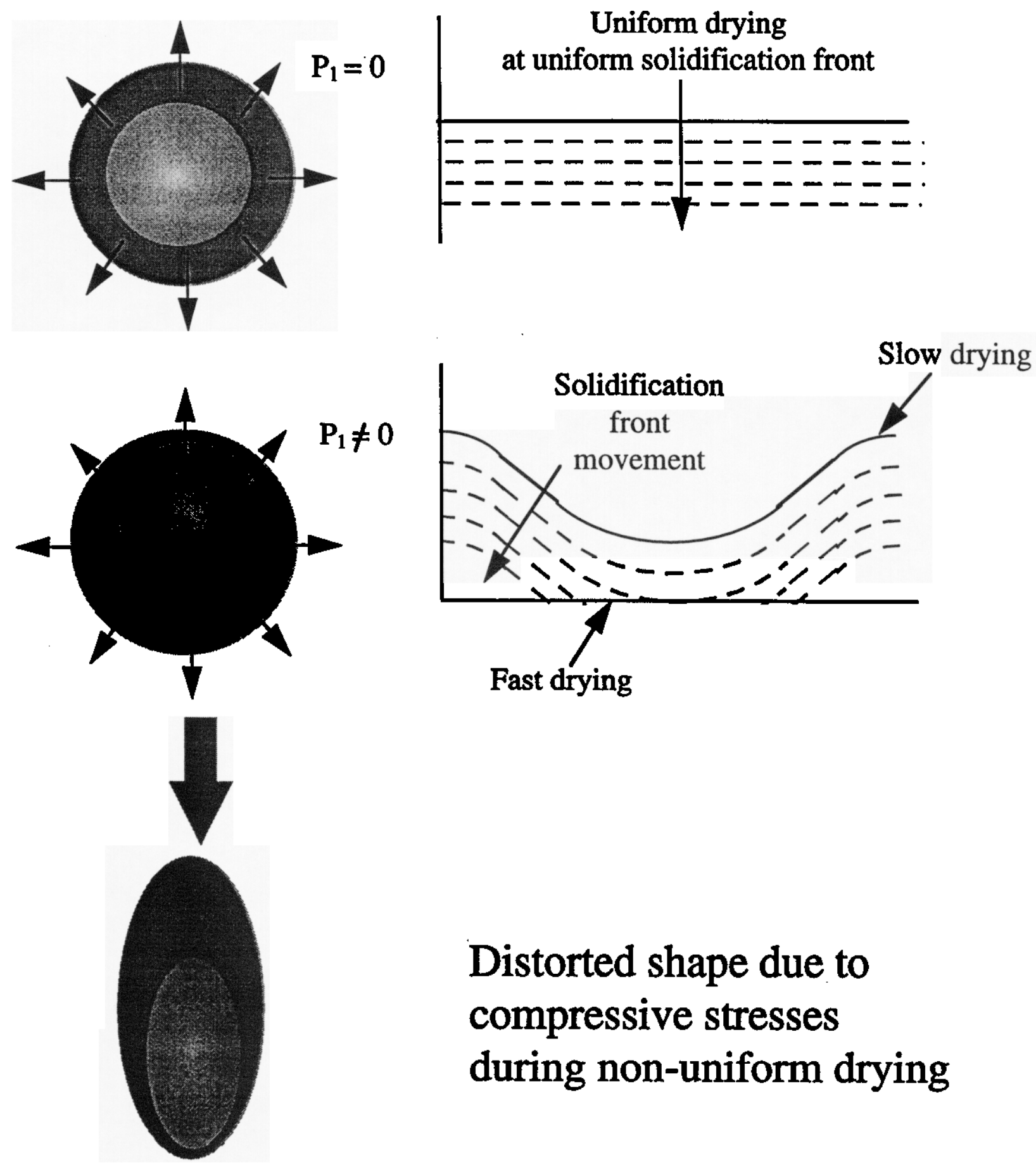

Distorted shape due to compressive stresses during non-uniform drying

Fig. 26b: Conjecture on the possible mechanism to explain the connection between droplet / shell concentricity / wall uniformity and sphericity. 
(Ristic, 1983; Auld, 1973; Gruan, 1996). This process is quite complex, but we believe it is a tractable one. The description and motion of a spherical interface is quite complex in this environment. The difficulty is magnified exponentially when a second concentric interface is added and the physical properties of one the phase is time dependent.

\subsubsection{Do Shells Float or Sink?}

To be able to answer the question of whether the shells sink or float in the solidification bath, it is necessary to calculate the composite shell density throughout the solidification process. It is the oil phase density which is changing dramatically during solidification; however the overall composite droplet density (Fig. 27) does not vary that much $\left(\Delta \rho=0.003 \mathrm{~g} / \mathrm{cm}^{3}\right)$ during solidification because a majority of this weight in the core aqueous fluid (whose density is presumed to be invariant). One may compare these values for both PS and P $\alpha$ MS in F-Benzene (Fig. 28). For convenient comparison, these values have been given as specific gravity (i.e., relative to the density of water at a particular measurement temperature). This graph clearly shows why the PS shells float more easily than the PoMS shells; they have a lower overall specific gravity. The shell specific gravity is also a function of starting weight percent polymer in the oil phase since this affects the amount of nonvolatile mass. This has been calculated for 15, 30, and 50 vol\% PoMS at $65^{\circ} \mathrm{C}$ (Fig. 29). The question is: How much $\mathrm{NaCl}$ is needed to enable the shells to float? and are the predictions close to the experiment. The easiest way to answer this is to superimpose the solidification density curves on a plot that gives the density of the possible saline solutions (Fig. 29b). These curves show that only modest salt concentrations are needed to enhance the buoyancy of the shells enough to get them to float. For shells starting with $15 \mathrm{wt} \%$ polymer and a relative encapsulation flow rates ratio of 3:1 (core to oil flow rates), $0.4 \mathrm{wt} \%$ is needed for P $\alpha$ MS buoyancy and $0.23 \mathrm{wt} \% \mathrm{NaCl}$ is needed to maintain shell buoyancy throughout the solidification process.

\subsubsection{Density Gradient Column}

The use of a density gradient column has been envisioned as means to monitor solvent transport out of the droplet /shell during solidification. This is possible due to the differences in density between P $\alpha \mathrm{MS}$ and F-benzene. As the droplet solidfies, it becomes more dense. If this shell is placed in a density gradient column of known density and gradient, it is possble calculate the composite density of the shell, the amount of residual solvent, and diffusion coefficients. Another benefit of the column is it provide an alternate solidification environment to the one provided by the 1L-beaker: a) the environment is controlled, b) the bath fluid is stagnant for an isothermal column, and it is possible to observe the solidification of a single shell throughout the entire process, $c$ ) most of the hydrodynamic phenomena are eliminated (thereby examined only hydrostatic effects and eliminating several complications accompanying a moving droplet), d) the shell is essentially neutrally bouyant throughout the entire solidification process. In this environment, it is possible to produce a shell in an environment free from shear fields. 


\section{Fig. 27- Shell Composite Density Change During Solidification (for an initial concentration of 10 vol\% P $\alpha$ MS)}

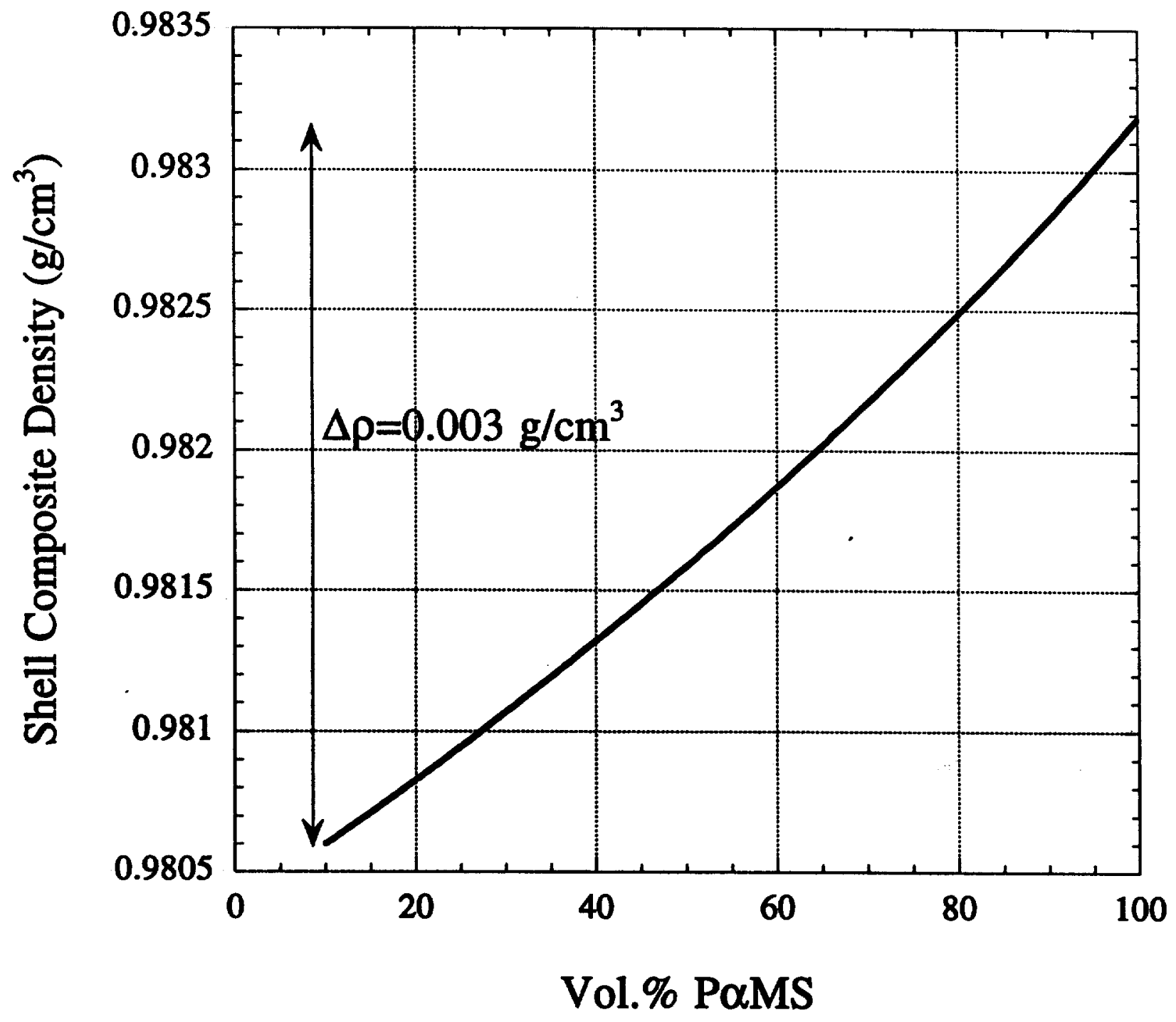


Fig. 28 - Comparison of Shell Composite Specific Gravity Relative to Water for PS to that of P $\alpha \mathbf{M S}$

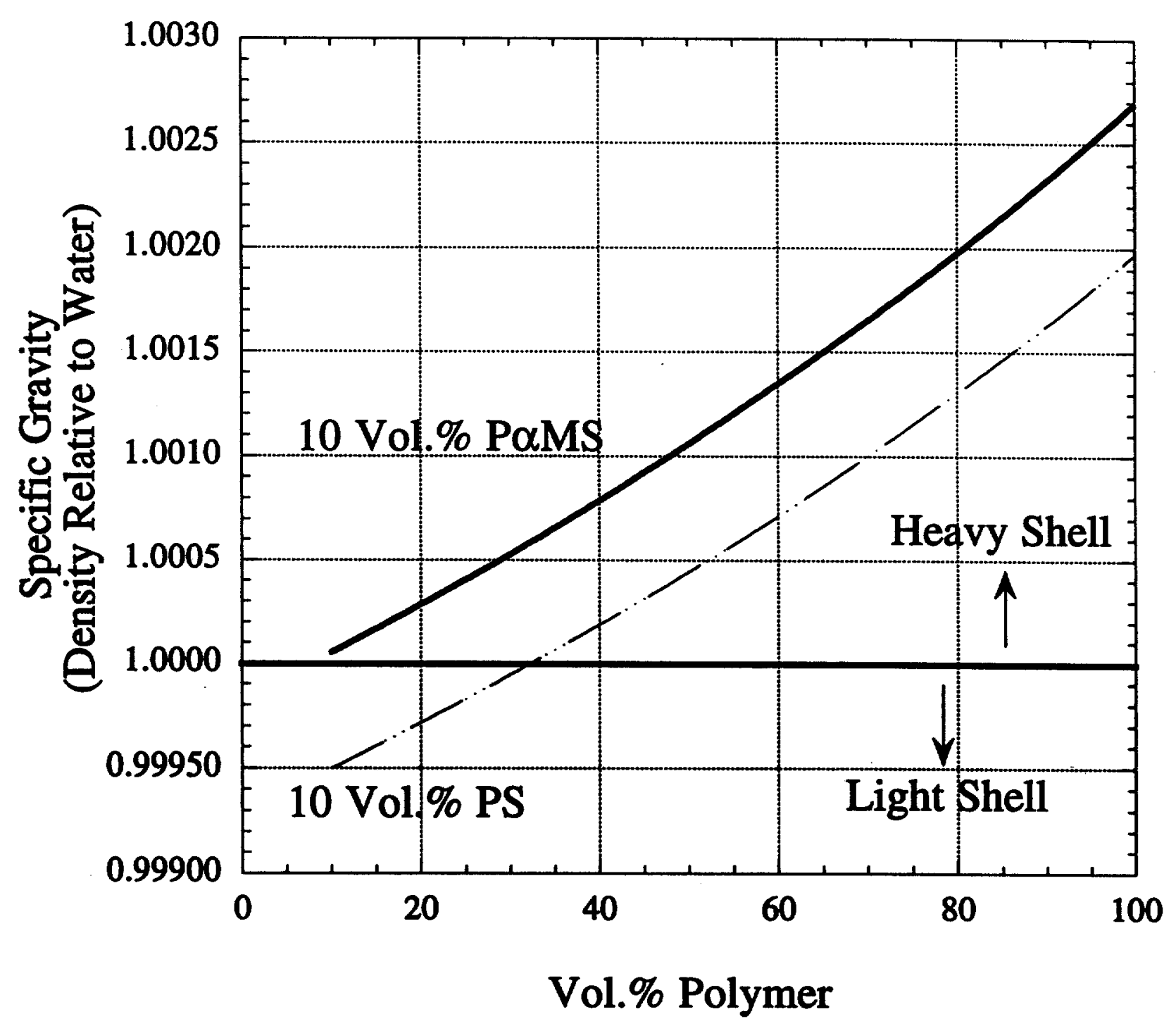


Fig. 29 - Comparison of P $\alpha$ MS Shell Composite Densities for Varying initial polymer Concentrations.

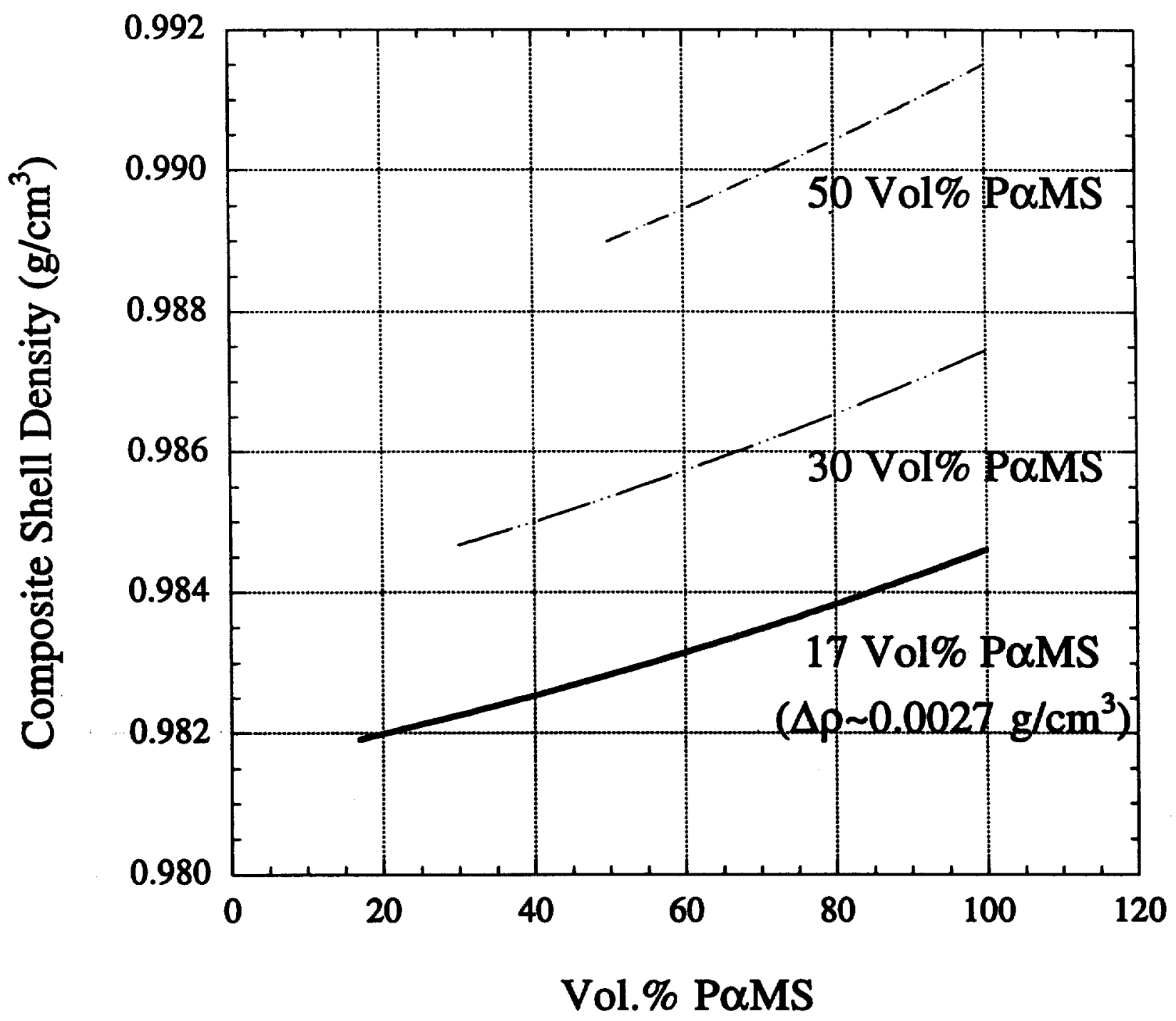


Fig 29b - Comparison of Composite Shell Specific Gravity (SG) vs. PVÁ / NaCl Solution SG

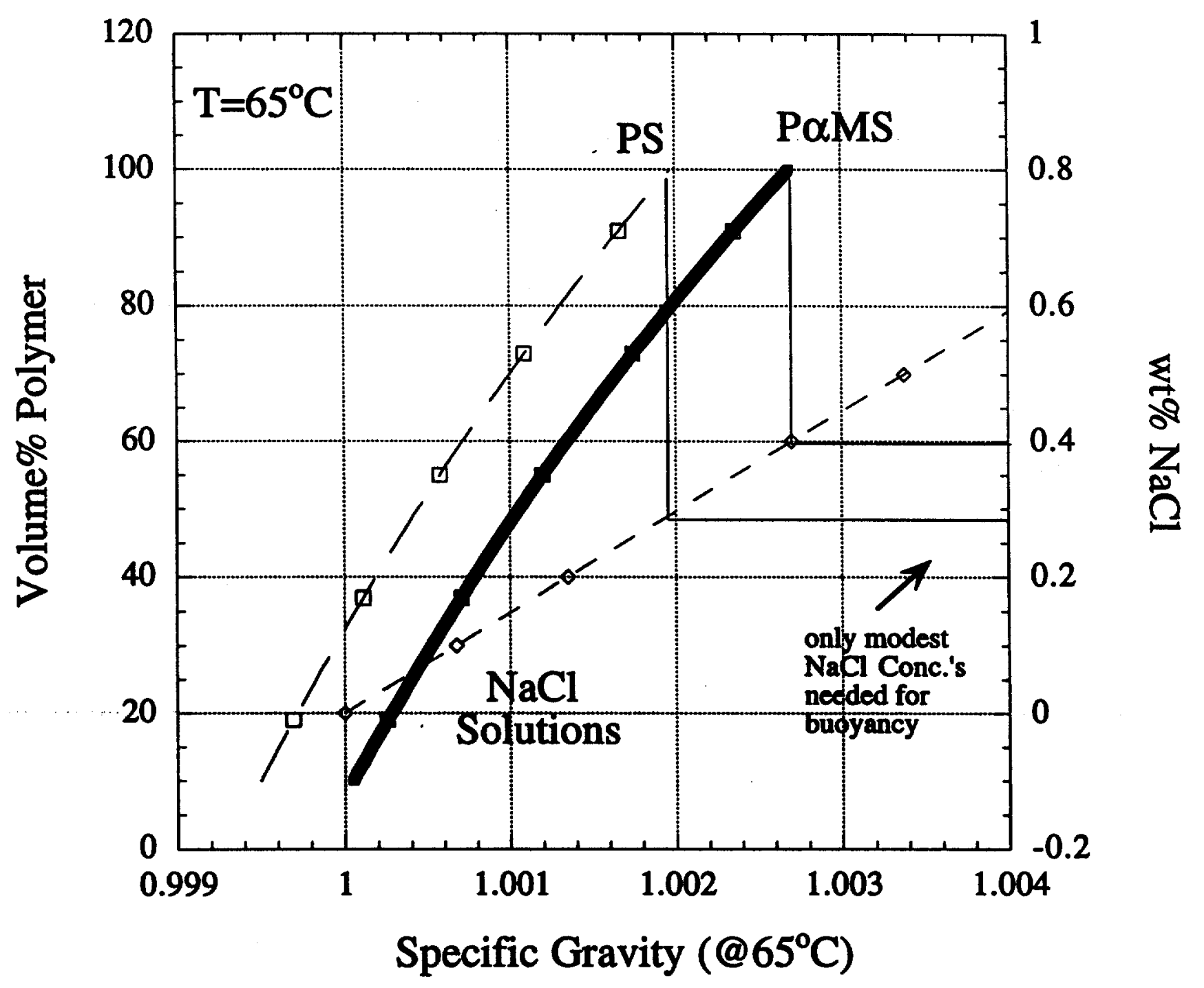


Five density gradient columns $(\nabla \rho)$ have been run. The density gradient column we have available is $78 \mathrm{~cm}$ high with a $4 \mathrm{~cm}$ diameter and is constructed out of glass. It is thermally jacketed on all sides except the top one. The temperature can be controlled up to $80^{\circ} \mathrm{C}$. The columns are made by mixing two miscible fluids in a controlled fashion (two hydrostatically linked reservoirs of different densities). The magnitude of the density gradient is determined by the difference in fluid densities of the two starting fluids. The first test we performed was making a column ranging in concentration from $0 \mathrm{wt} \%$ to $10 \mathrm{wt} \% \mathrm{NaCl}$ with a corresponding density range of $0.9882 \mathrm{~g} / \mathrm{cm}^{3}$ to $1.0643 \mathrm{~g} / \mathrm{cm}^{3}$ at $22{ }^{\circ} \mathrm{C}$ and $\rho=0.9805 \mathrm{~g} / \mathrm{cm}^{3}$ to 1.0467 $\mathrm{g} / \mathrm{cm}^{3}$ at $65^{\circ} \mathrm{C}$. The actual column density can be measured with several externally purchased and verified calibration floats made of glass and partially filled with air. The position of the glass floats (and their corresponding known densities) can be compared against the calculated densities based on a constant density gradient of the two starting column fluids (Fig 30). The position of the floats was monitored with time and at elevated temperature. For the most part, the density gradient is maintained (Fig 31).

\subsubsection{Monitoring Solvent Efflux from Shells}

Two runs have been completed in a density gradient column with actual microencapsulated droplets. Because the density difference is expected to be rather small, the density gradient was reduced; the $\mathrm{NaCl}$ concentration ranged from $0-2$ wt\% corresponding to a density range of $0.9805 \mathrm{~g} / \mathrm{cm}^{3}$ to $0.9994 \mathrm{~g} / \mathrm{cm}^{3}$ instead of the less sensistive column with 0-10 wt\% $\mathrm{NaCl}$. Each run contained 3-5 droplets. The droplets were added to a column that had already reached $65^{\circ} \mathrm{C}$. The position of each was monitored with time (Fig. 32). From this measurement one can estimate the shell velocity (Fig. 33). In magnitude is quite small, on the order of a few $\mu \mathrm{m} / \mathrm{sec}$. From the position of shell within the column, one can calculate its composite density. From this value, we can calculate the amout of solvent left in the shell wall or the \% solvent removal (Fig. 34 ). There are some inconsistencies in the F-Benzene transport. This can be traced to small errors (from measurement and calculation) in the densities. It is expected that these values can be refined. One would like to be able to calculate an average diffusion coefficient that could be used in other calculations. We would also like to correlate the F-benzene transport data to the shell sphericity. The MOOR values for the shells solidified in the density gradient column are 186-700 $\mu \mathrm{m}$ OOR (or 9-32\% OOR). This is quite a bit higher than the shells made in a $1 \mathrm{~L}$ beaker $(20-120 \mu \mathrm{m}$ OOR or $1-6 \%$ OOR).

\subsubsection{Sphericity of Shells in a $\nabla \rho$-column.}

The shells obtained from the density gradient column are not round. In fact, they appear to be elliptical, egg-shaped, or cone shaped. The degree of out-ofroundness is not trivial. For the four shells obtained, we observed OOR values of $186,325,604$, and 697 . This corresponds to $9.3,16.5,28.0,31.6 \% O O R$, respectively. For $118 \mathrm{k}$ P $\alpha \mathrm{MS}$, the expected $O O \mathrm{R}$ values typically range from $20-120 \mu \mathrm{m}$ on a 2$\mathrm{mm}$ shell solidified in a $1 \mathrm{~L}$ vessel at $65^{\circ} \mathrm{C}$. There are several possible reasons for this: a) we removed essentially all of the hydrodynamic factors since these shells are almost stationary $(\sim 5 \mu \mathrm{m} / \mathrm{sec}), \mathrm{b})$ we removed all convection currents, $c)$ the shells 


\section{Fig. 30 - Density Gradient Column Calibration}

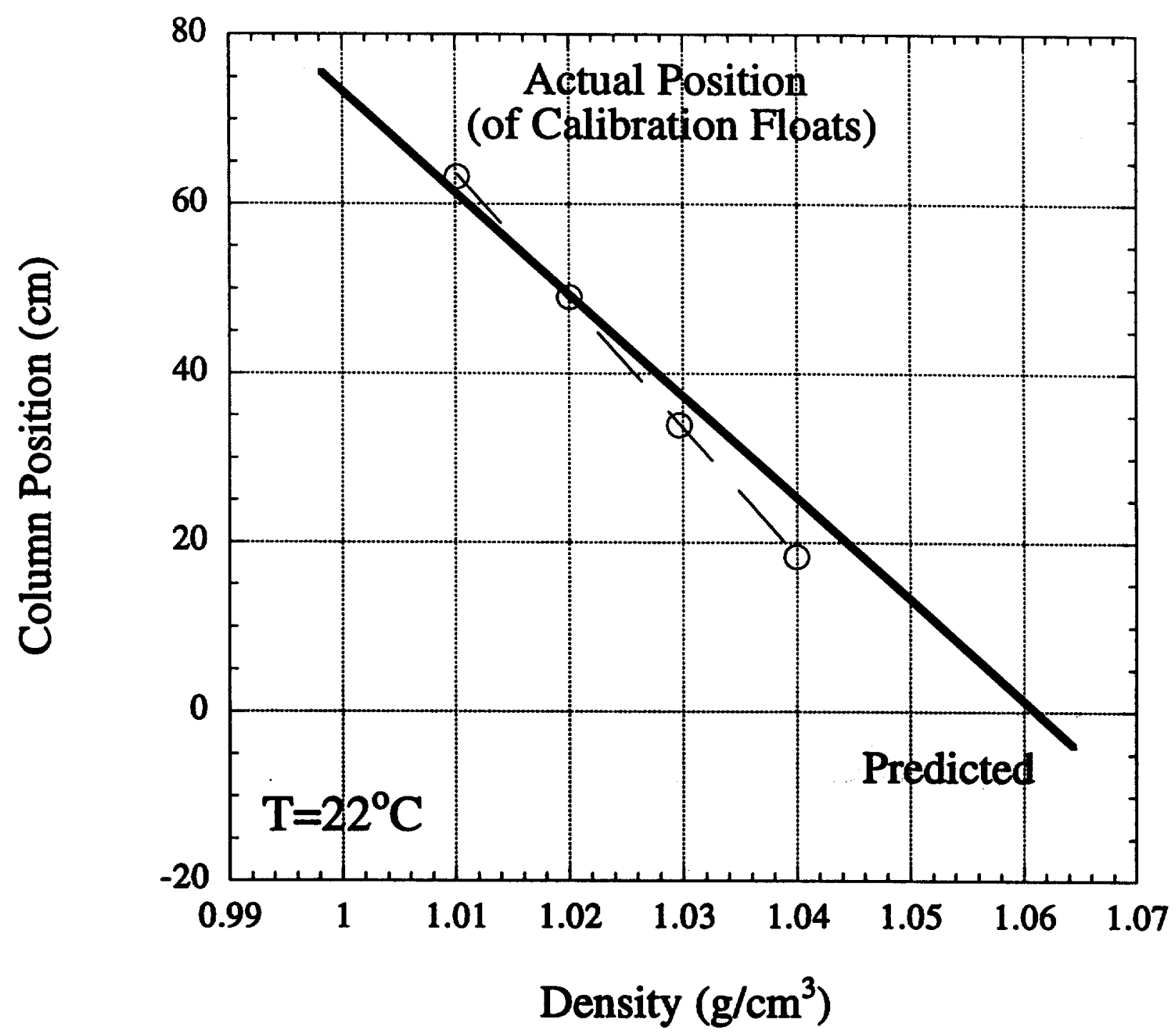




\section{Fig. 30b - Density Gradient Column Calibration}

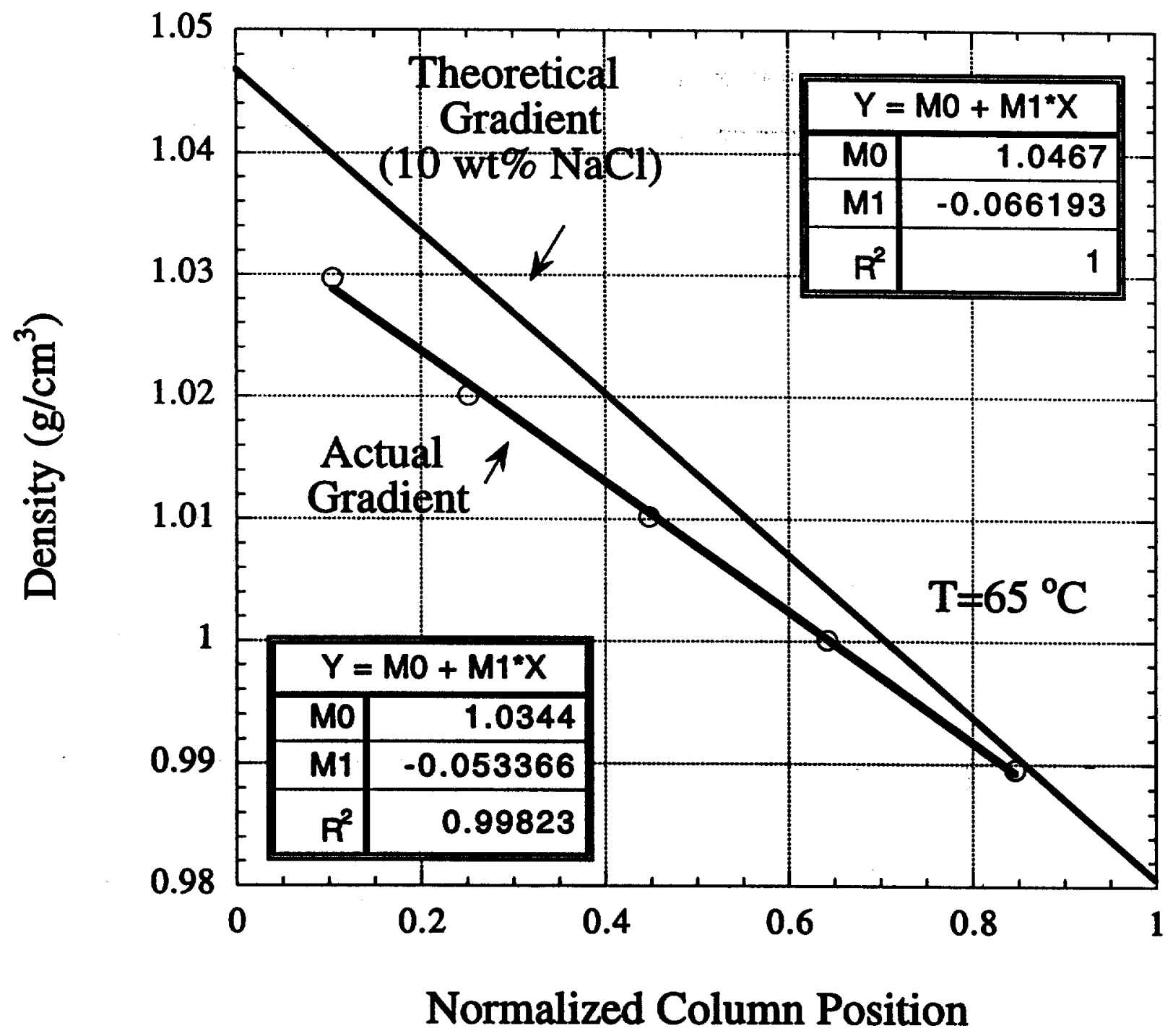




\section{Fig. 31a - Density Gradient Column Stability (Calibration Float Position as a function of time)}

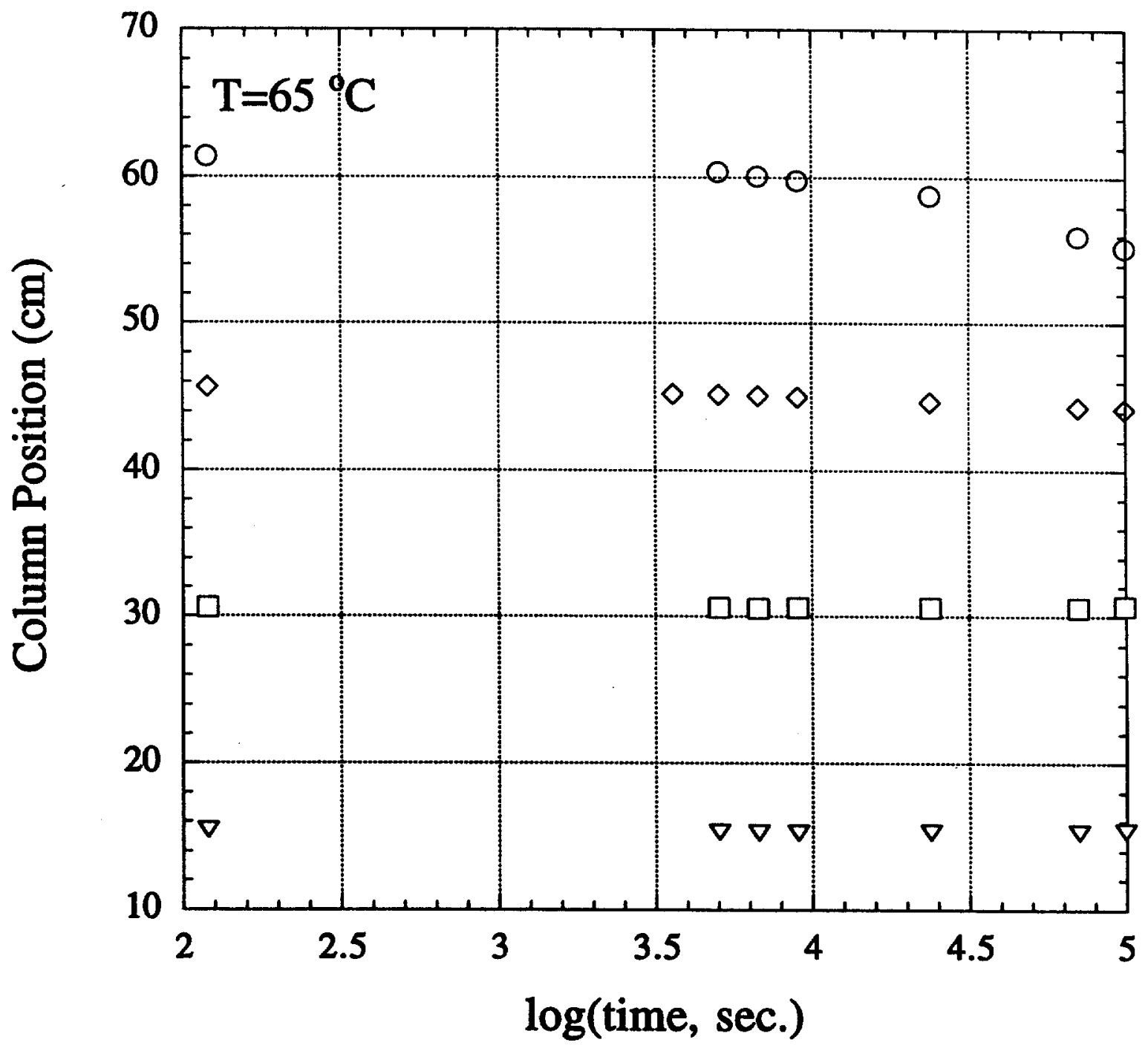


Fig. 31b - Density Gradient Column Stability

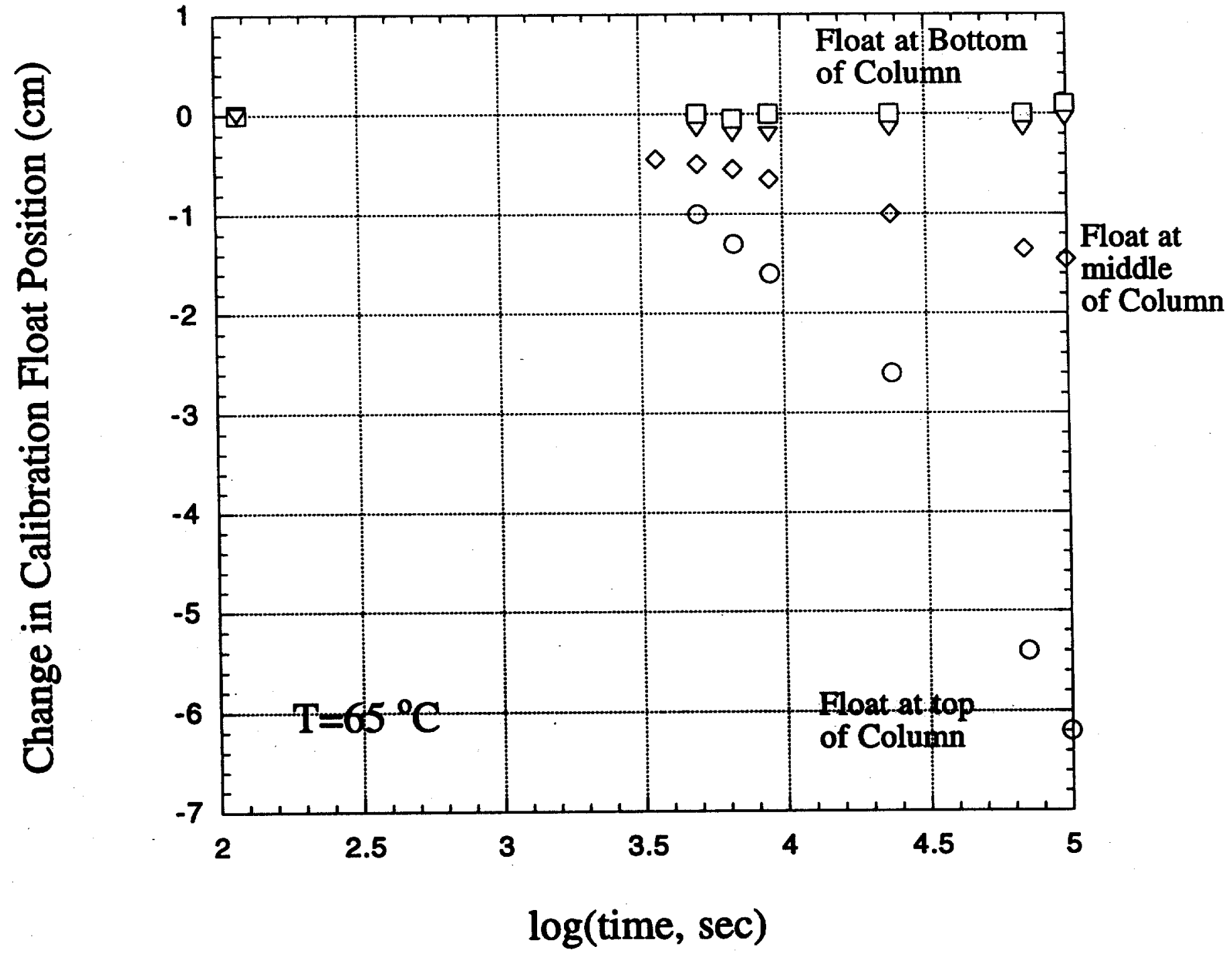


Fig. 32 - Changes in Shell Composite Density During Solidification at $\mathrm{T}=65^{\circ} \mathrm{C}$ as reflected by column position

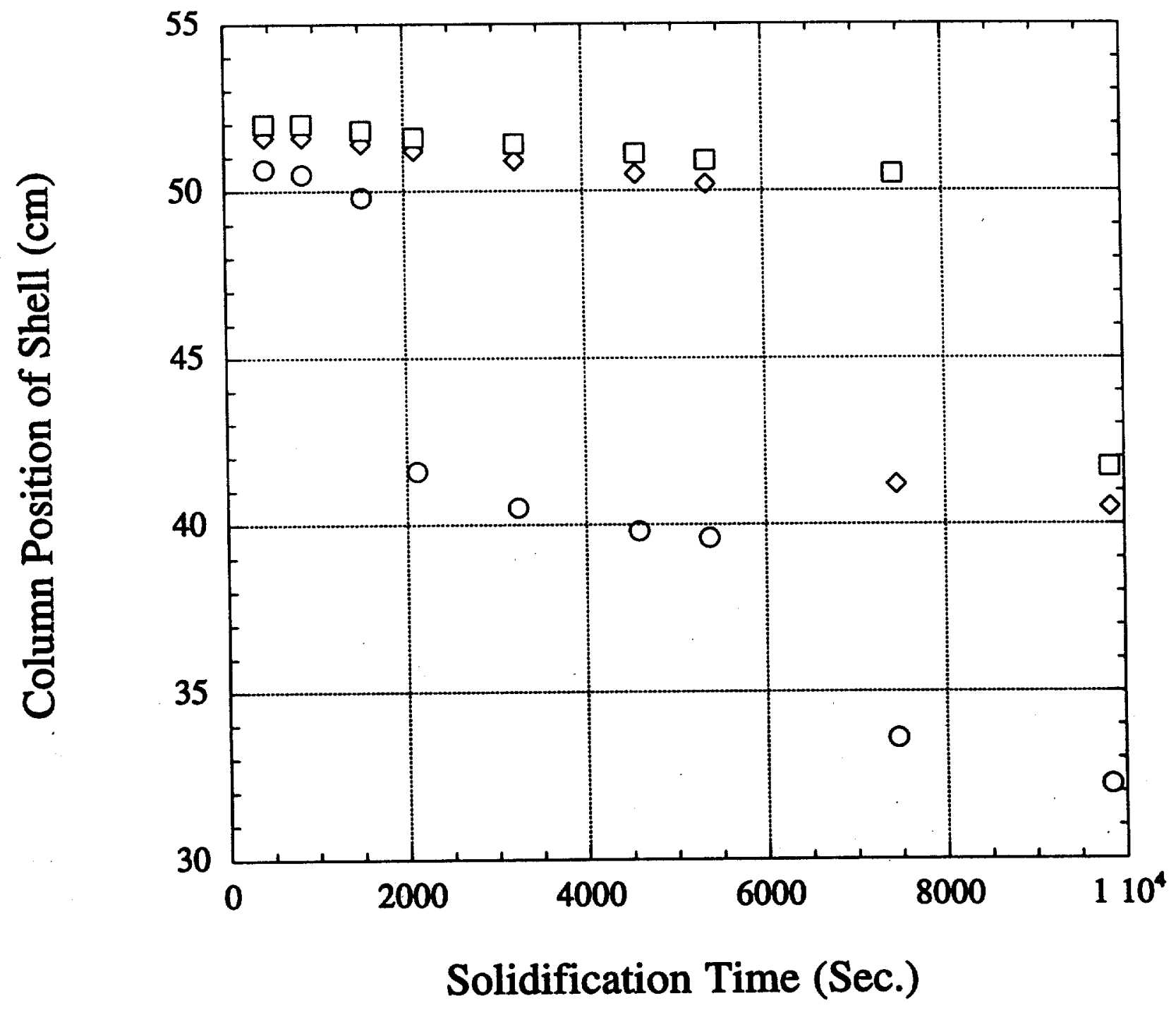


Fig. 33 - Calculated Shell Velocity in a Density Gradient Column at $65^{\circ} \mathrm{C}$.

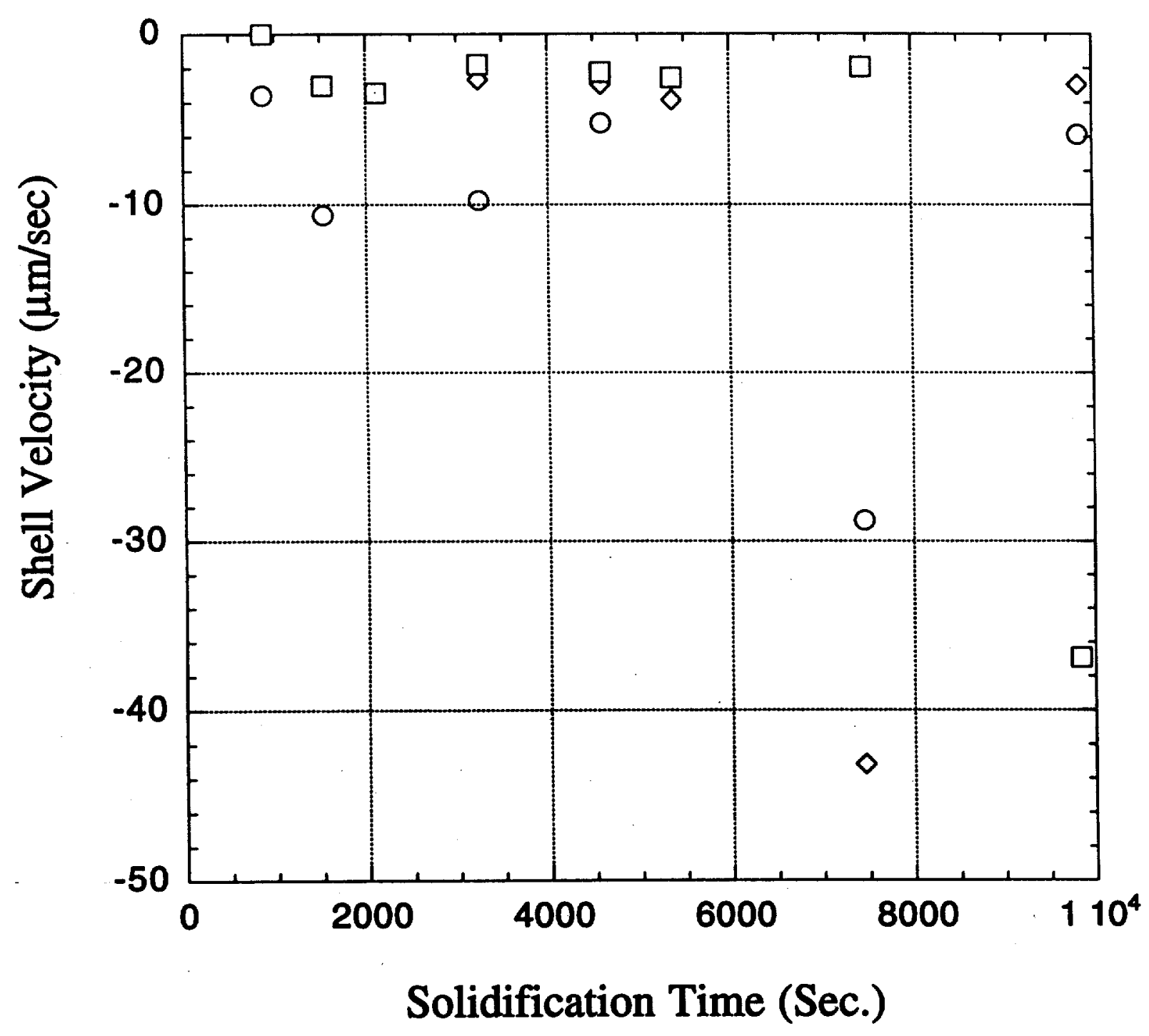


Fig. 34: \% F-Benzene Removal from P $\alpha$ MS Beads

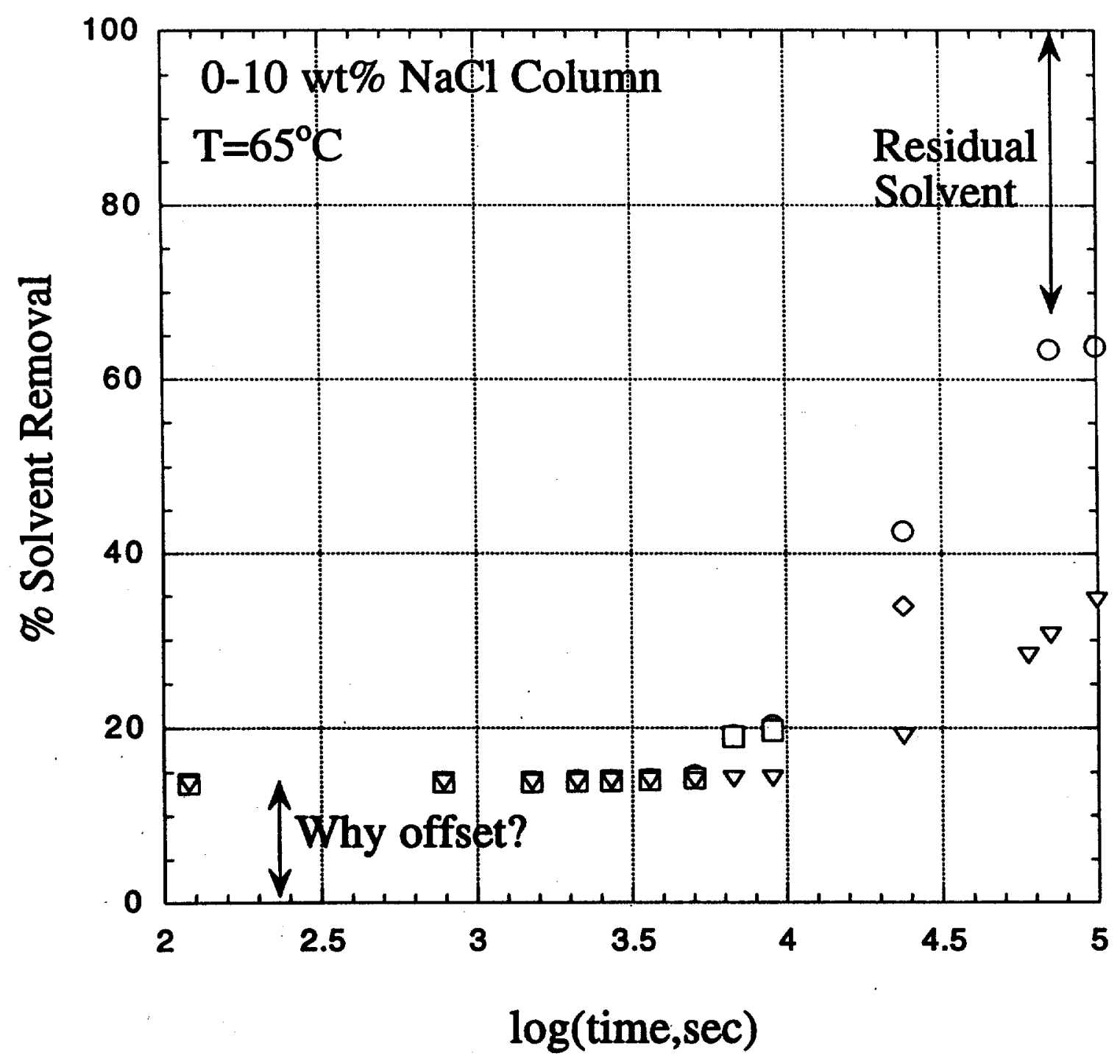


are distorted because we have a density gradient column (this has recent been calculated to be a small contribution for the density gradients we are using), d) the core - oil density mismatch, e) manifestation of mechanical stresses built up in the forming film (before this effect was averaged by the the motion of the shell, $f$ ) the shells do not reorient, $g$ ) lack of reorientaion coupled with the phase density mismatch will result in the elongation of the droplet and resulting shell (The core fluid in a stationary shell moves linear with respect to time while the core in a reorienting shell undergoes a random walk, and its motion goes with the square root of time. More testing is needed to delineate the possible cause(s) of this extreme OOR behavior. Based on a hydrostatic calculation a 2-mm bead would be $0.0080 \mu \mathrm{m}$ out-of-round for the $0-10 \mathrm{wt} \% \mathrm{NaCl}$ column and $0.0024 \mu \mathrm{m}$ out-of round for the $0-2$ $\mathrm{wt} \% \mathrm{NaCl}$ column. At this point is believed that the shell's OOR is due to either e) or $\mathrm{g}$ ).

Because shells made with PS had a tendency to be quite round (MOOR $=3-20$ $\mu \mathrm{m})$, it was of interest to examine the level of shell sphericity one would obtain in a density gradient column since this environment should remove all deleterious hydrodynamic forces. Shells made with PS are less dense than the ones made with P $\propto$ MS (and more importantly, less dense than water). The PS shells intially would float on top of the $0-2 \mathrm{wt} \% \mathrm{NaCl}$ due to the high F-benzene content. To hold a shell within the column fluid, it was necessary to reduce the density of the top of the column. This was accomplished by addding $5 \mathrm{wt} \%$ ethanol to the water. Unfortunately, the column was not that stable (persistant convection currents were observed), and these shells solidified with high MOOR values.

Overall, there were some stability problems with the density gradient column as indicated by Fig. 31. The source of these problems is thermal convection currents and various thermal gradients ( $\partial \mathrm{T} / \partial \mathrm{r}$ and $\partial \mathrm{T} / \partial \mathrm{z}$ in cylindrical coordinates) that drive the convection currents. Problems with convection (i.e., homogenization of column) by radial thermal gradients and start-up thermal transients (dT/dt). This problem is evidenced by: a) sustained thermal convection of PS shell (especially near top of column) due to gradients, $\partial \mathrm{T} / \partial \mathrm{r}$ and $\partial \mathrm{T} / \partial \mathrm{z}, \mathrm{b}$ ) non-linear (step-like discontinuties in the electrical conductivity of the fluid with respect to column position as measured by a conductivity probe, c) step-like shell position vs. time data. To measure this more effectively, more calibration floats with the proper density resolution would be helpful (but these are expensive). It would be useful to have some expression that describes the stability of stratified media; this will depend on the density gradient, concentration gradient, the temperature, and the temperature gradients. If a column is not as stable as needed, perhaps a column with several discrete steps would be useful.

It had been questioned whether the sources of the out of roundness was due to mechanical stress development in a thin-walled shell (due radial and angular concentration gradients present during solidification and non-uniform shinkage). To examine this experimentally one could incrementally change the wall thickness (which is still an interesting set of experiments) or eliminate the wall completely by forming beads. Beads have been formed with $15 \mathrm{wt} \% 118 \mathrm{k}$ P $\alpha \mathrm{MS}$ (the same as used for the shells) in the droplet generator by removing the core fluid. Several of these beads were placed in a $0-10 \mathrm{wt} \% \mathrm{NaCl}$ density gradient column and their position 
monitored with time (Fig. 35). As expected, the droplets with the smallest diameter (and highest S/V ratio) sunk / dried the most rapidly. The out-of-round values were difficult to determine on some of the beads because they did not dry completely.

\subsection{CONCLUSIONS}

* The Soane-like generator is more convenient to use as a droplet generator; the Osaka /GA generator appears to be somewhat cumbersome.

* Problems were observed with the use of a two solvent scheme due large differences in permeation rates.

* The size of the shell can be control and predicted by controlling the drag force experienced by the shell (proportional to $\mathrm{v}^{2}$ not $\mathrm{v}$ (as would be with Stokes' Law)). * A "Standard" shell making procedure has been adopted including:

a) relative core to oil flow rate ratio of $3: 1(1.8$ and $0.6 \mathrm{ml} / \mathrm{min})$.

b) $\mathrm{T}$ (solidification) $=65^{\circ} \mathrm{C}$

c) $3.25 \mathrm{~mm}$ ID collection tube

d) $\sim 25 \mathrm{ml} / \mathrm{min}$ PVA solution flow rate

e) $\sim 15 \mathrm{wt} \%$ Polymer

* Mechanical suspension is, in general, too harsh on the fragile $w-0-w$ emulsion droplets.

a) this is absolutely the case for $2.3-2.6 \mathrm{~mm}$ droplets

b) RPM of $0-30$ are possible for $2.0 \mathrm{~mm}$ droplets. It is possible to agitate 2.0 mm shells at a rate of 0-30 RPM.

* Because of droplet attrition during mixing, solidification protocol depending on thermal convection and near neutrally buoyant conditions has been developed.

* The degree of out-of-roudness of the shell is not entirely controlled by the hydrodynamics in the solidification bath fluid.

* The shell OOR-ness depends on shell diameter

- larger shells with smaller radii of curvature yield higher OOR values

$-S / V$ goes down as $3 / R$ and the miminization of interfacial energy is not as strong

* The shells' OOR values are a function of molecular weight (including

polydispersity and modality).

* The shells' OOR values are a function of polymer repeat unit.

* The shells OOR values appear to be a function of polymer solubility in the oil phase solvent.

*The shells' OORness does not appear to be a function of the polymer's unplasticized glass transition temperature.

*The shells OORness were not found to be a function of F-benzene transport, but this is worth retesting .

* The shell walls are believed to be developing stress as they solidify. This appears to be responsible for the non-spherical shell geometry.

*The density gradient column is a useful means for monitor solvent transport and offers an noteworthy environment for shell solidification. Shells solidified in this manner are grossly out-of-round. 


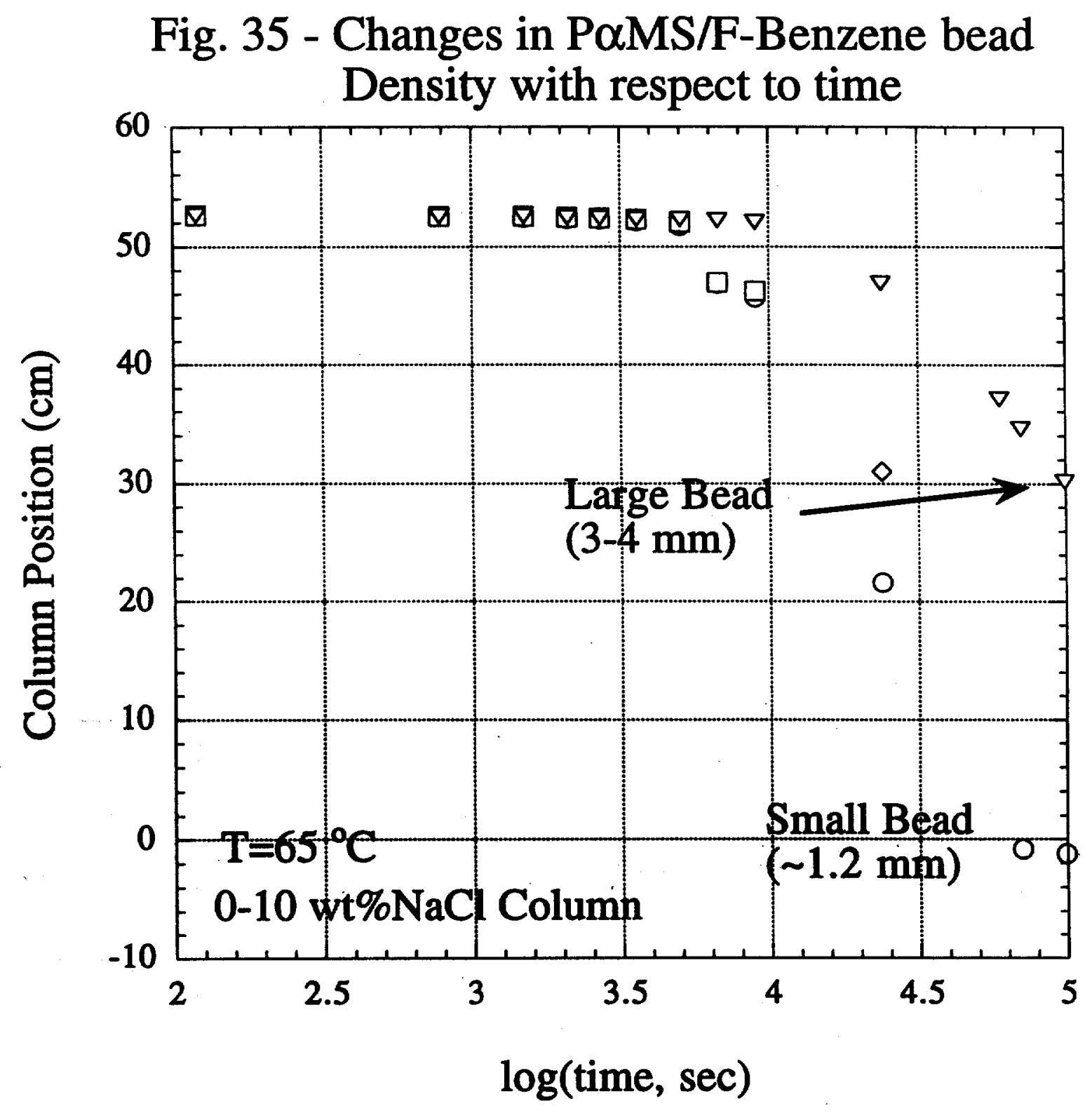


* The best shells obtained thus far (of any kind) in the 2-mm size range are $3 \mu \mathrm{m}$ OOR. At this point, it is believed that a NIF-quality mandrel will have to be less than $1 \mu \mathrm{m}$ OOR.

* The activities occuring at the oil-water interface are more complicated than originally envisioned and reflected by interfacial tension measurements.

* A study of this kind is complicated by the degree of phenomena coupling. Fluid transport, mass transport, polymer solubility, polymer molecular weight (\& dispersity), and mechanical stress are linked. It is difficult to change one without also changing all of the other parameters.

\subsection{FUTURE DIRECTION (\& Unresolved questions):}

We are at the stage of identifying the key parameters involved in shell spherity. The only factor driving a shell to a spherical geometry is interfacial tension. We would like this to be as high as possible. Unfortunately, there is not that much control of this value, and there appears to be only forces that drive the shell into a non-spherical configuration (weight, core-oil density mismatch, shear stress, interaction with solid surfaces, etc.). We will be looking at a number of tests to elucidate the cause(s) of the shell's out-of-roundness. This will include: the effect of agitation on sphericity during solidification, effect of wall thickness, role of solidification temperature, use of alternate solvents, involvement of osmotic pressure, effect of solidification rate (solvent transport). Some level of finite element modelling (GOMA, FIDAP, or ALGOR) of the transport and mechanical stresses would be helpful in addressing a number of the experimentally difficult questions. Comparison to experiment data and measureable properties will be done whenever feasible.

There are some unresolved questions that will we attempt to answer. Are the two interfaces hydrodynamically coupled? Is there a link between sphericity and concentricity? Is stress responsible for the difference in ooR-ness for P $\alpha \mathrm{MS}$ and PS? for various Mw PoMS? Will acoustically driven oscillations in the composite shell drive the core to center and reduce the level of non-uniform drying (and lower the OOR-ness of the shell)? How does F-benzene transport affect the OOR-ness (and presumeably the levels of stress)? How does the OOR-ness of shell mandrels compare to the OOR-ness obatined from a bead (either a solvent-free/melt bead or a solvent-loaded bead)? Does mixing at low shear rates (subcritical perturbations) enhance or inhibit shell sphericity? It is known that the large amount of mixing (high shear forces) is detrimental to shell survival. Is some small level of mixing useful? What are the time constants for a non-spherical droplet to become spherical (after a perturabation)? Finally, are there any physical limitations for making shells with the NIF specifications, or is it a matter of implementation? 


\section{References}

Abdel-Alim, A.H, Hamielec, A.E., "A theoretical and Experimental Investigation of the Effect of Internal Circulation on the Drag of Spherical Droplets Falling at Terminal Velocity in Liquid Media", Ind. Eng. chem. Fundam., 14(4), 1975, 308-312.

Adamson, A.W., Physical Chemistry of Surfaces, 5th ed., New York, John Wiley \& Sons, 1990.

Arshady, R., "Preparation in Microspheres and Microcapsules by Interfacial Polycondensation Techniques, "J. Microencapsulation, 6(1), 13, (1989).

Auld, B.A., Acoustic Fields and Waves in Solids, New York: John Wiley \& Sons, 1973.

Becher, P., (ed.), Encyclopedia of Emulsion Technology, Vol. 1, Basic Theory, New York, Marcel Dekker, Inc., 1983.

Bird, R.B., Stewart, W.E., Lightfoot, E.N., Transport Phenomena, New York: John Wiley \& Sons, 1960.

Bird, R.D, Armstrong, R.C., Hassenger, O., Dynamics of Polymeric Fluids, 2nd ed., Vol 1: Fluid Mechanics, (NY: John Wiley \& Sons, Inc., 1987).

Boone, T., Cheung, L., Nelson, D., Soane, D., Wilemski, G., Cook, R., "Modeling of Microencapsulated Polymer Shell Solidification," in Hollow and Solid Spheres and Microspheres-Science and Technology Associated with Their Fabrication and Application, D. L. Wilcox et al., Eds. (Materials Research Society, Pittsburgh, PA), pp. 193-198 (1995).

Chhabra, R.P., Bubbles, Drops, and Particles in Non-newtonian Fluids, CRC Press, Boca Raton, FL, 1993.

Cook, R., "Production of Hollow Microspheres for Inertial Confinement Fusion Experiments," in Hollow and Solid Spheres and Microspheres-Science and Technology Associated with Their Fabrication and Application, D. L. Wilcox et al., Eds. (Materials Research Society, Pittsburgh, PA), pp. 101-112 (1995).

Cowie, J.M.G., Polymers: Chemistry \& Physics of Modern Materials, New York: Chapman \& Hall, 1991.

Crank, J.S., Park, G.S., Diffusion in Polymers, New York: Academic Press, Inc., (1968).

Doerner, M.F., Oliver, W.C., Pharr, G.M., Brotzen, F.R., Thin Films: Stresses and Mechanical Properties II, (Materials Research Society Symposium Proceedings, Vol., 188), Pittsburgh, 1990. 
Edge, R.M., Grant, C.D., "The terminal velocity and Frequency of Oscillation of drops in a pure systems", Chem. Eng. Sci., 1971, 26, 1001-1012.

Finch, C.A. (ed.), Polyvinyl alcohol - Developments, New York, John Wiley \& Sons Ltd., 1992.

Flory, P.J., Principles of Polymer Chemistry, Cornell University Press, 1954.

Flumerfelt, R. W., "Drop Breakup in Simple Shear Fields of Viscoelastic Fluids", Ind. Eng. Chem. Fundam., 11(3), 1972, 312-318.

Friberg, S.E., Godlsmith, L.B., Hilton, M.L., in Theory and Emulsions (G.S. Banker, M.L. Reiger, H.A. Lieberman, eds.), Marcel Dekker, NY, 1988.

Fujita, H., Polymer Solutions, (New York: Elsevier, 1990).

Gould, Robert, F. (ed.), Contact Angle: Wettability and Adhesion, (Washington, D.C.: American Chemical Society, 1964).

Gruan, A., Ripoche, J., Ziegler, F. (eds.), Acoustic Interactions with Submerged Elastic Structures, River Edge, NJ: World Scientific Publishing Co. Pte Ltd., 1996.

Haan., S.W., et al., "Design and Modeling of Ignition Targets for the National Ignition Facility," Phys. Plasmas, 2, 2480 (1995).

Hamilton, K.E., Letts, S.A., Buckley, S.R., Fearon, E.M., Wilemski,G, Cook, R.C., Schroen-Carey,D., "The Role of Reactant Transport in Determining the Properties of NIF Shells made by Interfacial Polycondensation, Fusion Technol., 1997, 31(4), 391401.

Hammel, H.T., Scholander, P.F., Osmotic and Tensile Solvent , (Springer-Verlag, Berlin, 1976.).

Happel, J., Brenner, H., Low Reynolds number Hydrodyrnamics: with special attention to Particulate Media, Prentice-Hall, Englewood Cliffs, New Jersey, 1965.

Kollar, L., Dulacska, E., Buckling of shells for engineers, New York, John Wiley \& Sons, 1984.

Lagisetty, J.S., Das, P.K., Kumar, R., Gandhi, K.S., "Breakage of Viscous and NonNewtonian Drops in Stirred Dispersions," Chem. Eng. Sci., 41(1), 1986, 65-72.

Johnson, R.E., Sadhal, S.S., "Fluid Mechanics of Compound multiphase drops and bubbles," Ann. Rev. Fluid Mech., 1985, 17, 289-320. 
Leal, L.G., Laminar Flow \& Convective Transport Processes: Scaling Principles and Asymptotic Analysis, Boston, Butterworth-Heinemann, 1992.

Lee, M.C., Feng, I., Elleman, D.D., Wang, T.G., Young, A.T., “Generation of a Strong Core-Centering Force in a Submillimeter Compound Droplet System," p.107-111, in Le Croissette, D. H. (ed.), Proceedings of the Second International Colloquium on Drops and Bubbles, 1981, JPL Publication 82-7.

Letts, S.A., et al., "Preparation of Hollow Shell ICF Targets Using a Depolymerizing Mandrel," in Hollow and Solid Spheres and Microspheres-Science and Technology Associated with Their Fabrication and Application, D. L. Wilcox et al., Eds. (Materials Research Society, Pittsburgh, PA), pp. 125-130 (1995a).

Letts, S.A., et al., "Fabrication of Special Inertial Confinement Fusion Targets Using a Depolymerizable Mandrel Technique," J. Vac. Sci. Technol. A, 14, 1015 (1996).

Letts, S.A., et al., "Fabrication of Polymer Shells Using a Depolymerizable Mandrel," Fusion Technol., 28, 1797 (1995b).

Koh, C.J., Leal, L.G., "The stability of drop shapes for translation at zero reynolds number through a quiescent fluid," Phys. Fluids $A$,1(8) 1989, 1309.

Kubo, U. Tsubakihara, H., J.Vac.Sci. Tech. A4, 1986, 182.

Manning, C.D., Scriven, L.E., "On Intefacial Tension measurement with a spinning drop in gyrostatic equilibrium," Rev. Sci. Instrum, 48(12), 1977, 1699-1705.

McQuillan, B.W., Nikroo, A., Steinman, D.A., Elsner, F.H., Czechowicz, D.G., Hoppe, M.L., Sixtus, M., Miller, W., "The P $\alpha$ MS/GDP Process for Production of ICF Target Mandels", Fusion Technology, 1997, 31(4), 381-384.

Merkuliev, Y.A., et al., "Study of Production and Quality of Large (1-2 mm) Polystyrene Hollow Microspheres," in Hollow and Solid Spheres and MicrospheresScience and Technology Associated with Their Fabrication and Application, D. L. Wilcox et al., Eds. (Materials Research Society, Pittsburgh, PA), pp. 119-124 (1995).

Myers, D., Surfactant Science and Technology, 2nd ed., New York, VCH Publishers, 1992.

Myers, D. Surfaces, Interfaces and Colloids: Principles and Applications, New York, VCH Publishers, 1991.

Nakano, H, Kubo, U. "Fabrication of a Large-Sized Plastic Shell Target," Proceedings from the Eleventh Target Fabrication Specialists' Meeting, Sept, 1996, Orcas Island, Washington. 
Nikitenko, A.I., Tolkonnikov, S.M., Cook, R., "The Design of the Ballistic Furnace and Initial Microshell Formation," Fusion Technol., 1997, 31(4), 385-390.

Olbricht, W.L., Leal, L.G., "The Creeping motion of liquid dips through a circular tube of comparable diameter: the effect of density differences between fluids," J. Fluid. Mech. (1982), 115, 187-216.

Ramm, E. (ed.), Buckling of Shells, New York: Springer-Verlag, 1982.

Riddick, J. A., Bunger, W. B., Sakano, T.K., Organic solvents: physical properties and methods of purification, 4th Ed. (New York: John Wiley \&Sons, 1986).

Ristic, V.M., Principles of Acoustic Devices, New York: John Wiley \& Sons, 1983.

Sadhal, S.S., Oguz, H.N., "Stokes flow past compound multiphase drops: the case fo completely engulfed drops / bubbles," J. Fluid. Mech, 1985, 160, 511-529.

Saffren, M. Elleman, D.D., Rhim, W.K., "Normal Modes of a Compound Drop" in Le Crosissette, D. H. (ed.), Proceedings of the Second International Collogium on Drops and Bubbles, Jet Propulsion Laboratory Publication (82-7), 1981, 7-14.

Serway, R.A., Physics for Scientists and Engineers, 2nd. ed., (NY: Saunders College Publishing), 1986.

Smith, A.L, (ed.), Theory and Practice of Emulsion Technology, Academic Press, London, 1976.

Sterbacek, Z., Tausk, P., Mixing in the Chemical Industry, New York: Pergamon Press, 1965.

Stone, H.A., Leal, L.G., "Breakup of concentric double emulsion droplets in linear flows," J. Fluid Mech., (1990),211, 123-156.

Takagi, M., Norimatsu, T. Yamanaka, T, Nakai, S., "Development of Deuterated Polystyrene Shells for Laser Fusion by Means of a Density-matched Emulsion Method," J. Vac. Sci. Technol. A, 2(4), 2145 (1991).

Takagi, M., et al., "Development of Foam Shell with Plastic Ablator for Cryogenic Laser Fusion Target," J. Vac. Sci. Technol. A, 11(5), 2837 (1993).

Uhl, V.W., Gray, J.B (eds.), “Mixing: Theory \& Practice” Vol. 1, New York: Academic Press, 1966.

Uhl, V.W., Gray, J.B (eds.), “Mixing: Theory \& Practice" Vol. 2., New York: Academic Press, 1967. 
Uhl, V.W., Gray, J.B (eds.), "Mixing: Theory \& Practice" Vol. 3, New York: Academic Press, 1986.

Vonnegut, B. "Rotating Bubble Method for the Determination of Surface and Interfacial Tensions," Rev. Sci. Instrum., 1942, 13, 6-9.

Ward, I.M., Mechanical Properties of Solid Polymers, 2nd ed., New York: John Wiley \& Sons, 1983.

White, F.M., Fluid Mechanics, 2nd ed. (NY: McGraw-Hill Book Co.), 1986.

Wilemski, G., et al., "Prediction of Phase Separation during the Drying of Polymer Shells," Fusion Technol., 28, 1773 (1995). 


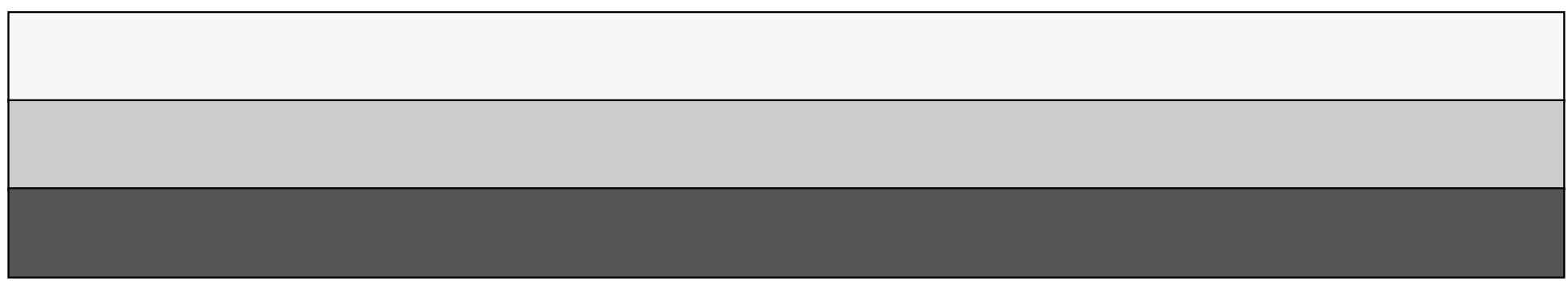

